https://theses.gla.ac.uk/

Theses Digitisation:

https://www.gla.ac.uk/myglasgow/research/enlighten/theses/digitisation/

This is a digitised version of the original print thesis.

Copyright and moral rights for this work are retained by the author

A copy can be downloaded for personal non-commercial research or study, without prior permission or charge

This work cannot be reproduced or quoted extensively from without first obtaining permission in writing from the author

The content must not be changed in any way or sold commercially in any format or medium without the formal permission of the author

When referring to this work, full bibliographic details including the author, title, awarding institution and date of the thesis must be given

Enlighten: Theses

https://theses.gla.ac.uk/

research-enlighten@glasgow.ac.uk 


\section{THE EFFECT OF DIETARY INCLUSION OF YEAST CULTURE \\ ON DIGESTION IN SHEEP}

BY

\section{INZANISAI CHADEMANA B.SC, AGRIC. (HONS). UNIVERSITY OF ZIMBABWE}

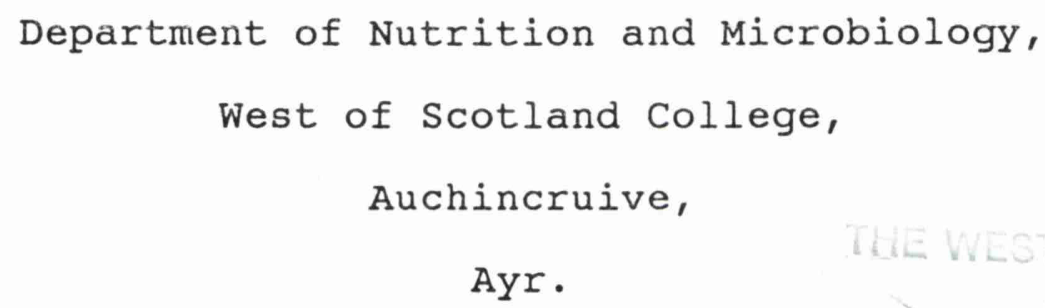

Submitted for the Degree of Masters of Science

$$
\text { of }
$$

The University of Glasgow

Britain

June, 1989 . 
ProQuest Number: 10656330

All rights reserved

INFORMATION TO ALL USERS

The quality of this reproduction is dependent upon the quality of the copy submitted.

In the unlikely event that the author did not send a complete manuscript and there are missing pages, these will be noted. Also, if material had to be removed, a note will indicate the deletion.

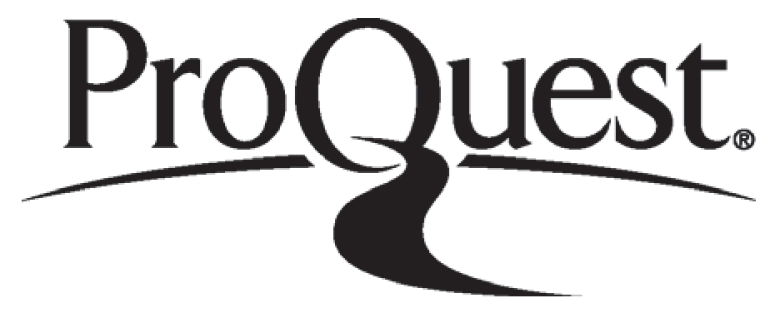

ProQuest 10656330

Published by ProQuest LLC (2017). Copyright of the Dissertation is held by the Author.

All rights reserved.

This work is protected against unauthorized copying under Title 17, United States Code Microform Edition @ ProQuest LLC.

ProQuest LLC.

789 East Eisenhower Parkway

P.O. Box 1346

Ann Arbor, Ml $48106-1346$ 


\section{THE WEST OF SCOTLAND \\ COLLEGE \\ LIBRARY}

DEDICATED TO THE SPIRITS OF MY DECEASED MOTHER AND FATHER 
"I WILL INSTRUCT THEE AND TEACH THEE IN THE WAY WHICH THOU SHALT GO: I WILL GUIDE THEE WITH MINE EYE" (Psalms 32: 8) 
LIST OF TABLES AND FIGURES

ACKNOWLEDGEMENTS

ABBREVIATIONS

SUMMARY

INTRODUCTION.

CHAPTER 1: IITERATURE REVIEW......................

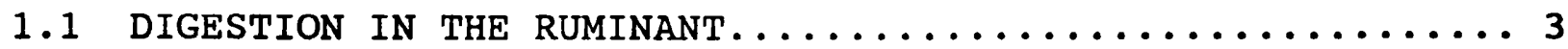

1.2 RUMEN MICROORGANISMS AND THEIR REQUIREMENTS.......... 5

$1.2 .1 \quad$ Bacteria.......................... 6

$1.2 .2 \quad$ Protozoa........................

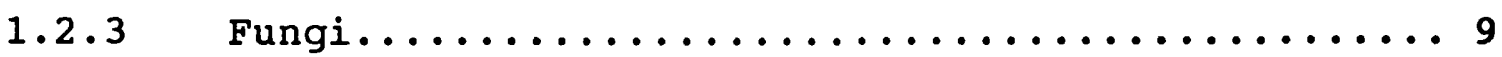

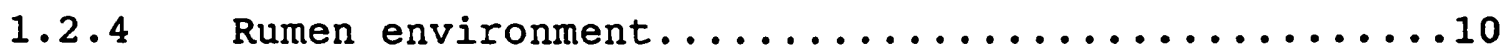

1.2.5 Microbial nutritional requirements...........11

1.3 FERMENTATION CHARACTERISTICS..................13

1.3.1 The volatile fatty acids...................

1.3.2 Molar proportions of volatile fatty acids......16

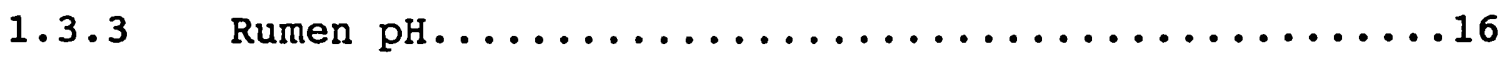

1.3.4 Microbial species and the roughage diet.......18

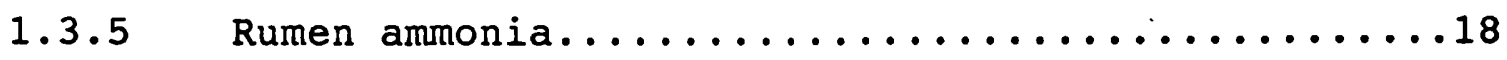

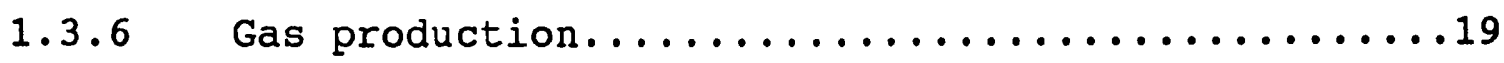

1.4 FACTORS AFFECTING THE FERMENTATION CHARACTERISTICS.......19

1.4.1 Forage : concentrate ratio.................19

1.4.1.1 Volatile fatty acids and forage : concentrate

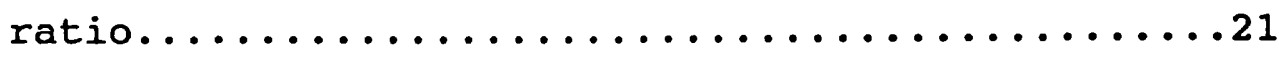




\section{INDEX (CONTINUED)}

$1.4 .1 .2 \mathrm{pH}$ and forage to concentrate ratio..........23

1.4.1.3 Fibre digestion.......................

1.4.1.4 Rumen ammonia concentration and

forage : concentrate ratio.................30

1.5 RUMINATION AND SALIVATION AND FORAGE : CONCENTRATE RATIO..31

1.5.1 Particle size of the diet.................

1.5.2 Chemical characteristics of the diet..........32

1.5.3 Rumination and milk production.............33

1.5.4 Forage : concentrate ratio and liquid movement

through the rumen........................

1.6 FERMENTATION CHARACTERISTICS AND ANIMAL PERFORMANCE.....36

1.7 MANIPULATION OF RUMEN FERMENTATION................. 39

1.7.1 Monensin.........................

1.7.2 Sodium Bicarbonate...................41

1.7 .1 Antibiotics......................

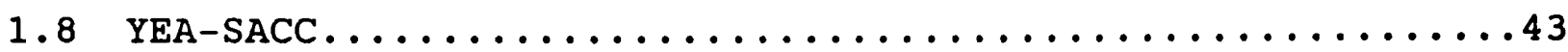

1.8 .1 What is Yea-Sacc $2 \ldots \ldots \ldots \ldots \ldots \ldots \ldots \ldots \ldots$

1.8.2 Yeast culture and animal production aspects.....44

1.8.2.1 Growing and fattening ruminants............44

1.8.2.2 Milk production and milk composition.........46

1.8.3 Yeast culture and dry matter digestibility.....48

1.8.4 Yeast culture and rumen metabolism...........49

1.8.4.1 Yeast culture and cellulolysis.............49

1.8.4.2 Yeast culture and $\mathrm{pH}$ in the rumen...........51 
1.8.4.3 Yeast culture and Acetate : Propionate ratio....51 1.8.4.4 Yeast culture and rumen ammonia............52 1.8.5 Yeast culture and liquid dilution rate........52

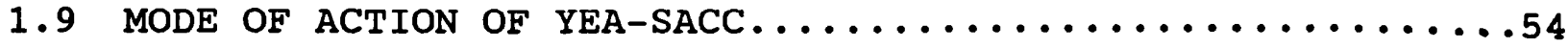

1.9 .1 Yeast growth in the rumen.................54 1.9.2 Yeast culture supplies growth factors........56 1.9.3 Yeast cells digest and utilize starch.........57 1.9.4 Yeast culture and methane production.........58 1.9.5 Yeast culture and diet palatability..........58 1.9.6 Yeast culture and saliva flow..............59

CHAPTER 2: EXPERIMENT..........................61

2.1 AIM OF EXPERIMENT...........................61

2.2 MATERIALS AND METHODS........................61 2.2 .1 Animal and Design..................61

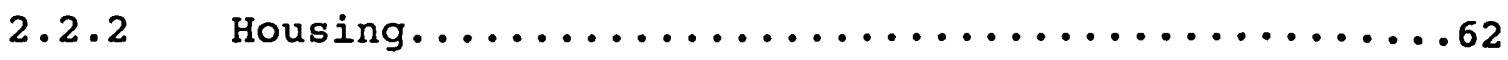
$2.2 .3 \quad$ Diet..............................62

$2.2 .4 \quad$ Measurements.......................63

2.2 .5 Analysis of samples..................63

2.2 .5 .1 Rumen fluid.........................63 2.2.5.2 Measurement of dry matter digestion in the rumen.64 2.2.5.3 Iiquid outflow rate determination...........65 2.2.5.4 Determination of overall feed digestibility.....67 $2.2 .6 \quad$ Data analysis........................68 


\section{INDEX (CONTINUED)}

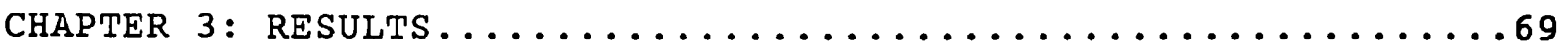

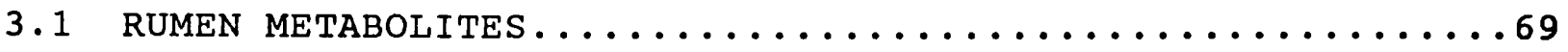

3.1.1 Volatile fatty acids..................69

3.1.2 Molar proportions of volatile fatty acids......72

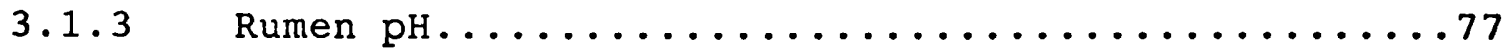

3.1.4 Rumen ammonia concentration............... 79

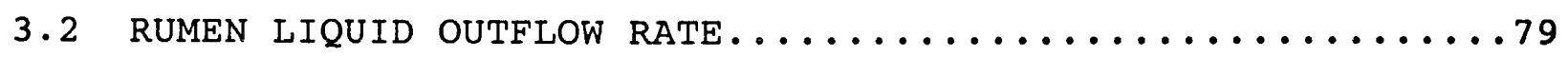

3.3 IN SACCO DigeStibiLity OF HAY.................. 83

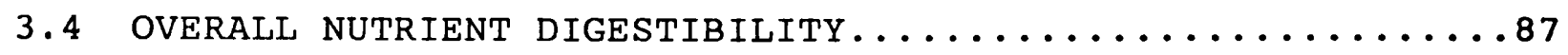

CHAPTER 4: DISCUSSION AND CONCLUSION................90

4.1 THE EFFECT OF FORAGE : CONCENTRATE PROPORTION ON

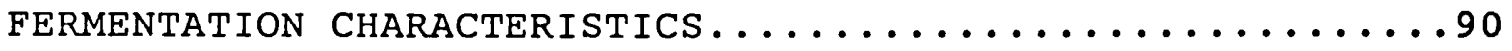

4.2 THE EFFECT OF FORAGE : CONCENTRATE ON HAY DIGESTIBILITY...95

4.3 THE EFFECT OF FORAGE : CONCENTRATE RATIO ON LIQUID

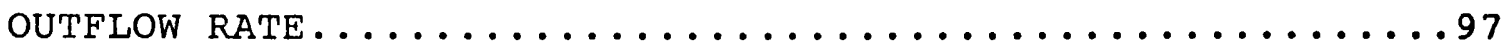

4.4 THE EFFECT OF FORAGE : CONCENTRATE RATIO ON NUTRIENT

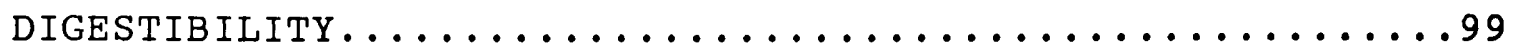

4.5 THE EFFECT OF YEA-SACC ON RUMEN FERMENTATION

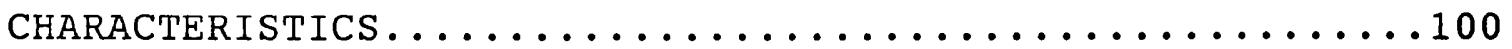

4.6 THE EFFECT OF YEA-SACC ON IN SACCO HAY DIGESTIBILITY ....101

4.7 THE EFFECT OF YEA-SACC ON THE LIQUID OUTFLOW RATE......102 


\section{INDEX (CONTINUED)}

4.8 THE EFFECT OF YEA-SACC ON NUTRIENT DIGESTIBILITY......103

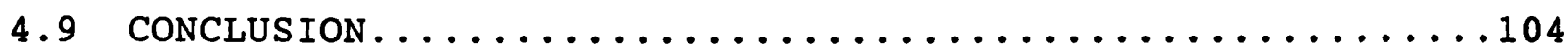

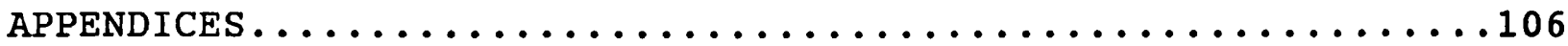

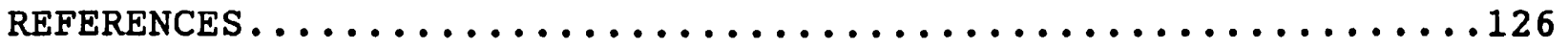


LIST OF TABLES AND FIGURES

\section{TABLES}

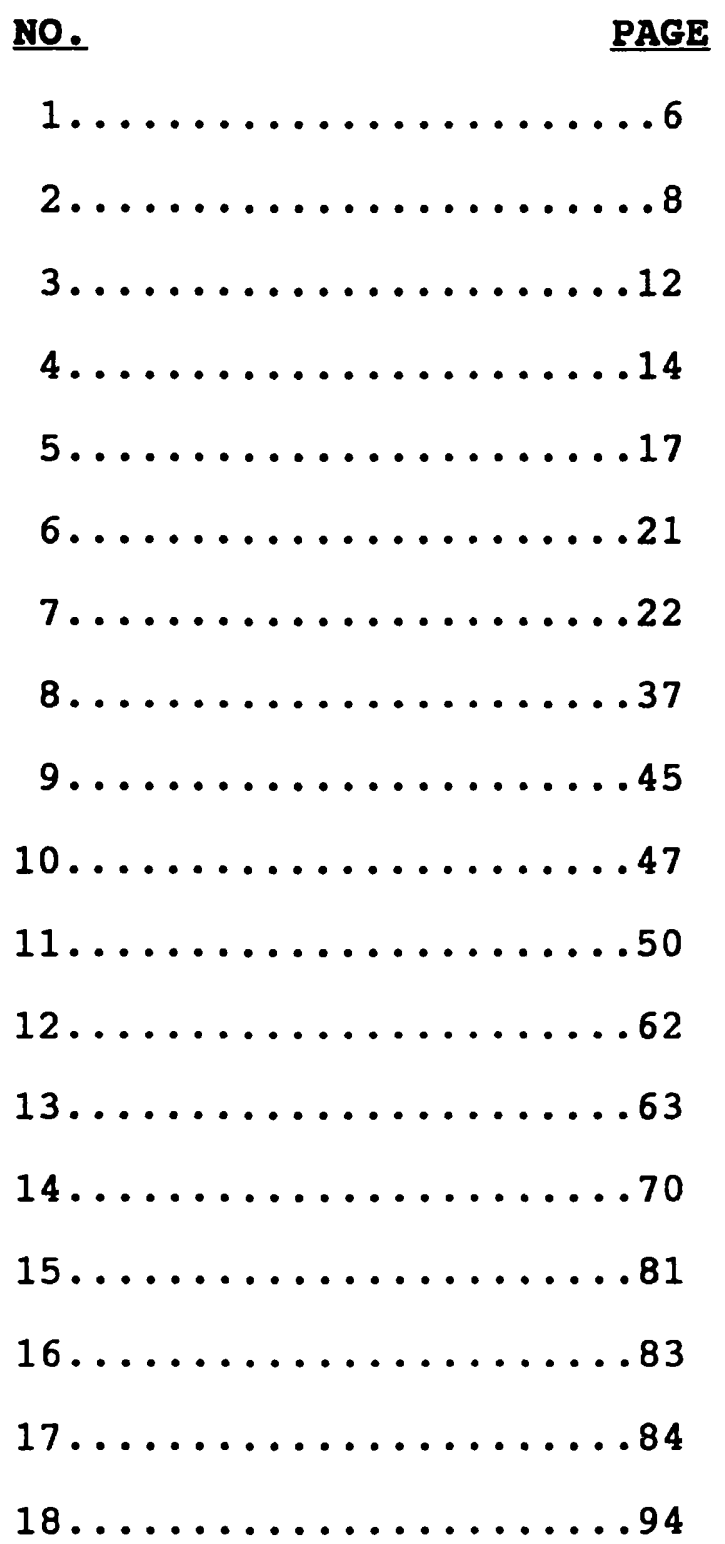

\section{F IGURES}

$1 \ldots \ldots \ldots \ldots \ldots \ldots \ldots$

$2 \ldots \ldots \ldots \ldots \ldots \ldots \ldots$

$3 \ldots \ldots \ldots \ldots \ldots \ldots \ldots \ldots$

$4 \ldots \ldots \ldots \ldots \ldots \ldots \ldots 27$

$5 \ldots \ldots \ldots \ldots \ldots \ldots \ldots$ 


\section{LIST OF TABLES AND FIGURES (CONTINUED)}

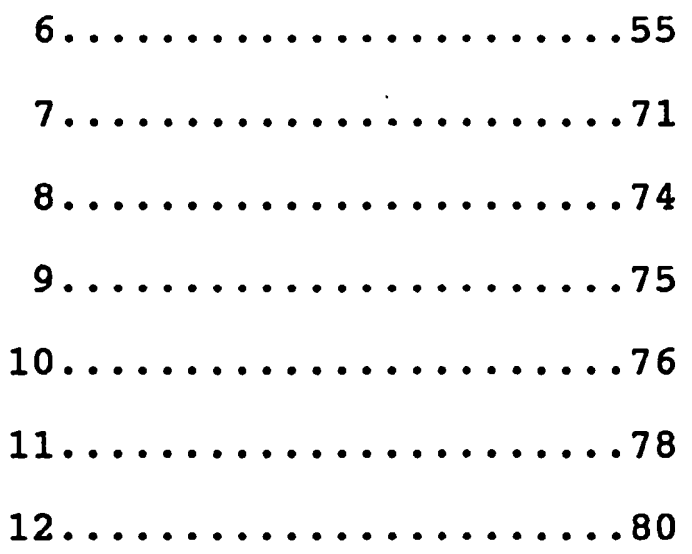

$13 \ldots \ldots \ldots \ldots \ldots \ldots . \ldots . \ldots . \ldots$

$14 a \ldots \ldots \ldots \ldots \ldots . \ldots . \ldots 85$

$14 b \ldots \ldots \ldots \ldots \ldots . \ldots . \ldots 86$

$15 a \ldots \ldots \ldots \ldots \ldots . \ldots 88$

$15 b \ldots \ldots \ldots \ldots \ldots . \ldots . \ldots 89$

$16 \ldots \ldots \ldots \ldots \ldots \ldots . \ldots . \ldots 96$ 


\section{ACKNOWLEDGEMENTS}

I wish to express my profound and sincere gratitude to my supervisor, Dr. N.W. Offer for his methodical suggestions and the useful discussions I had with him throughout the course of this research. He definitely made my work a lot easier.

Many thanks to Irene Yuill and John Wyllie for their assistance in feeding the sheep during the experimental stages of this research.

I am indebted to the technicians, Arlene Hamilton, Marianne Hunter and Kenneth McIsaac, for their help in carrying out the chemical analyses.

The Statistics and Computer Department cannot go unmentioned for their help with the data analysis and computor programming.

Thanks to the Librarian for making rare references available.

Finally I with to thank my beloved sisters and brothers for the encouragement and support I received from them. 


\section{ABBREVIATIONS}

\begin{tabular}{|c|c|c|}
\hline$\underline{\text { ad }} \underline{\text { lib }}$ & $=$ & ad libitum \\
\hline${ }^{\circ} \mathrm{C}$ & $=$ & Degrees Centigrade \\
\hline $\mathrm{cm}^{3}$ & $=$ & Cubic centimetre \\
\hline$d$ & $=$ & Day \\
\hline et $\underline{a l}$. & $=$ & and others \\
\hline$g$ & $=$ & Grams \\
\hline $\mathrm{kg}$ & $=$ & Kilogram \\
\hline 1 & $=$ & Litre \\
\hline $\mathrm{m}$ & $=$ & Metre \\
\hline mg & $=$ & Milligram \\
\hline MJ & $=$ & Mega Joule \\
\hline $\mathrm{ml}$ & $=$ & Millilitre \\
\hline $\mathrm{mm}$ & $=$ & Millimetre \\
\hline $\mathrm{mM}$ & $=$ & Millimole \\
\hline NS & $=$ & Non Significant \\
\hline $\mathrm{nM}$ & $=$ & Nanometre \\
\hline no. & $=$ & Number \\
\hline ppm & $=$ & Parts per million \\
\hline $\mathbf{P}$ & $=$ & Probability \\
\hline rpm & $=$ & Revolutions per minute \\
\hline $\mathrm{SE}$ & $=$ & Standard Error \\
\hline $\mathrm{uM}$ & $=$ & Micromole \\
\hline wt & $=$ & Weight \\
\hline 8 & $=$ & Percentage \\
\hline * & $=$ & Significant \\
\hline
\end{tabular}




\section{SUMMARY}

Six mature sheep fitted with rumen cannulae were assigned to six diets in a $6 \times 6$ Latin Square Design to examine the effects of a yeast culture (Yea-Sacc) on ruminal metabolism, rumen liquid outflow rate, fibre digestion and overall nutrient digestibility. The six dietary treatments were three diets differing in hay : concentrate ratio (90: 10, $65: 35$ and $40: 60$ ) fed either without (control) or with a supplement of $4 \mathrm{~g} /$ day of Yea-Sacc. Treatment periods were of three weeks duration.

There were significant $(P<0.05)$ effects of dietary forage : concentrate ratio on rumen function in agreement with the previous reports in the literature. Rumen $\mathrm{pH}$, rumen ammonia concentraticn, total volatile fatty acids concentration, and molar proportions of acetate, propionate and butyrate were not significantly affected by the inclusion of yea-Sacc in the control diets $(\geq<0.05)$. Ruminal liquid outflow rate was not different between treatments. Supplemental Yea-Sacc did not affect the overall nutrient cigestibility of organic matter, neutral detergent fibre and digestible energy measured in vivo.

The disappearance of hay organic matter from nylon bags incubated in the rumen for 24 hours was significantly ( $P<0.05)$ higher in sheep fed diets supplemented with Yea-Sacc than for those receiving the ursupplemented control diets. The values with and without Yea-SइCC for high, medium and low forage diets were 0.482 and $0.432,0.423$ and $0.366,0.360$ and 0.321 respectively. However, Yea-Sacc had no effect on hay disappearance when bags were incubated for 48 hours. Yea-Sacc 
appeared to increase initial rate of forage digestion in the rumen without altering overall feed digestibility or the pattern of production of fermentation end products. 


\section{INTRODUCTION}

Cereal grains and other concentrates are fed to cattle and sheep to provide a readily available energy source to the rumen microbial population, and thus improve animal productivity. However this often results in negative associative effects on digestion of structural carbohydrates presumably due to inhibition of cellulolysis resulting from changes in the rumen environment experienced by the cellulolytic bacteria (Mould et al., $1983 / 84$ ).

Several methods have been used successfully to manipulate the rumen microbial activity. The use of feed additives such as Monensin, have altered both the fermentation pattern and rumen liquid dilution rate (Lemenanger et al., 1978; Adams et al.., 1981). Recently dietary supplements of Yeast Culture have been reported to improve milk yields and increase milk fat percentages (Lyons, 1987; Williams, 1988) as well as increasing live weight gains and feed conversion efficiency (Adams et al., 1981; Fallon, 1987). The response have been inconsistant and contradictory in some cases and the mode of action of yeast cells on rumen metabolism remains unclear.

The effects of Yeast Culture on ruminal fermentation, liquid outflow rate and fibre digestion have been examined in a limited number of studies. The purpose of this study was therefore to examine the effect of dietary inclusion of a Yeast Culture, Yea-Sacc, on 1) rumen fermentation characteristics;
2) liquid outflow rate;
3) fibre
digestion and;
4) overall 
nutrient digestibility when sheep were fed restricted diets differing in their forage to concentrate ratios. The experiment aimed to identify the dietary type which gives the greatest response to yeast supplementation with a view to providing a basis for deciding when yeast supplementation is likely to be worthwhile in practice. Further, it was hoped that the experiment would provide information on the mode of action of Yeast Cultures and thus help to explain some of the inconsistant and contradictory responses found in practice. 


\subsection{DIGESTION IN THE RUMINANT}

The ruminant stomach is divided into four compartments namely, the rumen, the reticulum, the omasum and the abomasum. The last mentioned compartment corresponds to the stomach of the non-ruminant animals. The rumen contains one of the most varied and dense microbial population known in nature (Hungate, 1966). The role of these microorganisms is to modify the food consumed by the animal prior to its (food) exposure to chemical digestion in the lower tract. Here digestion is brought about by the enzymes secreted by host animal's own digestive juices, though plant enzymes can make a minor contribution to digestion (McDonald et al., 1988). The rumen microbiota possess an ability to convert plant material containing high propotions of cellulose and hemicellulose which would otherwise be indigestible, into products of nutritional value to the animal. Lignin, which occurs in association with cellulose, hemicellulose and pectin, when present in high quantities may however physically protect these cell wall materials from degradation by the rumen microbes. The rumen microorganisms also enable upgrading of low quality dietary protein to high quality proteins, as well as enabling ruminants to utilise dietary non-protein nitrogen as a protein source.

The end products of microbial fermentation include volatile fatty acids (principally acetic, propionic and butyric, VFAs) and gases as microbial waste products, and the microbial cells. The VFAs leave the rumen mainly by absorption across the rumen wall, 
and to a lesser extent by passage to the abomasum. In the host's tissues the VFAs are then oxidised and supply part of the animal's energy needs. The primary function of microbial fermentation is therefore to supply microbial energy requirements first, and those for the host animal come second. The microbial cells will eventually pass down to the abomasum and the intestines, together with the undegraded food components, where they will be utilised as a protein source and as a source of other nutrients required by the animal. The microbial mass synthesized in the rumen provides about 208 of the nutrients absorbed by the host animal depending on the composition of micro-organisms present in the rumen. The plant tissue which passes undigested from the rumen undergoes secondary fermentation in the caecum and large intestines and provides 8-308 of total digestible energy (Orpin and Anderson, 1988). Ruminal fermentation is however the main site of energy digestion as it provides 60-658 of digestible energy. The passage of the solid contents out of the rumen is a controlled flow which involves two important processes; the rhythmic movement of the rumen and rumination (Czerkawski, 1986). The gases, on the other hand, are removed by the process of eructation, and are regarded as heat loss. Finally, the microorganisms contribute to the host animal's vitamin supply, especially the $B$ vitamins (Lewis and Hill, 1983).

The host animal in return, provides the microbial population with a large fermentation vessel (rumen volume of sheep is 5-10 litres and that of cattle is 60-100 litres) through which a steady supply of the selected food is introduced, while the 
fermented products and food residues are continually removed. The host animal's physiological processes of chewing, mixing of rumen contents, salivation and rumination are of significance to the metabolic function of the rumen microorganisms. Chewing prepares food for microbial metabolism by reducing it to particles of smaller sizes. The mixing process is more of a means of communication within the rumen contents, hence brings the microbes in contact with the food particles, as well as spreading saliva throughout the rumen, and reducing the tendency of plant fragments to float. Rumination is equally important as it produces new fracture sites on the plant cell walls for microbial colonization. The rumen therefore provides a very favourable environment for the survival and activity of the microbes and a symbiotic relationship thus exists between the rumen microorganisms and their host animal.

\subsection{THE RUMEN MICROORGANISMS AND THEIR REQUIREMENTS}

The microbial ecosystem in the rumen is very complex. Vast numbers of microorganisms are found in the rumen, approximately $10^{6}-10^{9}$ cells/ml bacteria and $10^{6} \mathrm{cells} / \mathrm{ml}$ protozoa. The bacterial population constitutes 40-50\% of the total biomass while the protozoal species take up the other 40-508 (Coleman, 1975). Estimates of microbial numbers (Van Soest, 1982) are shown in Table 1. Protozoa are fewer than bacteria, but because of their large sizes they occupy a similar mass as the bacteria. The remaining mass of $5-108$ is occupied by the rumen fungi (Akin, 1986). Bacteria, Protozoa and Fungi have been observed to exist in three distinct but interacting habitats; rumen liquid, digesta 
Table 1. Relative volumes and numbers of microbial organisms (Van Soest, 1982).

\begin{tabular}{|c|c|c|c|c|c|}
\hline & $\begin{array}{c}\text { Nos/ml } \\
\times 10^{6}\end{array}$ & $\begin{array}{r}\text { Mea } \\
\text { vol }\end{array}$ & $\begin{array}{l}\text { cell } \\
\left(u^{3}\right)\end{array}$ & $\begin{array}{l}\text { Net } \\
\mathrm{mg} / 1\end{array}$ & $\begin{array}{l}\text { mass }^{2} \\
100 \mathrm{ml}\end{array}$ \\
\hline small bacteria & $16000^{b}$ & & 1 & 1 & 600 \\
\hline Selemonads & 100 & & 30 & & 300 \\
\hline \multicolumn{6}{|l|}{ flagellates } \\
\hline \multicolumn{6}{|l|}{ Cilliate protozoa } \\
\hline Entodinium & 0.3 & 10 & 000 & & 300 \\
\hline Dasytricha, Diplodium & 0.03 & 100 & 000 & & 300 \\
\hline Isotricha, Epidinium & 0.011 & 1000 & 000 & 1 & 100 \\
\hline
\end{tabular}

a estimated cell weight per $100 \mathrm{ml}$ rumen fluid assuming a density of 1.0

b organisms estimated by direct count from rumen contents of sheep fed alfalfa and wheat chaff.

fragments, and rumen wall.

\subsubsection{Bacteria}

Over 60 species of bacteria which widely vary in cell size, shape, structure and in metabolism exist in the rumen. About $30 \%$ of the total bacterial species live free in the liquid media of the rumen and approximately $70 \%$ are attached to feed particles while the remaining species had been observed to be adhering to the epithelial lining of the rumen, or attached to protozoa (mainly methanogens). The rumen bacteria can be divided into three major groups based on their substrate preference : (i) 
fibre, ( $i i)$ starch and sugar and ( $i i i)$ secondary digesters. Table 2 summerises some of the substrates that are digested in the rumen and the microorganisms which attack them; their general description and the fermentation products which result. The fibre digesting group consists of many species but the most significant are Fibrobacter ruminantum (Bacteroides succinogenes), Ruminococcus flavefaciens and $\underline{\text { Ruminococcus albus. }}$ Similarly the most important amylolytic species are streptococcus bovis, Selemonas ruminantium, B. amylophilus and Butryvibrio species. Some of the starch digesters can be cellulolytic too. Not all the fermentation products shown in Table 2 are found in the rumen. This is because of the existence of another group of bacteria, here referred to as secondary-digesters. This group utilise such products as succinate and lactate to produce the observed end products. Methanobacterium species which utilise hydrogen and carbon dioxide or formate to form methane are a further example. Bacteria also degrade proteins to peptides and amino acids.

\subsubsection{Protozoa}

About thirty-five anaerobic species of the ciliate protozoa have been identified in the rumen and they vary slightly. Flagellates are also found in both the rumen and the caecum (williams, 1986). The two ciliate groups, Isotrichide (holotrich) and Entodiniomorphid (oligotrich) include the genera Isotricha and Dasytricha, and Ophryoscolex, Diplodium and Entodinium respectively. Protozoa can ferment constituents of the plant material to energy for growth and maintenance (Hungate, 


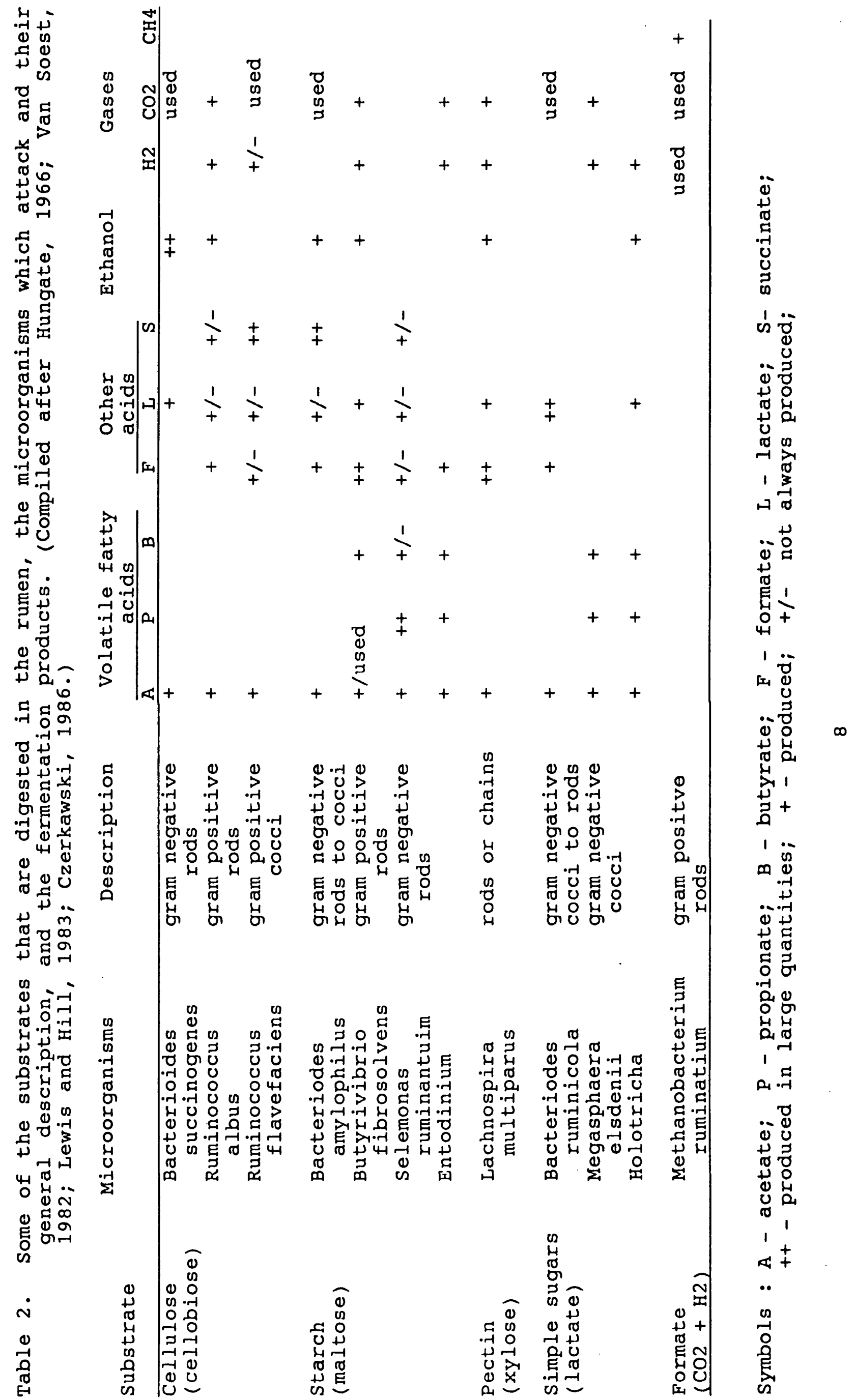


1966), but their major substrate appear to be soluble sugars and starch particles. In this way they often buffer the pH of

the rumen. Protozoa are also known to be proteolytic, engulfing and degrading bacteria, thus removing essential protein for their host animal (Hungate, 1966; Coleman, 1975). The principal protozoal fermentation products are acetate, butyrate and hydrogen, propionate being minor. Besides this, the actual role of protozoa in rumen metabolism and digestion is much less clear. Unlike bacteria, protozoa are difficult to cultivate in vitro for extended periods. Defaunation frequently has little effect on rumen digestion (Eadie and Mann, 1970) but may influence the balance of end-products.

\subsubsection{Fung 1}

The presence of anaerobic phycomycete fungi in the rumen of sheep and cattle has been demonstated recently. Anaerobic fungi have been isolated and cultured from a number of animal species, including sheep, goats and cattle, and some members of the deer family (Bauchop, 1979). For many years the flagellate organisms observed in the rumen, particulally in defaunated sheep were described as protozoa. At least three species, Sphaeromonas communis, Piramonas communis and Neocallimastix frontalis, are now known to inhabit the rumen, (Orpin, 1984) and more are being discovered. All three can ferment plant material as a source of energy. Fungi appear to be the first to attach, colonise, grow and commence digestion of structural plant fragments (Bauchop, 1979 ; Orpin, 1984; Akin, 1986; Preston and Leng, 1988) suggesting that they may play a significant role in fibre digestion. 


\subsubsection{Rumen Enviroment}

The two main factors which determine the successful growth and survival of rumen microorganisms, hence efficient food digestion, are the provision of a stable environment and the supply of energy together with the essential nutrients.

Most of the rumen microbes are facultative anaerobes and therefore can survive in the rumen. Anaerobic conditions are maintained in the rumen at almost all times, for any oxygen entering with the food and water or by diffusion across the rumen wall is quickly used up. Under normal conditions the $\mathrm{pH}$ remains fairly constant between 5.5 and 7.0 (Hungate, 1966; Van Soest, 1982), and most microbial species can grow in this range. The rumen $\mathrm{pH}$ is maintained within this range by the production and buffering capacity of saliva secreted by the animal. In addition, the rapid removal of the fermented VFAs (Van soest, 1982; McDonald et al., 1988) and ammonia (Briggs, et al., 1957; McDonald et al., 1988) help to stabilise the rumen $\mathrm{pH}$. It is both warm and moist in the rumen, with temperatures remaining around that of the host animal $\left(38-42^{\circ} \mathrm{C}\right)$. The osmotic pressure of the rumen contents is relatively constant and is kept near that of blood.

On the whole, the rumen environment appears to be controlled by the following :

- the type and quality of food eaten,

- periodic mixing through contraction of the rumen,

- salivation and rumination,

- diffusion or secretion into the rumen and

- passage of material down the digestive tract. 
Only under abnormal circumstances is the rumen environment drastically perturbed.

\subsubsection{Microbial Nutritonal Requirements}

There is considerable information on the nutrional requirements of the rumen microorganisms although most of this information is on bacterial needs rather than that of the protozoa and fungi. Table 3 shows that many bacterial species require carbon dioxide, ammonia, amino acids and vitamins, together with one or more of the branched or straight chain fatty acids for their growth and reproduction (Hungate, 1966; Van Soest, 1982; Lewis and Hill, 1983). Ammonia is the prefered nitrogen source of most rumen bacteria, especially the fibredigesting bacteria $\underline{B}$. succinogenes and $\underline{R}$. flaveflaciens. However, there are exceptions such as succinovibrio dextrinosolvens which require several preformed amino acids. Some starch digesters like $\underline{B}$. amylophilus can use ammonia as a sole source of nitrogen. The branched chain fatty acids (BCFA) iso-butyric, iso-valeric and 2-methyl-butyric acids and n-valeric acid are growth stimulators of certain ruminal bacteria, especially the cellulolytic organisms (Hungate, 1966; Klusmeyer, et al., 1987). Biotin, p-aminobenzoic acid or folic acid, thiamin, pyridoxine and pantothenic acid are among the vitamins required by some microbial species (Hungate, 1966; Sniffen, 1987). Most of these species also require. minerals such as calcium, magnesium, potasium, phosphorus, cobalt, iron, selenium, nickel, zinc and manganese. The rumen protozoa, on the other hand, do not require any complex organic nutrients synthesized by 
Table 3. Nutritional requirements of some bacteria of the rumen (complied from Hungate, 1966; Van Soest, 1982; Lewis and Hill, 1983).

\begin{tabular}{|c|c|c|c|c|c|}
\hline & $\begin{array}{r}\text { Carbon } \\
\text { dioxide }\end{array}$ & $\begin{array}{l}\text { Fatty } \\
\text { acid }\end{array}$ & $\begin{array}{l}\text { Amino } \\
\text { acid }\end{array}$ & Ammonia & Vitamins \\
\hline $\begin{array}{l}\text { Fibrobacter } \\
\text { ruminantum }\end{array}$ & $\mathrm{E}^{\mathrm{a}}$ & $E$ & - & $E$ & $\begin{array}{l}B(E) \\
\operatorname{PAB}(E)\end{array}$ \\
\hline $\begin{array}{l}\text { Ruminococcus } \\
\text { species }\end{array}$ & $E$ & $\mathrm{E}$ & + & $\mathrm{E}$ & $\begin{array}{l}B(E), \quad F(E) \\
P A(E), \\
R F(+/-)\end{array}$ \\
\hline $\begin{array}{l}\text { Bacteroides } \\
\text { amylophilus }\end{array}$ & $E$ & - & - & $E$ & none \\
\hline $\begin{array}{l}\text { Butyrivibrio } \\
\text { species }\end{array}$ & $+1-$ & $\mathrm{E} /-$ & $E /-$ & $E /-$ & $\begin{array}{l}B(E), \quad P(E) \\
P A B(E)\end{array}$ \\
\hline $\begin{array}{l}\text { Bacteriodes } \\
\text { ruminocola }\end{array}$ & $E$ & $E /-$ & - & $+1-$ & $\mathrm{E}$ \\
\hline $\begin{array}{l}\text { Selenomonas } \\
\text { ruminantium }\end{array}$ & $+1-$ & $\mathrm{E} /-$ & $\mathrm{E} /-$ & - & \\
\hline $\begin{array}{l}\text { Streptococcus } \\
\text { bovis }\end{array}$ & + & $+1-$ & $\mathrm{E} /-$ & $+1-$ & $\begin{array}{l}\mathrm{B}(\mathrm{E}), \mathrm{T}(+) \\
\mathrm{PTA}(+/-)\end{array}$ \\
\hline $\begin{array}{l}\text { Methano- } \\
\text { bacteruim }\end{array}$ & $\mathrm{E}$ & $E$ & & $E$ & $\mathrm{~B} 12(\mathrm{E})$ \\
\hline
\end{tabular}

a E : essential for growth; + : growth stimulation; - : not stimulatory; B : biotin; $\mathrm{F}$ : folic acid; $\mathrm{P}$ : pyridoxal; $\mathrm{PA}$ : pyridoxamine; $\mathrm{PAB}$ : p-aminobenzoic acid; PTA : pantothemic acid; RF : riboflavin; $T$ : thiamin;

the host animal (Hungate, 1966) and the rumen fluid is not essential for their growth. It has been observed however that they require proteins, peptides and amino acids. Little is known regarding requirements of rumen fungi other than the fact that elevated sulphur in the diet appears to enhance the number of these organisms. 


\subsection{THE FERMENTATION CHARACTERISTICS}

Carbohydrates are the major portion of the diet of ruminants, and they can be divided into the structural or fibrous and the non-structural or readily fermentable carbohydrates. Modern methods attempt to distinguish these two fractions. A neutral detergent solution had been used to extract cell contents of a feed, and the residue from this extraction (neutral detergent fibre or NDF) is considered to consists predominantly of cell walls, that is, the structural carbohydrates. structural carbohydrates include hemicellulose (extractable with acid detergent solution) and cellulose plus lignin (that is, acid detergent fibre or ADF). Starch, sugars and pectins fall under the non-structural carbohydrate (NSC) group. Figure 1 summerises the classfication of carbohydrates. Carbohydrates are fermented by the microbial mass in the rumen to give three main fatty acids; acetic, propionic and butyric acids, together with carbon dioxide, methane (Table 4) and heat. Proteins present in

Figure 1. Classfication of carbohydrates (after Sniffen, 1987).

Total Carbohydrate
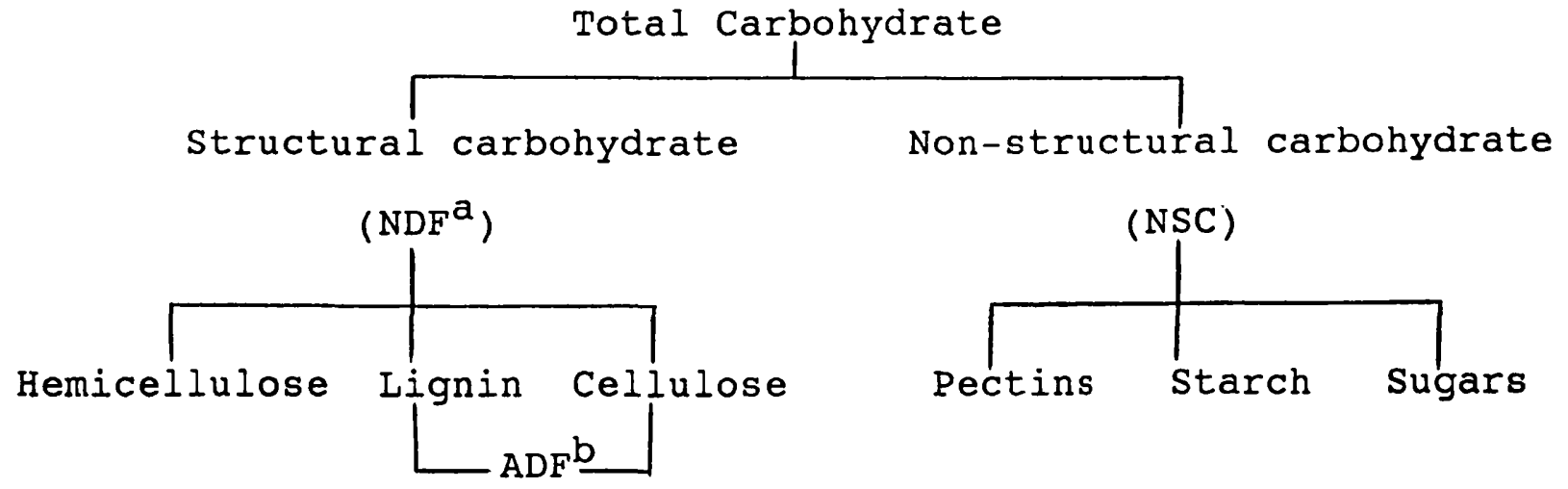

a neutral detergent fibre; b acid detergent fibre 
Table 4. Rumen fermentation products (modified from Bauchop, 1977; McDonald et al., 1988).

\begin{tabular}{lccccc}
\hline & $\begin{array}{c}\text { Total } \\
\mathrm{mM}\end{array}$ & Acetic & $\begin{array}{c}\text { Propionic } \\
\text { Molar }\end{array}$ & Butyric & Gases \\
litres
\end{tabular}

ruminant diets are degraded mostly to ammonia and some organic acids namely iso-butyric, iso-valeric and valeric acid. These acids are derived from the deamination of amino acids. Ammonia (and to a lesser extent small peptides) serve as the nitrogen source for microbial growth and thus become incorporated into microbial cell proteins. In cattle a typical daily production has been calculated to be $3.7 \mathrm{~kg}$ acetic acid, $1.1 \mathrm{~kg}$ propionic acid, and $0.6 \mathrm{~kg}$ butyric acid, which yields $399 \mathrm{~g}$ of bacterial and $315 \mathrm{~g}$ protozoal cells (dry weight) (Orpin and Anderson, 1988).

\subsubsection{The Volatile Fatty Acids}

Regular diurnal variations occur in the production of fermentation end-products in response to feeding. The fermentation characteristics of the rumen are therefore influenced by the composition of the diet as well as the time that has elapsed since the previous meal. For an animal fed with a 'normal' diet largely composed of forage or hay there is a rise in concentration of total and individual volatile fatty acids (VFAs) (Reid, 1957; Hungate, 1966; Van Soest, 1982). This is followed by a slow recovery to the original conditions (Figure 2). This is as expected besause total VFA concentration is closely related to the fermentation rate (Giesecke, 1970) which 


\section{Figure 2}

Rumen pH \& VFA of two sheep fed chopped alfalfa (Briggs et al., 1957).

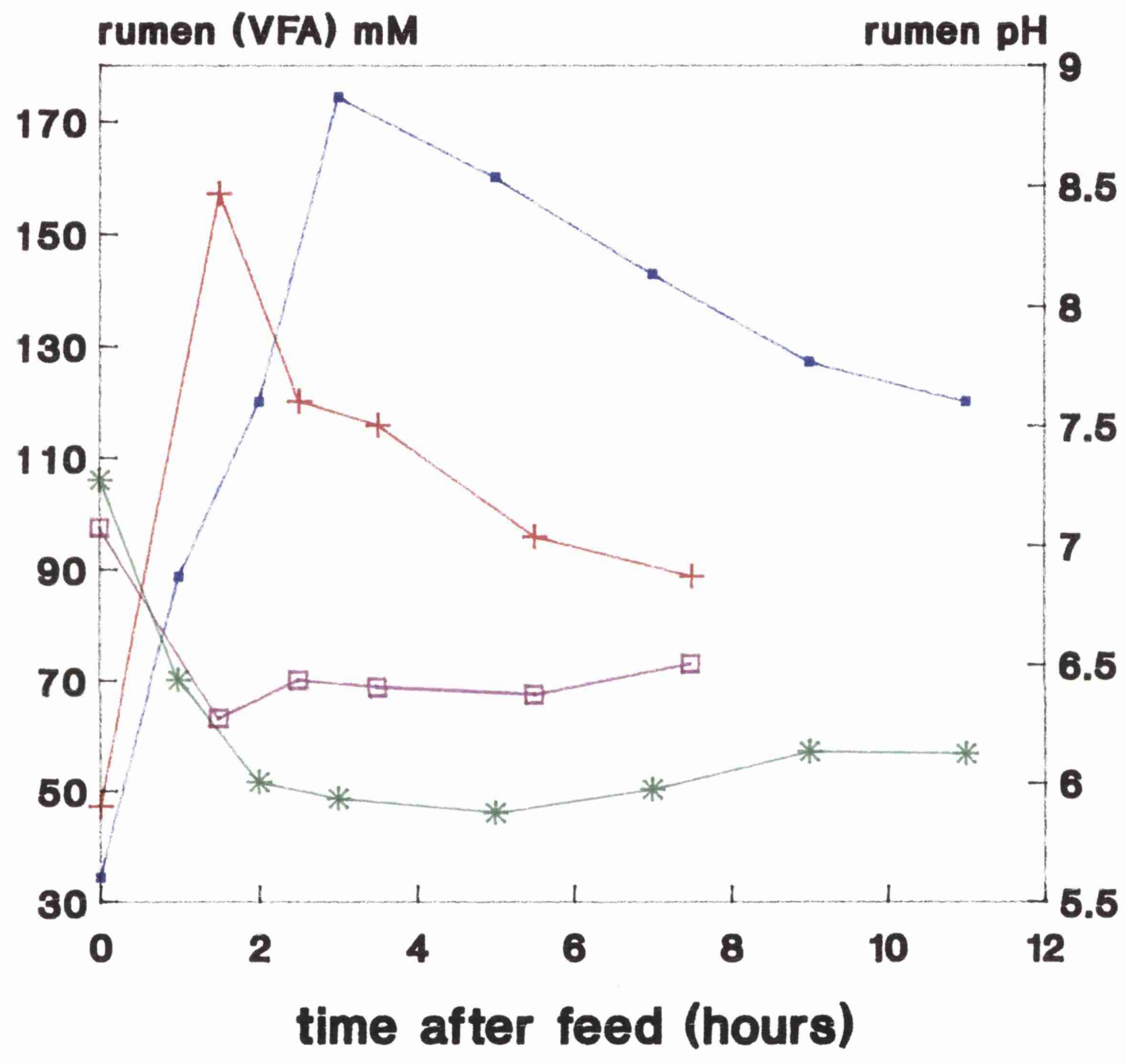

-.. VFA Sheep 1

+ VFA 8heep 2

* pH sheep 1

- P PH Sheep 2 
increases after the supply of substrates and decreases either because substrates are exhausted or accumulation of endproducts inhibit fermentation process.

\subsubsection{Molar proportion of volatile fatty acids}

The relative molar proportions (or fermentation pattern) of acetic, propionic and butyric acid also vary with time and diet composition. Pre-feeding fermentation pattern is normally fairly constant for roughage-fed animals with acetic acid predominating (Reid, 1957; Hungate, 1966; McDonald et al., 1988). After feeding, the relative molar proportions of acetic acid decreases while that of propionic and butyric acids increase (Table 5). Butyric acid's response is sometimes variable. Reid (1957) showed that the lowest level of acetic acid $(+62.0)$ and the highest for propionic acid $(+24.0)$ coincided with the maximum total VFA (98-101mM) level at 3-4 hours post-feeding. This is in agreement with other workers (Hungate, 1966; Barry et al., 1977a; Barry et al., 1977b) although slightly higher total VFA concentrations were observed in in vitro studies (Barry et al., 1977b). The fermentation pattern with roughages thus remains at $65: 20: 15$ for molar percentages of acetic, propionic and butyric acids respectively. Barry et al. (1977a) observed that for a roughage diet, VFA ratios were relatively constant, both within each day, and from day to day over 21 days.

\subsubsection{Rumen pH}

on forage diets, rumen $\mathrm{pH}$ is closely associated with VFA levels in the rumen. (Briggs et al., 1957) with pH falling after feeding and reaching the lowest values approximately 4 hours 
Table 5. Amounts and proportions of volatile fatty acids in sheep rumen contents at various times after feeding (Hungate, 1966).

\begin{tabular}{|c|c|c|c|c|c|c|}
\hline \multirow{2}{*}{\multicolumn{2}{|c|}{ Ration }} & Hours after & Total VFA & & $\%$ molar of & acids \\
\hline & & feeding & umole/ml & Acetic & Propionic & Butyric \\
\hline \multirow{7}{*}{\multicolumn{2}{|c|}{ wheat hay }} & 0 & 49.0 & 69.4 & 16.7 & 13.9 \\
\hline & & $1 / 2$ & 58.1 & 67.3 & 19.6 & 13.1 \\
\hline & & 1 & 67.6 & 66.0 & 20.4 & 13.6 \\
\hline & & 4 & 93.4 & 61.3 & 24.4 & 14.3 \\
\hline & & 7 & 108.0 & 61.9 & 23.5 & 14.6 \\
\hline & & 12 & 109.0 & 66.8 & 19.6 & 13.6 \\
\hline & & 24 & 82.5 & 69.1 & 17.0 & 13.9 \\
\hline \multirow{7}{*}{\multicolumn{2}{|c|}{ alfalfa }} & 0 & 51.4 & 69.6 & 14.8 & 15.6 \\
\hline & & $1 / 2$ & 112.0 & 67.4 & 18.7 & 11.9 \\
\hline & & 1 & 138.0 & 68.1 & 20.2 & 11.7 \\
\hline & & 4 & 176.0 & 70.1 & 18.9 & 11.0 \\
\hline & & 7 & 193.4 & 71.2 & 18.7 & 9.8 \\
\hline & & 12 & 187.0 & 71.8 & 17.7 & 10.5 \\
\hline & & 24 & 75.7 & 68.3 & 16.1 & 15.6 \\
\hline
\end{tabular}

later before rising slowly to initial levels (Figure 2). Roughage diets lead to only a small pH depression such that the $\mathrm{pH}$ value is normally not below 6.0 (Reid et al., 1957; Bath and Rook, 1961; Barry et al., 1977b). $\mathrm{pH}$ is a function of both production and absorption of the VFAs and a change in their proportion has little effect because pKa values of acetic, propionic and 
butyric acids are very similar $(4.73,4.85,4.82$ respectively). However, excessive production of lactic acid, for example when high concentrate diets are fed, reduce $\mathrm{pH}$ due to the acid's low pKa value (3.86) (Briggs et al., 1957; Williams, 1987). It cán be concluded that through out the day the rate of fermentation in the rumen, as assessed by the $\mathrm{pH}$ and total VFA, is not constant but is minimal immediately before feeding and reaches a peak a few hours after, before it decreases.

\subsubsection{Microblal species and the roughage diet}

In the rumen of roughage-fed animals there is little variation in the numbers and types of rumen microbes. However, slightly higher bacteria concentrations (numbers/ml) were observed before feed consumption than several hours after. Probably the diminishing count during feeding was a result of the dilution effect of both feed and saliva. Saliva contains about 998 water (McDonald et al., 1988) and cattle and sheep produce 150 litres and 10 litres per day respectively. The fibredigesters dominate with roughage diets. No changes have been recorded for protozoa species and fungi although less protozoa numbers were observed with high concentrate diets in a few studies.

\subsubsection{Rumen Ammonia}

The sources of ammonia in the rumen include proteins, peptides, amino acids and other nitrogenous compounds. Urea, uric acid and nitrate are rapidly converted to $\mathrm{NH}_{3}$ in the rumen. The levels of $\mathrm{NH}_{3}$ in the rumen vary from $0-230 \mathrm{mg} / 1$ (Hungate, 1966). Like other fermentation products, the concentration of $\mathrm{NH}_{3}$ in the rumen contents vary with time after a meal, as well as the 
content and type of protein in the diet. With forage diets, the concentration generally increases to maximum at about 4 hours after feeding before it falls back to normal levels.

\subsubsection{Gas production}

Carbon dioxide and methane are the major gases produced in the rumen accounting for approximately $65 \%$ and $27 \%$ (McDonald et al., 1988) respectively of the total produced per day. The remaining percentage is composed of nitrogen and traces of oxygen, hydrogen and hydrogen sulphide. Cattle can produce up to 600 litres of gases per day and 90 litres in sheep. The rate of production is most rapid immediately after a meal. Concentration of oxygen and nitrogen increase during feeding whilst those of carbon dioxode and methane decrease (Barry et al., 1977a). Thereafter the latter gases rapidly increase. These workers also found that the carbon dioxide : methane ratio increased rapidly following feeding and then decreased to base levels $2-4$ hours after feeding.

\subsection{FACTORS AFFECTING THE FERMENTATION CHARACTERISTICS}

\section{4 .1 Forage : concentrate ratio}

Concentrates such as cereal grains and molasses are added to roughage diets of ruminant animals in order to meet, within the animal's intake capacity the great demand for nutrients of highly productive ruminants such as the dairy cow. Carbohydrates, particularly starch, have been far the most important quantitatively because of their surperiority as a source of energy under anaerobic conditions. Increasing the proportion of concentrate (concentrate in this text refers to the high energy 
concentrate) to forage in a ration however, resulted in several deviations from the 'normal' or roughage fermentation characteristics. The 'concentrate' pattern is characterised by :

- reduced mean molar percentage of acetic acid and increased molar percentage of propionic acid;

- reduced ratio of acetate : propionate;

- decreased rumen $\mathrm{pH}$;

- reduction in the numbers of cellulolytic and other fibre digesting bacteria;

- reduced fibre digestion;

- increased numbers of lactic acid and propionic acid bacteria;

- disappearance of ciliate protozoa in most cases, and

- reduced methane production.

Table 6 sumarises some of these characteristics.

The extent and details of the fermentation changes are highly dependent on the actual proportions of concentrate replacing the forage part of the ration as well as its chemical composition assuming that the physical characteristics of the forage is standard. The chemical composition, in terms of dry matter percentages of structural carbohydrate (by difference), starch and soluble carbohydrate, for hay is as follows : 61.6, not determined, 13.4 ; for a concentrate mixture : $24.9,33.5,8.4$; and for flaked maize : $1.3,78.0,3.7$ respectively (Bath and Rook, 1963). Thus, concentrates and grains contain more soluble and easily digestible components in comparison to roughages. It is these components which cause fermentation in the rumen to progress more rapidly. 
Table 6. Fermentation characteristics of varying forage : concentrate ratios (Thomas and Rook, 1981; Van Soest, $1982)$.

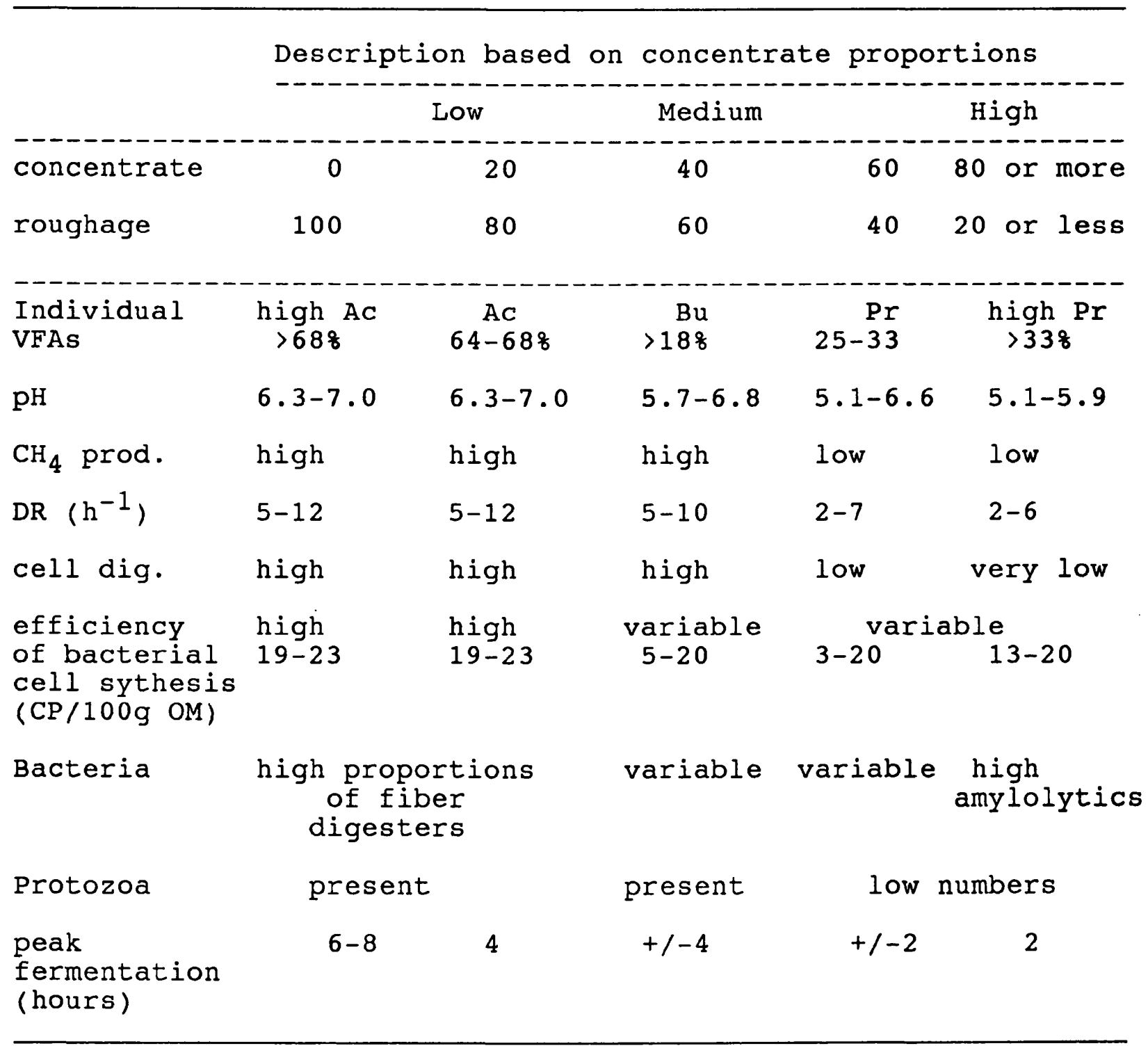

VFA Volatile fatty acids; Ac - acetic; Pr - propionic; $\mathrm{Bu}$ - butyric

prod. - production; dig. - digestion; $\mathrm{CH}_{4}$ - Methane

DR - dilution rate; OM - organic matter; CP - crude protein

\subsubsection{Volatile fatty acids and forage : concentrate ratio}

As the proportion of concentrate to forage in a ration 
increases, the molar proportion of propionic acid tends to increase. The increasing propionate proportion is accompanied by a fall in molar proportion of acetic acid and this is described as the establishment of a propionate fermentation pattern (Sutton, 1968; Harrison et al., 1976; Mould, Orskov and Mann, 1984/84). The response of butyric acid proportion to increasing concentrate levels is variable. Table 7 summarises the responses

Table 7. Volatile fatty acids (VFA) in the rumen liquor of cattle and sheep fed various hay : concentrate ratios (after Sulton, 1968; Nicholson and Sulton, 1969; McDonald et al., 1988).

\begin{tabular}{|c|c|c|c|c|c|c|c|}
\hline \multirow[t]{2}{*}{ Animal } & \multicolumn{2}{|c|}{ Diet } & \multirow[t]{2}{*}{$\begin{array}{l}\text { Total VFA } \\
\text { mMoles / }\end{array}$} & \multicolumn{4}{|c|}{$\begin{array}{c}\text { Individual VFAs } \\
\text { molar } 8\end{array}$} \\
\hline & & & & Acetic & Propionic & Butyric & Other \\
\hline \multirow[t]{5}{*}{ sheep } & 100 & 0 & 97 & 66 & 22 & 9 & 3 \\
\hline & 80 & 20 & 80 & 61 & 25 & 11 & 3 \\
\hline & 60 & 40 & 87 & 61 & 23 & 13 & 2 \\
\hline & 40 & 60 & 76 & 52 & 34 & 12 & 3 \\
\hline & 20 & 80 & 70 & 40 & 40 & 15 & 5 \\
\hline \multirow[t]{2}{*}{ sheep } & 75 & 25 & 51.3 & 69.6 & 19.6 & 7.8 & - \\
\hline & 20 & 80 & 61.8 & 66.7 & 17.0 & 13.1 & - \\
\hline \multirow[t]{2}{*}{ cattle } & $\begin{array}{c}40 \\
\text { (long) }\end{array}$ & 60 & 96 & 61 & 18 & 13 & 8 \\
\hline & $\begin{array}{l}40 \\
\text { elleted }\end{array}$ & 60 & 140 & 50 & 30 & 11 & 9 \\
\hline cattle 1 & 70 & 30 & 75.3 & 70.5 & 17.8 & 9.6 & 2.1 \\
\hline cattle 2 & 70 & 30 & 58.5 & 70.8 & 17.8 & 9.4 & 2.7 \\
\hline cattle 1 & 20 & 80 & 65.4 & 50.3 & 33.3 & 11.3 & 5.1 \\
\hline cattle 2 & 20 & 80 & 59.5 & 54.8 & 25.1 & 14.0 & 6.1 \\
\hline
\end{tabular}

conc. - concentrate 
of VFA proportions to various roughage-to-concentrate ratios.

It appears that the high levels of propionic acid in the rumen are obtained when more than $50 \%$ concentrate is included in the ration (Table 6 and 7). In fact, Mould et al., (1983/84) found that as the levels of barley were increased up to 508, the molar proportion of propionic acid remained fairly constant ( 248 ) before it increased slightly to 298 and sharply to 408 with 758 and 1008 barley respectively. This work is in agreement with earlier work by Bath and Rook (1963). These authors observed little change in molar proportion of propionate between hay : concentrate ratios of $3: 1$ and $1: 1$, but a large increase of this acid at the 1:3 ratio.

\section{$1.4 .1 .2 \mathrm{pH}$ and forage : concentrate ratio}

It is well documented that feeding high proportions of concentrates or cereal grains decrease rumen pH. pH levels below 5.0 (Briggs et al., 1957) are associated with an accumulation of lactic acid in the rumen on diets containing very high proportions of soluble carbohydrates or starch particularly when the diets are offered in large meals to animals that have not been accustomed to this type of diet. From the data obtained after feeding sheep with a wide range of diets, Briggs (1957) and his collegues concluded that the rumen $\mathrm{pH}$ rarely falls outside the range of 5.0-7.5 on diets where lactic acid never accumulates in the rumen after feeding.

In a study to examine the effects of levels and types of barley supplementation on rumen pH, Mould et al., (1983/84) observed that all forms of barley (Figure 3) up to and including 
508 dietary inclusion level depressed rumen $\mathrm{pH}$ to equal extents. Thereafter the decrease was greatest with the pelleted whole barley reaching $\mathrm{pH}$ values of 5.6 and 5.3 at levels of $75 \%$ and 1008 respectively. Corresponding values for pelleted ground and whole barley were 5.7 and 5.4 , and 6.1 and 5.8 respectively. These results show that processed barley depresses $\mathrm{pH}$ more than unprocessed barley. The $\mathrm{pH}$ depression was accompanied by reduced rates of hay and cotton thread degradation in the rumen for all diets up to 508 inclusion; partial inhibition at 758 level and total inhibition at 1008 grain. Low rumen $\mathrm{pH}$ is associated with decreased cellulose digestion (Stewart, 1977), hence decreased fibre degradation (El Sharzky, 1961; Stewart, 1977; Mould and Orskov, 1983/84; Mould et al., 1983/84; Hoover, 1986). Concentrate levels greater than 508 appear to have a greater

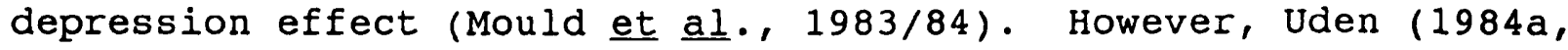
1984b) suggested that the rumen may be even more sensitive to concentrate and that inclusion of readily fermentable carbohydrate or grain in excess of 308 may depress fibre digestion.

\subsubsection{Fibre digestion}

Recently, Hoover (1986) proposed three theories to explain why high proportions of readily fermentable carbohydrate (RFC) in a ration depress cellulose digestion. The theories can be summarized as (i) the carbohydrate effect, (ii) the pH effect and (iii) competition for essential nutrients by amylolytic microbes.

These factors are similar to those proposed by El shazlky et al. (1961) and it is not easy to regard these theories separately. Theory one and two are interrelated, and Mould and Orskov 
Figure 3

Effect of level \& type of barley

supplement on pH (Mould et al., 1983/84)

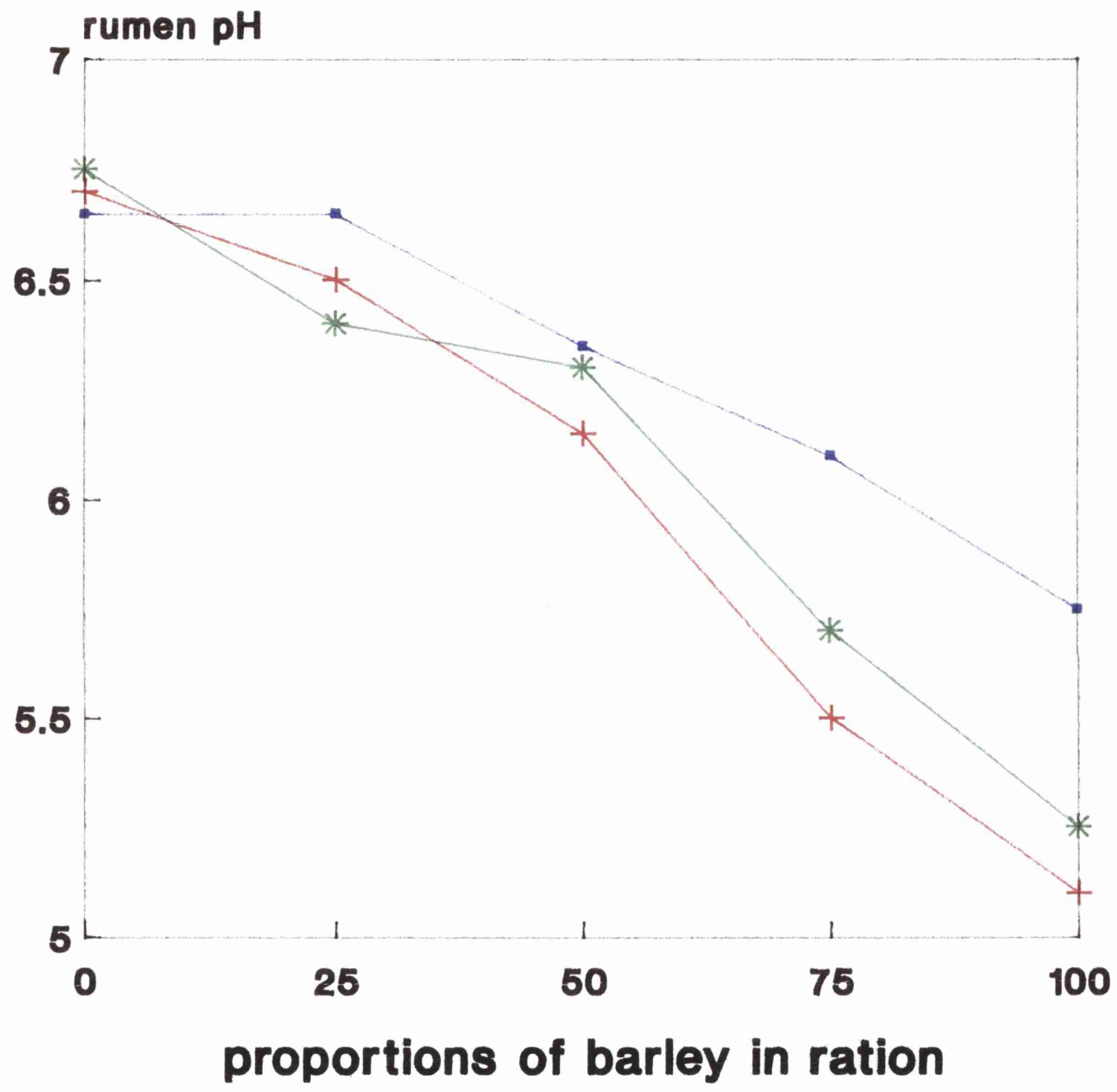

-Whole + Pelleted whole $*$ Pelleted ground 
(1983/84) suggested that added soluble sugars or starch decreased fibre digestion through a series of events involving carbohydrate preference, reduced rumen $\mathrm{pH}$ and decreased numbers of cellulolytic organisms.

\section{(i) Carbohydrate effects}

The non-structural carbohydrates (NSC), sugars and starch (see Figure 4) are easily and rapidily digested. Typical rumen digestibilities for starch and sugars are 1008 and $90 \%$ respectively. The value for starch is dependent on its source (for example, 968 of flaked maize, 928 of barley and 788 of ground maize is digested in the rumen of sheep) and level of intake. Starch and sugars are therefore preferred by the rumen microoganisms to the fibrous component. The fermentation of cell constituents (hemicellulose and cellulose) often does not commence until about six hours after feeding (Figure 4). This could be explained by the fact that cellulolytic bacteria need to attach themselves (through the glycocalyx present in their cells) to the fibrous substance before significant digestion occurs (McDonald et al., 1988; Van Soest, 1982). Protozoa and fungi have been found to attach to the plant fragments too. It appears that fungi attaches to the plant cell wall first and this allows bacteria to colonise the plant material more easily (Bauchop, 1979; Preston and Leng, 1988), hence this might reduce the lagphase of fibre digestion by the cellulolytic bacteria. However the NSC are attacked first by the microorganisms before the cell wall components. The preference for a readily fermentable energy source by the microbes is supported by Mould and orskov 


\section{Figure 4 \\ Theoretical curves for ruminal \\ fermentation patterns (Johnson, 1976)}

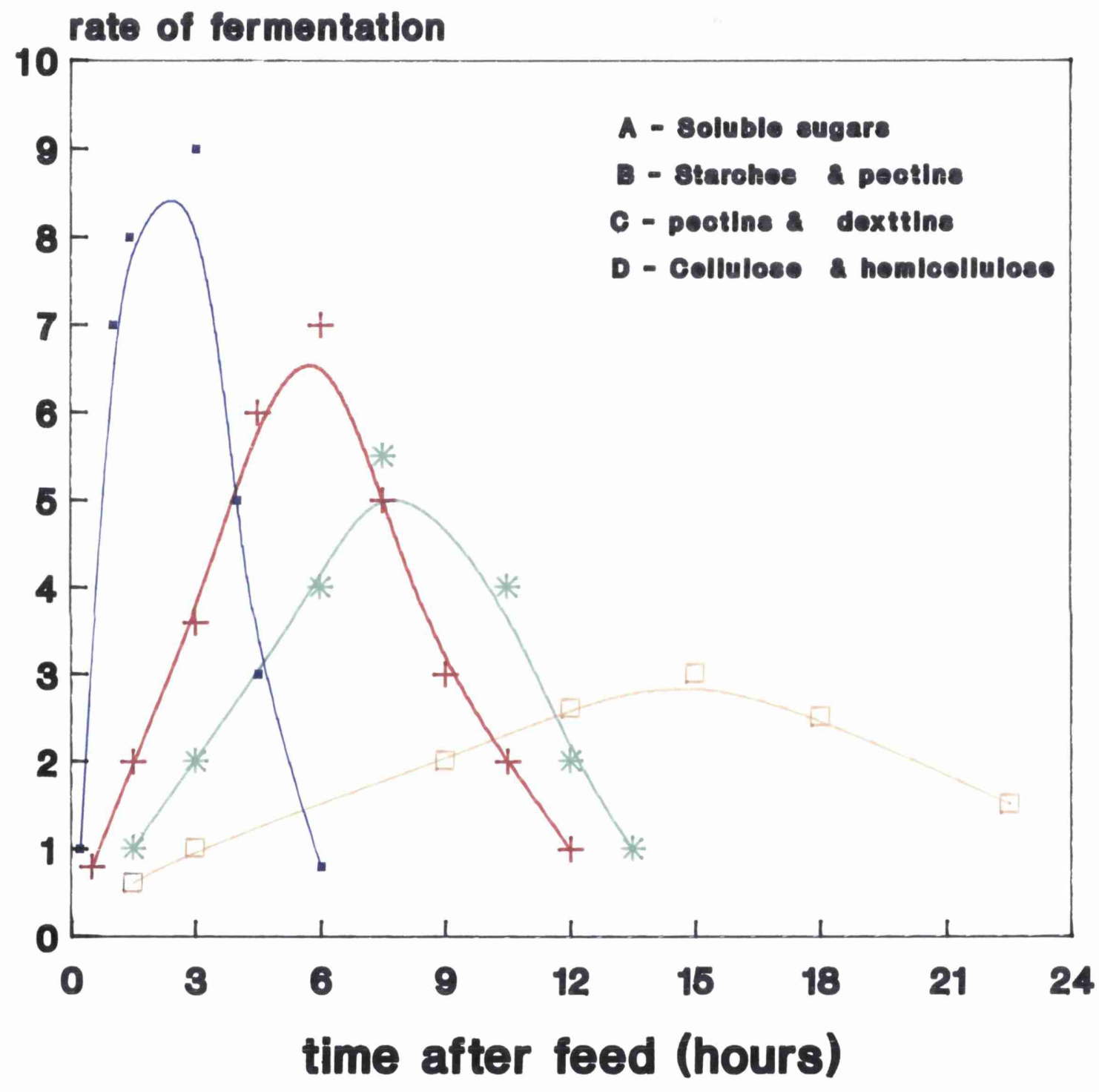

$\rightarrow \mathbf{A}+\mathbf{B} \rightarrow \mathbf{C} \rightarrow \mathbf{D}$ 
(1983/83)'s work. They observed that cellulolysis was only partially restored when the rumen $\mathrm{pH}$, for sheep fed a concentrate diet, was alleviated by infusion of a bicarbonate solution.

\section{(ii) pH effect}

A decrease in rumen $\mathrm{pH}$ depresses fibre digestion both in vivo and in vitro, and a fall in $\mathrm{pH}$ to 5.2 (Stewart, 1977) for the barley-supplemented rumen was associated with a marked depression of cellulolysis. No depressions were observed in the control vessel containing rumen fluid from sheep fed a roughage diet. This was also the case in another vessel whose contents were maintained at a $\mathrm{pH}$ value of 6.6. This work was in agreement with that of Mould and Orskov, (1983/84) who showed that as pH was moderately reduced from 6.8-6.0 only small depressions of fibre digestion were observed. A further decrease in $\mathrm{pH}$ to below 6.0 caused severe inhibition in cellulose digestion. This is confirmed by Mertens (1979) who indicated that a change in rumen $\mathrm{pH}$ to 6.4 , and to 6.0 reduced fibre digestion to 808 and 658 (respectively) of that occuring within the optimum pH range of 6.7-7.1. The $\mathrm{pH}$ 6.0-6.1 has thus been designated as the "cellulolysis threshold" (Mould et al., 1983/84), below which fibre digestion is criticaly depressed.

\section{(iii) Rumen spectes and fibre digestion}

There is a close relationship between the numbers and types of bacteria, and the depression or inhibition of fibre digestion. Mould and Orskov $(1983 / 84)$ observed that the number of cellulolytic microbes present in the fluid was reduced from $10^{6}$ to $10^{4} / \mathrm{ml}$ when diets were changed from all-hay to all-barley. $\mathrm{pH}$ was subsequently reduced. Stewart (1977) also found a 
simultaneous fall in the number of filter paper-degrading bacteria from $10^{6}$ to $10^{3} / \mathrm{ml}$ as $\mathrm{pH}$ dropped from 6.9 to 6.0 . On the other hand, the carbohydrate-utilising bacteria dominated (Leedle et al., 1982), while cellulolytics constituted lesser proportions in animals on a high concentrate diet. Therefore, cellulose digestion is almost completely inhibited below pH 6.0 because of the loss of activity at these $\mathrm{pH}$ levels, or because of depressed growth and gradual destruction of the cellulolytic organisms.

There are suggestions that attachment of microorganisms to fibre may be interferred with by the decreased rumen pH leading to reduced fibre digestion. Cheng et al. (1984) reported that low ruminal $\mathrm{pH}$ prevented a tight attachment of bacteria to cell walls. This concept has since received support from Shriver's et al. (1986) work with continuous cultures of rumen contents given a high concentrate diet. 45 \& less microbes were associated with fibre particles at $\mathrm{pH} 5.8$ than for the averages obtained at $\mathrm{pH}$ 6.2 and 7.0. The corresponding decrease in total microbial numbers was only $15 \%$.

(iv) Competition for nutrients among rumen microbes

It is suggested (Hoover et al, 1986) that under conditions of high fermentable carbohydrates (and also limiting protein), the ammonia concentration required for optimum growth of cellulolytic organisms may be increased. Cellulolytic growth activity, and cellulose digestion is reduced when readily fermentable carbohydrate (RFC) is fed to animals. In addition high RFC would encourage rapid growth of amylolytic microbes that require 
amino acids and peptides, which in turn would limit availability of amino acids and ammonia-nitrogen for the fibrolytic microbes

\subsubsection{Ammonia in the rumen and forage: concentrate ratio}

Many rumen microbes, including those fermenting cellulose, starch and sugars, ferment dietary protein consumed by ruminants as well as organic (e.g. amino acids, amides and amines) and inorganic (e.g. urea) non-protein compounds present in ruminant feeds. Ammonia and a mixture of organic acids are the main end products. Ammonia is essential for the growth and activity of many rumen microorganisms. The rumen microorganisms assimilate and incooperate amonia into cellular proteins (40-608 dry matter of microbial cells is protein). Ammonia in the rumen is therefore the key intermediate in the microbial degradation and synthesis of protein. Excess ammonia is absorbed through the rumen epithelium into the blood stream for excretion as urea although some of this may be recycled to the microbes via the saliva.

In the presence of large amounts of highly fermentable carbohydrates, providing a readily available energy source for the rumen microbial population, the demands for ammonia increase thus diminishing its concentration in the rumen pool. Therefore, feeding high proportions of energy-rich concentrates decreases the rumen ammonia concentrations (Annison et al., 1954). Sometimes ammonia levels may go below the minimum level (for example, when ammonia release from undegraded protein (UDP) is slow and unsynchronised with fermentation) for maximal fermentation rate, thus retarding the breakdown of the structural carbohydrates. The minimal level of ammonia concentration in the 
rumen required for maximum rate of fermentation or for optimal bacterial growth had been predicted at $235 \mathrm{mg} / 1$ or more in in vivo studies, and 50-60mg/l in in vitro studies (Rogers et al., 1986). Different optima, for example 5-8mg $\mathrm{N} / 100 \mathrm{ml}$, for maximum microbial synthesis rate have been found by other researchers (Satter and slyter, 1974) suggesting that diet may be a major influence of the optimum ammonia levels in the rumen.

\subsection{RUMINATION AND SALIVATION AND FORAGE :- CONCENTRATE RATIO}

The foregoing discussion emphasized the importance of the rumen microbial population and their activity in the rumen, and the changes both in population and fermentation end products when high proportion of concentrates are fed. Extensive physiological work is also necessary for ruminants to be able to use roughages. This work is mainly achieved by the processes of rumination and salivation. Significant differences between diets are thus expected to influence the functions of the two processes.

During rumination the fibrous rumen ingesta at the anterior end of the reticulo-rumen are drawn back into the oesophogus and returned to the mouth by a wave of contractions. The food is rechewed and mixed with saliva, a lactating dairy cow producing up to $182 \mathrm{~kg}$ saliva/day (Sniffen, 1987), sheep 6-10l/day and mature cattle up to $1501 /$ day. The formed bolus is then swallowed and returned back to the rumen. It is believed that rumination is induced by the tactile stimulation of the epithelium of the anterior rumen (Hungate, 1966; McDonald et al.,1988) while saliva secretion is stimulated probably by consumption of coarse fibrous foods as well as by the act of rumination. Thus diets composed 
predominantly of roughages would be more expected to stimulate salivary secretion and rumination than diets which lack these physical/fibrous characteristics. This conclusion assumes that mechanical stimulation is the main factor promoting the two processes.

\subsubsection{Particle size of the diet.}

Diets which contain little or no coarse roughage may fail to provide sufficient stimulation for rumination. It is now well established that feeding high proportions of concentrates and little roughage, or diets containing a normal proportion of finely ground roughage reduces ruminating time (Balch, 1971; Welch and Smith, 1971; Welch and Smith, 1972). Processed cereals reduce ruminating time more than the unprocessed grain. For example, feeding loose whole barley (Orskov et al., 1974) instead of pelleted whole increased ruminating time from 3.6 to $6.6 \mathrm{~h}$ per 24 hours. Grazing animals spend about 8 hours per day ruminating (McDonald et al., 1988) and 10-12 hours ruminating and chewing.

\subsubsection{Chemical characteristics of the diet}

Welch and Smith (1970) indicated that intake of cell wall constituents was highly related to rumination activity of sheep and cattle. Diets low in cell wall constituents such as concentrates and cereal grains, would be expected to reduce rumination. It has already been stated that concentrates and cereal grains reduce rumen $\mathrm{pH}$. Welch (1982) found that huge decreases in $\mathrm{pH}$ were associated with reduction and eventual cessation of rumination when sheep were fed large quantities of 
soluble carbohydrates. The pH values decreased from 7.48 before feeding to about 5.82 four hours later and 4.75 ten hours after feeding. The control diet, where rumination was not affected, $\mathrm{pH}$ changed insignificantly from 7.23 to 7.15 before rising back to normal. This emphasises the importance of the buffering capacity of rumination and salivation processes.

\subsubsection{Rumination and milk production}

An interaction exists between rumination, physical/fibrous nature of the diet, proportion of RFC in the ration, and feed particle size. In a study on rumination stimulation and milk fat depression, rumination and milk fat were depressed by feeding ground pelleted hay with concentrates and a limited amount of long hay (Welch and Smith, 1972). Stimulation of rumination by addtion of $5 \mathrm{~cm}$ long polypropylene ribbon returned rumination to normal but not milk fat content. Therefore other factors were affecting the milk composition other than rumination. Replacing ground hay and long hay returned both rumination and milk fat content to normal. Concentrates or diets high in RFC are known to reduce molar proportions of acetic acid in the rumen as compared to roughages, and this is required for milk fat formation. However it was not just the presence of hay which improved milk fat content, but the form of hay seemed to matter too. The size of particles passing from the rumen was observed to be critically important in controlling the appetite of ruminants, as well as rumination (Welch, 1982). Thus depriving ruminants of the rumination function reduced intake for steers fed hay.

The extent of rumination thus appears to be an important 
factor affecting the ability of the animal to control rumen $\mathrm{pH}$. It may act as a moderating influence on the severity of the effects caused by feeding high levels of RFC. If the effect of a change in diet is not only to increase rate of fermentation in the rumen, but also to inhibit rumination (e.g. by removal of all long forage from the diet), then the metabolic and production consequence of the dietary change would be greater than if rumination activity were to be maintained. Similarly any feed additive or process that could be shown to stimulate rumination would be expected to confer a degree of protection to the animal from the consequences of a large intake of RFC.

\subsubsection{Forage : concentrate and Liquid movement through the rumen}

The ruminant's complex physiological processes of chewing, mixing of rumen contents, salivation and rumination contribute to the stratification, which occurs in the rumen contents, into a liquid and a solid phase.

The liquid fraction contains water, soluble feed components, and the soluble degraded nutrients while the solid fraction contains the undegraded and indigestible material. The volume of the former fraction is generaly greater than that of the latter because of the water entering the rumen during ingestion as well as the salivary secretions produced during salivation and rumination processes. Several terms have been used to describe the movement of fluid through the rumen or out of it, and these include terms such as liquid outflow rate (LOR), liquid dilution rate $(L D R)$, liquid turnover rate and clearance rate. The LOR specifies a volume of liquid leaving the rumen per hour while the 
other terms refer to the proportion of total rumen fluid leaving the rumen per hour.

The amount of microbial protein synthesised per unit of carbohydrate fermented by the rumen microorganisms, and the flow of alpha-liked glucose polymers, total amino acids and total microbial amino acids to the small intestines are increased by an increase in the rumen LOR (Harrison et al., 1975). In addition, it was observed that the molar proportions of propionic acid varied inversely with the removal rate of the rumen fluid (Harrison et al., 1975; Hodgson and Thomas, 1975). Dietary factors such as concentrate level, intake level and physical characteristics of the diet (Hodgson and Thomas, 1975) have been shown to affect liquid outflow rates. A diet (e.g. a low forage high concentrate diet) which increases the molar proportion of propionic acid is therefore expected to reduce the LOR. Hodgson and Thomas (1975) reported that rumen volume, LOR and liquid turnover rate were decreased by increased grain content in the diet. The concentrate diet contained a mixture of ground barley, ground hay and flaked maize in the ratio 46:24:30 respectively while the forage diet consisted of chopped hay with ground, pelleted grass (92 : 8). Similarly Goetsch and Galyean (1982) observed that increasing the concentrate level of the diet from 258 to 758 at the same level of energy intake tended to decrease rumen fluid volume and the dilution rate while the turnover time was increased $(P<0.05)$. The molar proportion of propionic acid was higher for the $75 \%$ concentrate diet as compared to the low concentrate diet. 


\subsection{FERMENTATION CHARACTERISTICS AND ANIMAL PERFORMANCE}

The rate of fermentation of a given amount of dry matter consumed, together with the rate with which the digesta move through the gastrointestinal tract determines the amount of nutrients to be digested, absorbed and utilised by the animal. Much data has been accumulated over the past 30 years for the animal production responses obtained from feeding high proportions of concentrate in a ration. Most research has paid particular attention to the production responses such as rate of live weight gains, milk yield and milk composition. In general, replacing roughage by concentrate improves levels of production over a wide range of concentrate intakes although negative associative effects have been noted with high proportions of concentrate or grain in the diet.

When iso-nitrogenous and iso-energetic diets with varying concentrate ratios were fed to sheep (Ilian et al, 1986), the weight gain increased as the proportion of concentrate increased up to and including the $80 \%$ inclusion level and then decreased (Table 8). Feed intake behaved in a similar pattern but the decrease occured above 508 concentrate inclusion. With low forage diets, the digestibility of the forage part of the ration is lower than that of the concentrate part. This restricts intake of new food because of the increased fill of the rumen with undigested residues (Colucci et al., 1982; Uden, 1984a; 1984b). Uden (1984a) observed that neutral detergent fibre (NDF) decreased although organic matter digestibility (OMD) increased with increasing concentrate proportion in the diet. This is shown in Figure 5 and the response of NDF digestibility (NDFD) is 
Table 8. The effect of various diets varying in hay : concentrate ratio on weight gain per day and feed intake (Ilian et al., 1986).

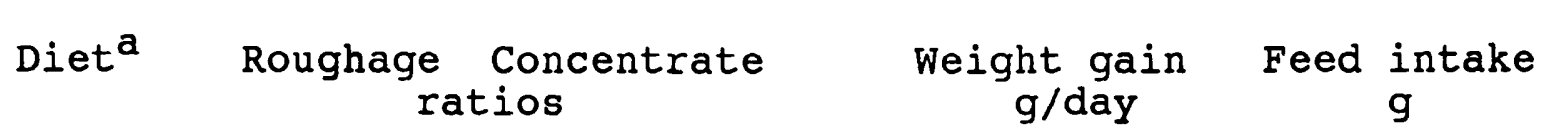

\begin{tabular}{lrrrr}
\hline A & 100 & 0 & 71 & 1247 \\
B & 60 & 40 & 77 & 1357 \\
C & 50 & 50 & 106 & 1487 \\
D & 40 & 60 & 134 & 1247 \\
E & 30 & 70 & 208 & 1397 \\
F & 20 & 80 & 266 & 1439 \\
G & 10 & 90 & 131 & 1225 \\
H & 0 & 100 & 171 & 1355 \\
\hline
\end{tabular}

a diet $\mathrm{A}$ contained $18.38 \mathrm{CP}$, diets $\mathrm{B}-\mathrm{G}$ were all iso-nitrogenous and iso-energetic, and diet $\mathrm{H}$ was the control.

curvilinear. Above the 308 concentrate level NDFD was greatly depressed.

The low breakdown rate of fibrous particles occurs in a propionate type of fermentation which is characterised by high molar proportions of propionic acid as compared to that of acetic acid. This is as expected because the molar proportion of the latter acid is strongly related to the structural carbohydrate content of the feed (Bath and Rook, 1963).

The fermentation pattern which favours production of propionic acid is more energetically efficient (Hungate, 1966) and theoretically reduces the large losses of methane associated 


\section{Figure 5 \\ Concentrate level effects on the \\ digestlbilities of OM \& NDF (Uden, 1984)}

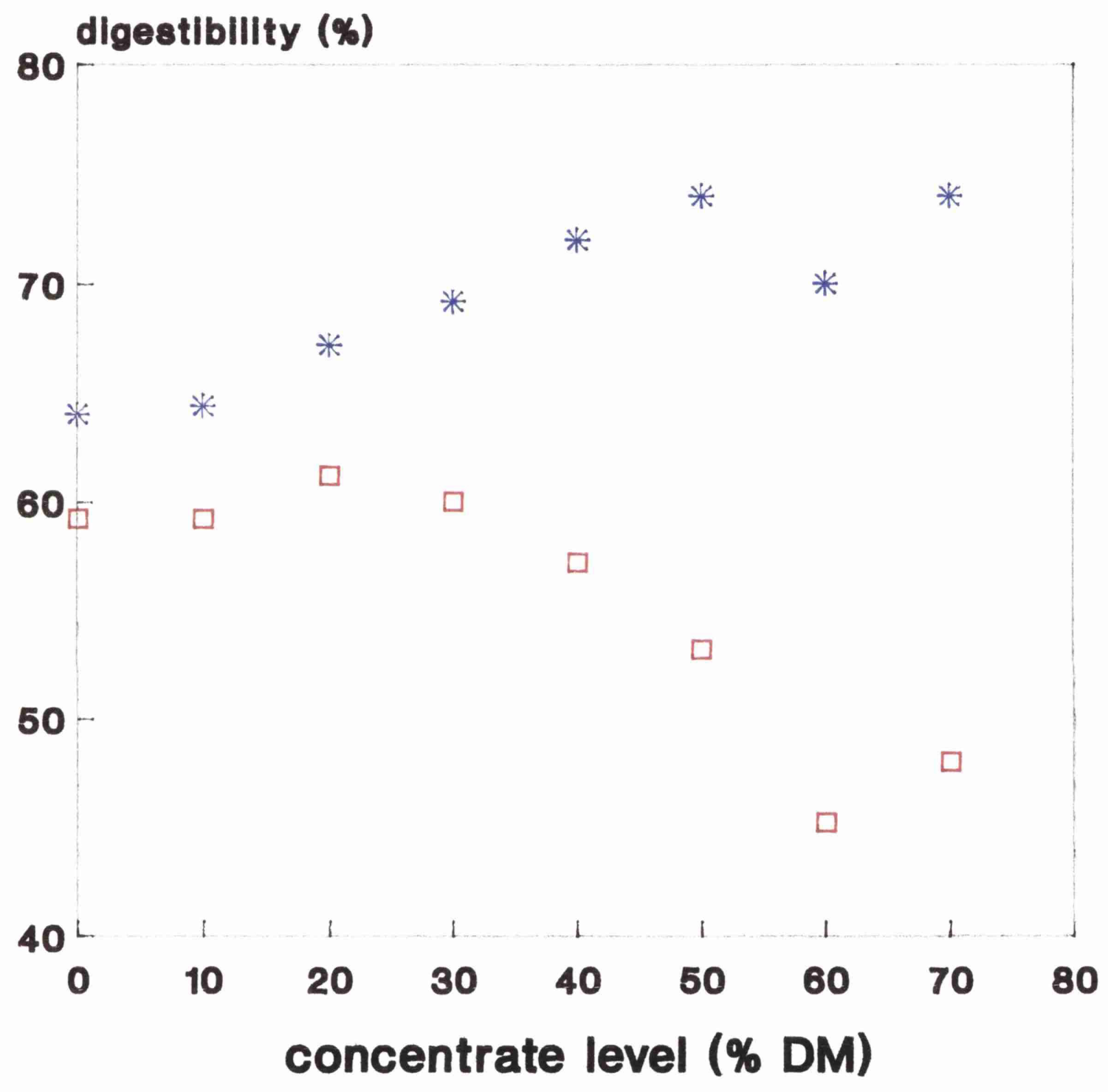

* OM $\square$ NDF 
with the production of acetic and butyric acids. Propionate fermentation thus apparently saves energy. In addition, propionic acid is utilised for fattening more efficiently (Armstrong and Blaxter, 1957) than acetic acid. In support of this concept Elliot and Loosi (1959) indicated that the efficiency with which digestible energy (DE) was utilised for production was highly correlated to the relative proportions of propionic acid in the rumen VFAs. In contrast, feeding of the VFAs in long term trials failed to confirm this (Orskov and Allen, 1966).

In some cases the advantages of increased rumen propionic acid production are offset by the reduced fibre digestion (Van Soest, 1982), giving reduced metabolisable energy. In lactating cows diets containing high proportions of starchy concentrates, giving high proportions of propionic acid depress milk fat content. The main mechanism of this affect is that acetate production is depressed yet it is a major precursor of milk fat. Narrowed acetate : propionate ratios thus result in low milk fat syndrome due to reduced acetate supply to the mammary gland. In fattening animals very high propionate fermentation, achived by feeding over 908 grain diets may lead to deposition of soft subcutaneous adipose tissue (Duncan, et al., 1972). This problem is considerably reduced by feeding whole instead of processed barley (Orskov et al., 1974).

\subsection{MANIPULATION OF THE RUMEN FERMENTATION}

Cereal grains and other concentrate feeds are fed to cattle and sheep because they contain high proportions of readily 
fermentable carbohydrate which can easily be used by the dense rumen microbial population as a source of energy under anaerobic conditions and enables the large energy demands of the highly productive animal to be met within its intake limitation. However, increasing the proportion of concentrate in relation to roughage in a ration results in several deviations from the 'normal' acetate fermentation pattern with associative effects on the fibre digestion and forage intake and overall on animal performance. Manipulation of rumen metabolism, with the final aim of improving animal productivity, can be considered as an optimization process. Optimal conditions are sought to maximize and/or to minimize fermentation processes. Rumen microbial protein production and fibre degradation need to be maximized while minimizing methane production and degradability of true protein fraction of the feed.

Several methods have been used successfully to manipulate the microbial activities and the fermentation pattern to the advantage of the host animal. The use of feed additives, direct manipulation of rumen microorganisms by genetic engineering and direct manipulation of protozoa as well as dietary manipulation are some of the methods which have been used. The most common feed additives having rumen-based effects include the ionophores (such as monensin, lasalocid and salinomycin), buffers (sodium bicarbonate), and antibiotics (such as Avoparcin and Thiopeptin).

\subsubsection{Monensin}

Monensin is a polyether ionophore derived from streptomyces cinnamonensis. The mode of action of ionophores is unknown. 
However, feeding monensin increases the molar proportion of propionic acid and decreases that of acetic acid in the rumen contents presumably due to its selective action against acetateproducing organisms thus giving propionate-producing organisms an advantage. Monensin also reduces methane production and liquid dilution rate (LDR) (Lemenager et al, 1978; Adams, 1981). When a 508 concentrate control diet (supplemented with 33 ppm monensin) was fed to steers, acetate concentrations and acetate : propionate ratios were lower $(P<0.01)$ (Adams et al., 1981) compared to values for the control diet. This is in agreement with Prange et al., (1978) who observed a similar response with $33 \mathrm{mg} / \mathrm{kg}$ monensin added to a control ration containing $5.9 \mathrm{~kg}$ hay and $2.5 \mathrm{~kg}$ concentrate. Rumen production of propionate increased from 7.74 to 11.18 moles/day. Rumen $\mathrm{pH}$ was slightly higher (6.42) before feeding and 4 hours later (6.18) with the monensin in the diet as compared to control diet whose corresponding values were 6.28 and 6.01 (Adams et al., 1981). High sensitivity of certain rumen organisms such as streptococcus bovis to ionophores may thus reduce acidosis. Improved average daily gains and feed conversion had been also reported (Adams et al., 1981; Corse, 1981), and they are explained as being caused by changes in fermentation pattern. On the whole, predominantly roughage diets gave greater responses.

\subsubsection{Sodium bicarbonate}

Buffers such as sodium bicarbonate had been used in ruminant feeds to counteract the less desirable effects of feeding concentrate, for example the reduced fibre digestion and lowered fat content associated with low rumen $\mathrm{pH}$ and reduced acetate : 
propionate ratio. Feeding or infusion of sodium bicarbonate raised rumen $\mathrm{pH}$ to above the critical level $(6.0 \mathrm{pH})$ for cellulolysis (Esdale and Satter, 1972; Adams et al., 1981; Rogers et al., 1986), and increased cellulolytic activity giving improved fibre digestion (Stewart, 1977).

In the experiment of Adams et al, (1981), the $\mathrm{pH}$ values dropped from $6.28,6.69$ and 6.71 before feeding to $6.01,6.41$ and 6.57 four hours after feeding the control diet (containing $50 \%$ roughage and 508 concentrate), control diet plus 2.58 or control plus $5 \%$ sodium bicarbonate respectively. It can be noted that the rumen $\mathrm{pH}$ values with inclusion of buffers remained higher $(P<0.05)$ than the values for the control diet. Kovacik et al. (1986) observed in both in vivo and in vitro experiments, that buffers reduced the proportion of time when ruminal pH was below critical levels for fibre digestion. While a fall in $\mathrm{pH}$ level reduces the rate of fibre degradation, the extent of depression is highly correlated to the time period (Istasse and orskov, 1983) when $\mathrm{pH}$ is below 6.0 .

In contrast to monensin, $\mathrm{NaHCO}_{3}$ supplementation to high grain diets increased proportions of acetate and the acetate : propionate ratio both in vivo and $\underline{\text { in }}$ vitro (Esdale and Satter, 1972; Harrison et al., 1975; Adams et al., 1981), although it was not always the case (Rogers et al., 1979). The low milk fat syndrome may thus be alleviated by feeding buffers although milk yield is not always affected (Rogers et al., 1982). Therefore buffers act by establishing a favourable rumen environment for the fibre digesters leading to improved animal performance. 
Another effect of buffers is that they increase rumen dilution rate (Harrison et al., 1975; Rogers et al., 1979; Adams et al., 1981; Rogers et al., 1982), which can improve the ruminant productivity by increasing efficiency of bacterial growth (particullarly the energetic efficiency of microbial protein sythesis), and the flow of nutrients to lower digestive tract (Harrison et al., 1975). There are also some suggestions that sodium bicarbonate may improve feed intakes.

\section{7 .3 Antibiotics}

Antibiotics such as Thiopeptin had been used to prevent lactic acidosis while lasalocid had been used for treatment of feedlot bloat. Monensin had been used as a coccidiostat in poultry diets. By similar action, it had been used to reduce parasitic infection of the lower gut and thereby increasing the energetic efficiency of the animal.

\subsection{YEA-SACC}

\section{8 .1 What is Yea-Sacc?}

Yea-Sacc is a feed additive which has been used over the past few years with the intention of improving production characteristics in a variety of species and feeding situations. Yea-Sacc (Alltech Inc.) is a yeast culture made from a selected yeast strain of Saccharomyces cerevisiae, dried under conditions which lead to the retention of most of the viability of the yeast cells. This description of Yea-Sacc satisfies the AAFCO (1986) defination of a yeast culture - "a dry product composed of yeast and the media on which it was grown, dried in such a manner as to preserve the fermenting capacity of the yeast. The media must be 
stated on the label". In other words a yeast culture is made up of the living yeast cell, together with the medium upon which it was grown, and this medium facilitates the yeast cell to grow in conditions where it would otherwise die.

\subsubsection{Yeast Culture and animal production aspects}

There are considerable claims suggesting that the addition of yeast culture improves the performance of ruminant animals. Among these claims are :

- calf starters increased weight gain and feed consumption

- dairy cattle increased milk yield and improved milk composition

- beef cattle improved feed efficiency and live weight gains

- sheep

- general increased dry matter digestibility, particularly fibre digestion.

\subsubsection{Growing and fattening ruminants}

The inclusion of yeast culture at a level of $2 \mathrm{~kg} /$ tonne in diets of calves increased live weight gain (LWG) by $10.1 \mathrm{~kg}$ and $3.4 \mathrm{~kg}$ in barley/soya and barley/corn gluten diets respectively (Table 9). The improved weight gains for the former diet was as a result of increased dry matter intake (DMI) for the feeding period of 84 days. The DMI was not affected by the addition of Yea-Sacc to the barley/corn diet (Fallon, 1987), instead the calves ate more of the feed than the barley/soya fed calves. For both diets, the feed conversion efficiency (FCE) was improved by inclusion of yeast culture in the ration.

Phillips and Von Tungeln (1985) observed similar responses when beef calves $(200 \mathrm{~kg})$ were fed with diets containing either 18 
or 28 yeast culture following shipping stress. The LWG for the groups fed yeast culture were over $7 \mathrm{~kg}$ better than the control group over a 28 day period.

The average daily gains (kg) and FCE (kg DM/kg gain) for diets containing 508 concentrate : 508 roughage (control), and for control diet plus yeast culture were 1.34 and 6.42 , and 1.39 and 6.32 respectively (Adams et al., 1981). Although these differences were not significant at $P<0.05$ the average daily gains were 38 more for the yeast-fed steers. The DMIs were slightly improved $(P<0.05)$.

Table 9. Effects of inclusion of Yea-Sacc in calf concentrate diets on calf performance (Fallon, 1987).

Treatment

$\begin{array}{llll}B^{a} & B S Y & C B & C B Y\end{array}$

$\begin{array}{lrrrr}\text { No of calves } & 20 & 20 & 20 & 20 \\ \text { Initial weight (kg) } & 45 & 45 & 45 & 45 \\ \text { LWG (kg/day) days 1-84 } & 0.63 & 0.75 & 0.64 & 0.68 \\ \text { DMI (kg) days 1-84 } & 100.4 & 113.3 & 112.2 & 112.9 \\ \begin{array}{l}\text { FCE (kg feed/kg gain) } \\ \text { days 1-84 }\end{array} & 1.90 & 1.80 & 2.09 & 1.98 \\ \text { DM Digestibility } & 0.79 & 0.81 & 0.69 & 0.71\end{array}$

a BS - Barley/Soyabean meal; CB - Corn gluten/barley;

$\mathrm{Y}$ - Yea-Sacc ( $2 \mathrm{~kg} /$ tonne)

LWG - live weight gain; DMI - dry matter intake;

FCE - feed conversion efficiency; DM - dry matter; 
In lambs the responses from addition of yeast culture to the ration have been variable. Ruf et al., (1953) observed that lambs receiving a ration containing yeast consumed $1.02 \mathrm{~kg} / \mathrm{head} / \mathrm{day}$ and made LWGs of $0.1 \mathrm{~kg} /$ day compared with $0.72 \mathrm{~kg} /$ day intake and $0.02 \mathrm{~kg} /$ day gains made by the lambs not receiving yeast.

\subsubsection{M11k Production and Composition}

In most on-farm trials milk yield, and milk fat and protein have been increased by the inclusion of Yea-Sacc in the ration, Table 10. This is in agreement with the results observed under experimental conditions where individual milk and feed intake records have been kept.

Williams (1988) indicated that the milk yield was maintained as lactation progressed in the Yea-Sacc fed cows. The cows not receiving Yea-Sacc showed a 108 drop in milk yield and an 118 drop in butterfat at 9 and 10 weeks of lactation compared to values for weeks 5 and 6 . On the other hand, the Yea-Sacc fed cows showed only a 28 fall in milk yield and 18 butterfat drop. Williams (1988) also observed that DMI was increased by $1.6 \mathrm{~kg} /$ day with the addition of Yea-Sacc. In all cases, the response was higher with cows given higher levels of concentrate (40\% roughage : 608 concentrate) compared to that for cows receiving 508 : 508 mixed diets.

In the experiment of Bax (1988) Yea-Sacc had no effect on milk composition but increased the milk yield by $0.66 \mathrm{~kg} /$ day and $0.28 \mathrm{~kg} /$ day in cows given silage and concentrate separately or as a complete diet respectively. Intake of silage dry matter of 
Table 10. Effects of including Yea-Sacc in the diet of American ${ }^{1}$ and European ${ }^{2}$ dairy cows on milk production (litres/day) and milk composition.

\begin{tabular}{|c|c|c|c|c|c|c|}
\hline & Milk & Yield & Milk & Butterfat & Milk & Protein \\
\hline & $c^{a}$ & $Y$ & C & $Y$ & C & $Y$ \\
\hline American & 28.7 & 30.3 & 3.60 & 3.60 & & \\
\hline \multirow[t]{6}{*}{ herds } & 29.1 & 31.0 & 3.60 & 3.60 & & \\
\hline & 20.4 & 20.9 & 3.40 & 3.80 & & \\
\hline & 29.5 & 31.3 & 3.20 & 3.80 & & \\
\hline & 33.6 & 36.8 & 3.60 & 3.60 & & \\
\hline & & & 3.14 & 3.50 & & \\
\hline & & & 3.20 & 3.60 & & \\
\hline European & 19.9 & 19.8 & 3.99 & 4.07 & 3.22 & 3.33 \\
\hline \multirow[t]{8}{*}{ herds } & 21.6 & 26.9 & 4.35 & 4.19 & 2.99 & 2.93 \\
\hline & 33.6 & 36.8 & 3.60 & 3.60 & & \\
\hline & 20.0 & 22.7 & 3.55 & 3.81 & 3.17 & 3.36 \\
\hline & 20.4 & 20.9 & 3.40 & 3.60 & 3.12 & 3.22 \\
\hline & 30.9 & 32.8 & 3.20 & 3.80 & 3.04 & 3.16 \\
\hline & & & 3.70 & 3.86 & 3.07 & 3.28 \\
\hline & & & 3.34 & 3.65 & 2.97 & 3.09 \\
\hline & 21.8 & 22.7 & 3.55 & 3.81 & 3.17 & 3.36 \\
\hline
\end{tabular}

1 after Lyons, 1987; 2 after Williams, 1988.

a C - control $\quad Y$ - control + Yea-SacC

cows in the separately-fed group was increased by $+0.57 \mathrm{~kg} / \mathrm{head} /$ day, and intakes of silage and concentrate were increased by +0.11 and $+0.05 \mathrm{~kg} /$ head/day respectively for cows 
given the complete diet. This experiment suggests that greater benefits are obtained when roughage is fed separately to concentrates.

The increase in live weight gains, and milk yield and butterfat percentages appear to be mainly due to increased feed intake rather than mobilization of the body reserves, or to increased efficiency of utilisation of dietary energy. It is however not clear whether the increase in DMI due to yeast culture inclusion is a result of direct stimulation of feed intake (perhaps due to enhanced diet palatability) or even just the changes in the rumen fermentation pattern.

The improved animal production could be due to an increase in the metabolisability of the diet through improved ration digestibility or reduced energy loss as a result of a reduction in methane production.

Milk production and fat content may also be improved by an increase in the supply of proteins to the lower gastrointestinal tract resulting from increased microbial biomass production in the rumen. Altenatively, the yields of milk constituents may be altered by changes in rumen VFA pattern as a result of Yea-Sacc inclusion.

\subsubsection{Yeast culture and dry matter digestibility}

Dry matter digestibilities (DMDs) have been increased with the inclusion of yeast culture in the diet (Fallon, 1987) and also by addition of yeast suspension (Richardson et al, 1956). Fallon (1987) obtained a 28 increase in DMD irrespective of whether the diet was composed of barley/soya or barley/corn 
gluten concentrate. This is in agreement with wiedmeier and Arambel (1987) who found that when either $90 \mathrm{~g} /$ day of yeast culture or $90 \mathrm{~g} /$ day of yeast culture combined with Aspergillus oryzae fermentation extract were added to a basal diet containing 508 concentrate, the digestibility of the dry matter (DM), crude protein (CP) and hemicellulose were increased by over two percentage units. However this was not always the case. Adams et al., (1981) observed no differences $(P<0.05)$ in the dry matter, organic matter, crude protein and acid detergent fibre (ADF) digestibilities between the control and the yeast culture fed animals. Similarly, fibre digestion was improved in most cases, though in some experiments it was unaffected.

\subsubsection{Yeast culture and Rumen Metabol1sm}

\subsubsection{Yeast culture and cellulolysis}

Feeding diets containing high proportions of readily fermentable carbohydrates (RFC) depress rumen $\mathrm{pH}$ which in turn reduce the viability of the cellulolytic bacteria, hence leads to reduced cellulolysis. Cellulose digestion is inhibited by over 508 at $\mathrm{pH}$ values below 6.5 (Stewart, 1977), and the depression in fibre degradability is directly correlated with the length of time the $\mathrm{pH}$ is depressed below 6.0 (Istasse and Orskov, 1983). Therefore $\mathrm{pH}$ is a major determinant of the rate and extent of fibre digestion in the rumen.

wiedmeier and Arambel (1987) observed that the increase in the digestibility of hemicellulose by $6.58(P<0.05)$ when Yea-Sacc was added to the diet was concurrent with the increased numbers and proportions of cellulolytic organisms measured. They observed a 1.3 fold increase in total viable bacteria and 1.5 
fold increase in cellulolytics in vivo. Similarly, Dawson (1987) found that the total anaerobic and fibre-digesting bacteria were consistently greater when Yea-Sacc was added to the rumen fluid at a rate comparable to $1 \mathrm{~g} /$ head/day (Table 11 ). The differences were more pronounced in fermenters receiving a hay-based ration than in fermenters receiving a high grain ration. More recently a 25 fold increase in cellulolytic bacteria has been obtained in a fermenter system following addition of viable yeast culture (Newbold, 1988).

The mechanism by which yeast supplements might influence the numbers of bacteria in the rumen is not yet clear. Dawson (1987) suggested that the yeast cells or the yeast culture could supply factors which stimulate the growth of certain types of rumen microbes and hence fibre digestion. Alternatively, the higher $\mathrm{pH}$ values (Dawson, 1987) resulting from the inclusion of yeast

Table 11. The effects of yeast culture supplements on the concentration of bacteria in the rumen-stimulating fermenter cultures (Dawson, 1987).

\begin{tabular}{llcc}
\hline & & Yea-Sacc added to fermenter \\
Group & Diet & None & $1 \mathrm{~g} / \mathrm{kg}$ \\
\hline Anaerobic & hay & $1.3^{\mathrm{a}}$ & $7.3^{\mathrm{b}}$ \\
$\left(10^{10} \mathrm{CFU} / \mathrm{ml}\right)$ & grain & 10.4 & 15.7 \\
Cellulolytics & hay & 0.8 & 1.6 \\
$\left(10^{9} \mathrm{CFU} / \mathrm{ml}\right)$ & grain & 13.8 & 16.0 \\
\hline
\end{tabular}

$a, b$, Means in the same row with different superscripts differ $(P<0.01)$. 
supplements could favour the growth and activity of cellulolytic bacteria when the mean $\mathrm{pH}$ levels are originally low and in the region of 6.0 (Williams, 1988).

\subsubsection{Yeast culture and $\mathrm{pH}$ in the rumen}

Adams et al. (1981) observed slight increases in the rumen $\mathrm{pH}$ before (0.04) and after (0.06) feeding steers with a yeast culture supplemented diet of alfalfa and steamed milo. This is in agreement with the increase of $0.2 \mathrm{pH}$ units observed by Dawson (1987). However, ruminal $\mathrm{pH}$ was not affected, though fibre digestion was increased, when a basal diet containing 508 concentarate was supplemented with yeast culture (Wiedmeier and Arambel, 1987). Similarly, Williams (1988) failed to demonstrate any changes in the mean rumen $\mathrm{pH}$ or diurnal variation of $\mathrm{pH}$ in young calves fed concentrate diets based on digestible beet pulp and no supplementary roughage with yeast culture. From these observations it does not appear as if the modulation of rumen $\mathrm{pH}$ is the main mechanism whereby yeast culture affects cellulolysis and hence fibre digestion.

\subsubsection{Yeast culture and Acetate : Proplonate ratio}

Including yeast culture in the ration may increase the proportion of acetate in the rumen liquor. Dawson (1987) obtained a small increase in the acetate : propionate ratio from $3.1: 1.0$ to $3.2: 1.0$, and a decrease in total volatile fatty acid (VFA) concentration when Yea-Sacc was added to the fermenters. Similarly, williams (1988) obtained a ratio of 2.3 : 1.0 with Yea-Sacc as compared to 1.6 : 1.0 acetate to propionate for the control diet. The total VFA concentration was unaffected. In a "Rusitec" fermenter system, addition of yeast 
culture increased the ratio of acetate to propionate from 1.8 : 1.0 to $2.05: 1.0$ (Newbold, 1988). In contrast to these observations the ratios were not affected when yeast culture was added to the diets of dairy cow (Wiedmeier and Arambel, 1987) and steers (Adams et al, 1981) where 508 of the diet was concentrate.

The production of more acetic acid and less propionic acid in the rumen fluid, and the increased numbers of cellulolytic bacteria strongly suggest that either the rate or extent of digestion of cellulose-containing substrate in the rumen is boosted by supplementation of diet with yeast culture. The fact that fibre digestibility is actually improved by inclusion of yeast culture (Fallon, 1987) had already been discussed. 1.8.4.4 Yeast culture and rumen ammonia

Ammonia concentrations were 338 lower in fermenters receiving yeast supplements (Dawson, 1987) compared to control values without yeast addition. Similar results were observed by Adams et al. (1981) who observed a decrease of 248 in rumen ammonianitrogen although this was statistically insignificant. Rumen ammonia contents were however not affected in some studies (Wiedmeier and Arambel, 1987). The decreased ammonia contents would suggest that when yeast cultures are added to diets, the incoporation of nitrogen into microbial protein is improved, implying a potential for supply of amino acids to the host animal and possible production benefits.

\subsubsection{Yeast culture and Liquid Dilution Rate}

The numbers, types and metabolism of rumen microorganisms can be influenced by the liquid outflow rates together with other 
various factors. The rumen liquid dilution rate (LDR), defined as the proportion of total rumen fluid leaving the rumen per hour, increases the energetic efficiency of bacterial growth, leading to increased microbial protein yield and increased flow of alpha-linked glucose polymers, total amino acids and total microbial amino acids to the small intestines (Harrison et al., 1975 ).

The effect of yeast culture on the liquid flow pattern is not well documented. The feeding of control diets containing $50 \%$ concentrate plus yeast culture increased the LDR from $10.18 /$ hour to 11.08/hour for the steers (Adams et al., 1981). This is similar to the observations made by Wiedmeier and Arambel (1987) who found that LOR was increased from 4.53 to $4.881 /$ hour $(P<0.05)$ and LDR from 8.90 to $9.528 /$ hour when yeast culture was added to a basal diet. The liquid volume and outflow rate were also increased in the two experiments while liquid turnover time was decreased. The effect of yeast culture on dilution rate is a potential mechanism for the improvement in efficiency of ruminant animal production often observed following yeast supplementation of the diet.

A change in LDR when Yea-Sacc is added to the diet may also result in an altered rumen fermentation pattern, and it has been observed that propionic acid is normally inversely related to the dilution rate (Hodgson and Thomas, 1972; Harrison et al., 1975; 1976). However, Adams, et al., (1981) and Wiedmeier and Arambel (1987) observed that volatile fatty acids proportions were not altered by yeast culture supplementations whilst in other studies where LDR was not measured, yeast culture supplements increased 
acetate : propionate ratios.

\subsection{MODE OF ACTION OF YEA-SACC}

The mechanism by which Yea-Sacc brings about the alterations in the rumen fermentations and dilution rates, and the resulting beneficial effects to animal production characteristics is not yet understood. However, the existing knowledge of the basic biochemistry and physiological properties of yeast cells, in particular those of Saccharomyces cerevisiae, may help to explain some of these effects. Williams (1988) suggested that these properties of yeast cells may integrate with the rumen metabolism resulting in either increased feed intake or metabolisability of the diet or, increased protein supply to the duodenum. Figure 6 attempts to show how some of the possible fundamental effects of yeast culture interact and might lead to beneficial changes in rumen metabolism and animal production.

\subsubsection{Yeast growth in the rumen}

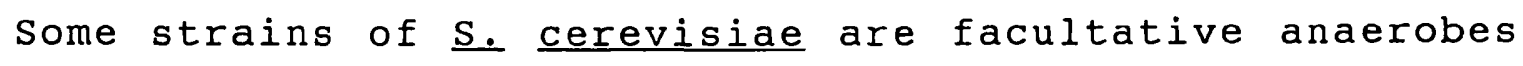
(Rose, 1980), a property not shared by many yeasts. Dawson (1987) showed that some of these strains grow in the rumen. In a rumen-stimulating fermenter fed a hay-based ration (fescue hay 77.58, craked corn - 7.98, soyabean meal - 8.58 and molasses 58) supplemented with Yea-Sacc, the concentration of yeast cells was consistently 3 to 6 times greater than could be accounted for by the yeast added in the supplement. This data suggests that under some conditions, the particular strains in the product are active and replicate in the rumen, and that such a viable yeast culture may be important in achieving the ruminal effects (Lyons, 


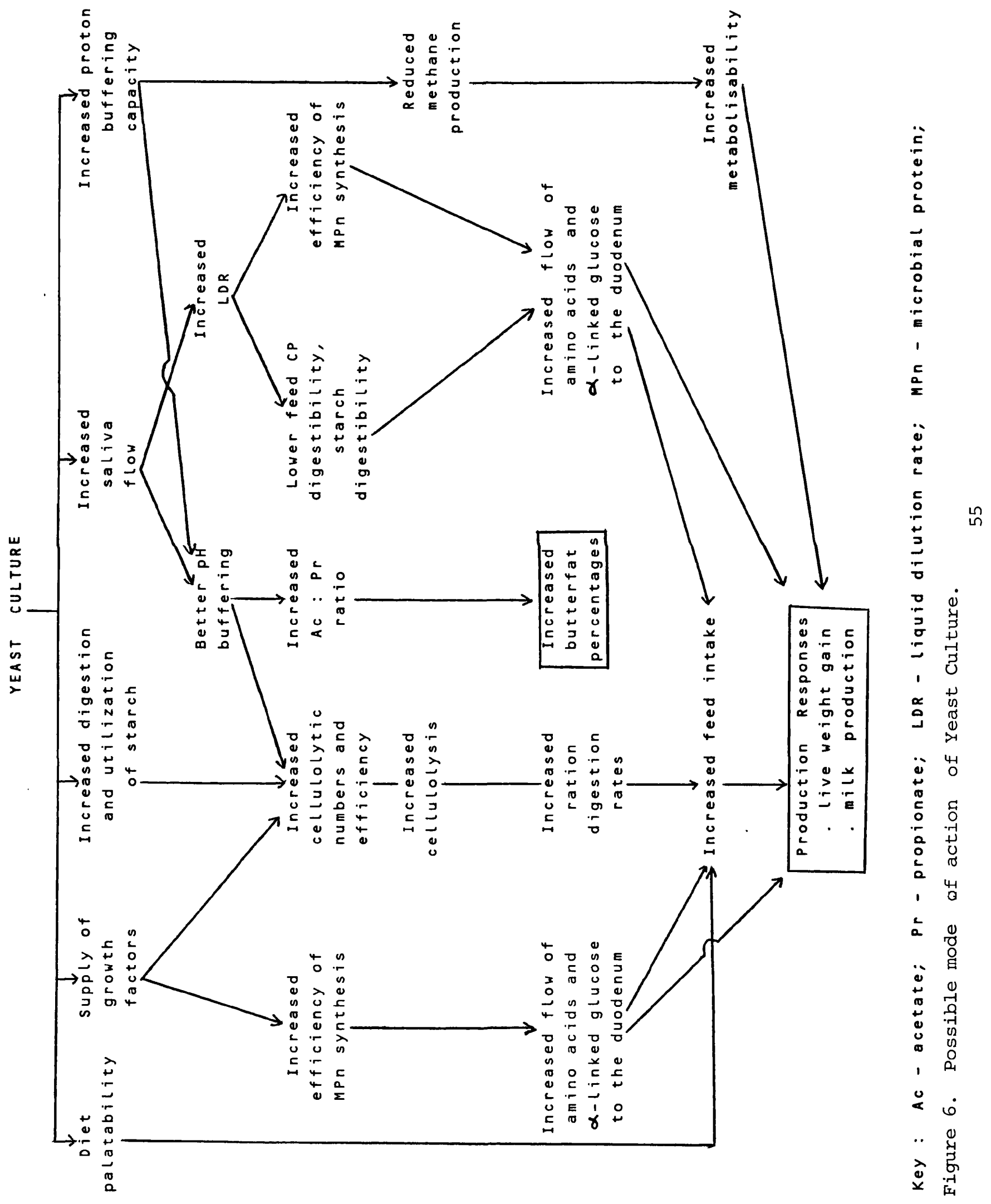


$1987)$.

The $\mathrm{pH}$ optima for yeast growth in aerobic media is between 3.5 and 5.0 (Rose, 1987). Assuming that under anaerobic conditions the $\mathrm{pH}$ optima for yeast cells is closer to the upper limit of the range, the yeast will thus be viable and will grow better in the rumen environment that exists when a concentrate is fed rather than a forage. Probably this is why greater responses were obtained with the inclusion of yeast culture in calf diets containing high levels of readily fermentable carbohydrates (RFC), and in dairy cow diets containing higher levels of concentrate (40:60) (Williams, 1988).

\subsubsection{Yeast culture supplies growth factors}

Yeast is protected by a cell wall which constitute as much as 308 by weight of the yeast. Chemically it consists of 408 proteins, 158 nucleic acids, 258 polysaccharides, 158 fats/lipids and 58 water soluble compounds such as nucleotides, amino acids, vitamins and minerals (Rose, 1987). This make it a rich source of a wide range of nutrients potentially valuable to either the endigenous rumen microbes or to the host animal.

The growth rate of yeast is reduced at $\mathrm{pH}$ values above 6.0 . The slow-growing cell under these conditions excretes large quantities of chemical compounds (nucleotides, amino acids and vitamins) which had originally been meant for new cell formation, as well as the lytic enzymes. The $\underline{S}$ cerevisiae cells showed signs of autolysis or self-digestion when they were grown at $\mathrm{pH}$ levels between 6.2 and 6.5 (Stewart and Russell, 1981). During this process amino acids, sugars and fatty acids are released into the cell environment, and may thus be available to 
rumen bacteria for growth. This could explain the increased numbers of viable bacteria and cellulolytic bacteria observed when yeast culture were added to rations (Wiedmeier and Arambel, 1987; Dawson, 1987; Williams, 1988). Yeast culture may therefore act by providing a supply of growth factors to cellulolytics leading to increased activity, hence improved cellulolysis, digestion, intake and production.

In addition to their potential ability to supply of nutrients to rumen bacteria, the yeast cells themselves will be available as protein sources to the host animal when they eventually die although, at the levels normally added to diets, the quantities of nutrients provided in this way are small.

\subsubsection{Teast cells digest and utilize starch}

When concentrates or RFC are added to the roughage diets in high proportions, cellulolysis is reduced due to low rumen liquor $\mathrm{pH}$ and the competive inhibition effect on cellulolytic bacteria. The rapidily growing amylolytic bacteria can utilize the large quantities of RFC better than the slow growing cellulolytics, thus leading to decreased numbers of the latter group, and hence cellulose digestion is depressed (Mould et al., 1983/84).

Recently, De Mot (1987) demonstrated that several varieties of $\underline{S}$. cerevisiae yeast cells possess amylase enzyme and have an ability to digest and utilize starch and simple sugars. Yeast cells had not previously been known to possess this enzyme (Rose, 1980). The removal of the starch substrate from the rumen by the actively growing yeast cells in the supplement when an is animal fed with a concentrate diet will help to reduce the competition 
for limiting nutrients between the cellulolytic and amylolytic bacteria. As a result, cellulose digestion may be enhanced.

\subsubsection{Yeast culture and methane production}

The production of methane in the rumen represents a significant loss of energy (8-148 of total energy loss) from the diet. The propionate type fermentation, as a result of high proportions of $\mathrm{RFC} /$ concentrate in the ration, is considered to be more energetically efficient (Hungate, 1966) in terms of ATP supply to rumen microbes.

Williams (1988) observed a 288 reduction while Newbold obtained a 508 reduction in methane production when yeast culture was added to diets given to young calves or to a fermenter system respectively. These data thus suggest that yeast culture could be of significance in energy saving.

This may be true because yeast cells have a large proton buffering capacity (Cartwright et al., 1986) thus can offer a highly efficient alternative form of hydrogen transfer to the production of methane when viable yeast cells are present in the rumen. This transfer of molecular hydrogen into microbial system rather than its loss as methane means that digestible energy (DE) is saved. The presence of methanogenic process however, is still of importance because it increases the efficiency of acetate production.

\subsubsection{Yeast culture and diet palatability}

Including yeast culture in the animal ration is known to make the ration more palatable (Rose, 1987) thus increasing feed intake. This is not surprising, for extracts and hydrolysates of yeast have for many years been used as flavour enhancing agents 
or condiments in human foods. Yeast components such as nucleic acids and their breakdown products, nucleotides and glutamic acid have a flavour enhancing property (Peppler, 1982). Nucleic acids are contained within the yeast cell but the nucleotides and glutamic acid are released by cells during growth, and so may be present in the dried medium component of yeast culture. This may provide a partial explanation of the stimulation of feed intake observed in some trials when yeast extract is included in the diet although the low level of inclusion used in practical diets makes it unlikely that this is the major mechanism.

\subsubsection{Yeast culture and saliva flow}

The fact that the inclusion of yeast culture in the ration induces an increase in rumen dilution rate seems to suggest that yeast culture may stimulate saliva flow. Intraruminal infusion of artificial saliva, though obviously impractible as a routine agricultural method, had been used to increase the liquid dilution rate (LDR) and to alter the rumen fermentation pattern. If yeast culture could act in a similar way, that is, inducing saliva flow, then this could explain why LDR was increased when the supplement was added to ruminant rations (Adams et al., 1981).

Additionaly, yeast cultures could increase the ruminating time in concentrate fed animals when rumination is often depressed (Orskov et al., 1974) thus creating a more favourable environment for microbial growth. Increased rumination would lead to improved comminution of feed and to more efficient mixing within the rumen. Also saliva productin may be increased which 
would provide a better $\mathrm{pH}$ buffering capacity in the rumen. There is however no evidence that the yeast cultures induce saliva flow although it is a potential mechanism for the effect of yeast extract on rumen $\mathrm{pH}$ observed in some trials. 


\section{CHAPTER 2: EXPERIMENT}

\subsection{AIM OF EXPERIMENT}

The aim of the study was to examine the effects of dietary inclusion of Yea-Sacc (Altech,Inc.) on rumen fermentation characteristics, liquid outflow pattern, fibre digestion and overall nutrient digestibility when sheep were fed restricted diets differing in their forage : concentrate ratios. It was hoped that this work would provide information on the mode of action of Yea-Sacc and thus help to explain the various responses such as improved milk yield, increased milk fat percentages and increased live-weight gains claimed in the literature. The possibility that responses of yea-Sacc in the rumen could be mediated through effects on the saliva production and hence rumen buffering capacity was tested by measuring rumen liquid outflow rates. Other factors, such as acetate : propionate ratios, fibre digestion and ration digestibility, related to rumen pH were also measured. The diet had been choosen to give a wide range of rumen conditions and fermentation patterns in the hope of determining the feeding situation in which Yea-Sacc would work best. This might help to explain the inconsistant and contradictory responses found in practice. Feed intake was. restricted and the physical characteristics of the diet were kept constant to reduce the number of variables in the experiment.

\subsection{MATERIAL AND METHODS}

\subsubsection{Animal and design}

Six rumen-cannulated mature (7-10 years old) sheep averaging above $55 \mathrm{~kg}$ were assigned to a $6 \times 6$ Latin Square Design (Appendix 
A). Each period was three weeks long and the first 14 days was an adaption phase to allow the animals to adjust to the diets.

\section{2 .2 Housing}

The sheep were housed individually in pens.

\section{2 .3 Diet}

Three diets differing in forage : concentrate ratios (90:10, 65:35 and 40:60) were fed to sheep. The forage portion of the diet was made up of medium quality chopped hay while the concentrate portion consisted of 508 rolled barley and 508 flaked maize supplemented with urea and minerals to Agricultural and Food Research Council (AFRC) standards. The chemical composition of the experimental diets is given in Table 12, and Table 13 shows the actual amounts of feed consumed by the sheep. (See Appendix $B$ for the amounts of fresh feed offered to sheep).

The concentrate portion was fed separately from the hay. sheep were fed individually twice per day with equal feed portions at 0900 hours and at 1630 hours. Yea-Sacc was added by sprinkling it ( $4 \mathrm{~g} / \mathrm{day}$ or $2 \mathrm{~g} / \mathrm{feed})$ on to the concentrate $\mathrm{mix}$ immediately before feeding. The sheep had free access to clean water at all times.

Table 12. Chemical composition of feeds.

\begin{tabular}{lcccc}
\hline & $\begin{array}{c}\text { Chopped } \\
\text { hay }\end{array}$ & $\begin{array}{c}\text { Rolled } \\
\text { barley }\end{array}$ & $\begin{array}{c}\text { Flaked } \\
\text { maize }\end{array}$ & Urea \\
\hline Dry Matter (g/kg) & 820 & 821 & 852 & 1000 \\
Organic Matter (g/kg DM) & 930 & 973 & 980 & 1000 \\
Crude protein (g/kg DM) & 82 & 90 & 90 & 291 \\
$\begin{array}{l}\text { Metabolisable energy } \\
\text { (MJ/kg DM) }\end{array}$ & 8.6 & 12.8 & 14.2 & 0 \\
\hline
\end{tabular}


Table 13 . Amounts of fresh feed consumed (g/day).

\begin{tabular}{lcccccc}
\hline Feedstuff & High & $\begin{array}{c}\text { High } \\
+\end{array}$ & Medium & $\begin{array}{c}\text { Medium } \\
\text { Yea-Sacc } \\
\text { Yea-Sacc }\end{array}$ & Low & $\begin{array}{c}\text { Low } \\
+ \\
\text { Yea-Sacc }\end{array}$ \\
\hline hay & 524 & 521 & 746 & 766 & 885 & 805 \\
rolled barley & 418 & 418 & 244 & 244 & 70 & 70 \\
flaked maize & 418 & 418 & 244 & 244 & 70 & 70 \\
urea & 14 & 14 & 14 & 14 & 14 & 14 \\
minerals & 14 & 14 & 14 & 14 & 14 & 14 \\
\hline
\end{tabular}

\section{2 .4 Measurements}

The following measurements were made :

a) Rumen metabolites : $\mathrm{pH}$, individual and total volatile fatty acids, and ammonia in rumen fluid.

b) Rate of fibre digestion in the rumen : measured by incubating hay samples in nylon bags within the rumen.

c) Rumen liquid outflow rate : determined by following the decay of Chromium concentration in faeces after administration of a single dose of Cr-EDTA into the rumen.

d) Overall feed digestibilty : measured by making a three-day faecal collection.

\section{2 .5 Analysis of samples}

All sampling was done during the last week of each period.

\section{2 .5 .1 Rumen fluid}

Rumen liquor samples for each sheep were withdrawn through the cannulae just before the morning feed at 0900 hours on day one of each sampling week period. Rumen liquor samples were also 
taken at $1030,1200,1500$ and 1630 hours. The pH was immediately determined using a portable pH meter (Cranwell CR 99-digital). $8 \mathrm{ml}$ of the rumen liquor sample were then pipetted (with a wide mouthed pipette) into a labelled stoppered centrifuge tube to which $2 \mathrm{ml}$ of preservative solution (158 metaphosphoric acid) were added. This solution was to stop microbial activity in the sample of rumen fluid. After mixing and spinning down in a centrifuge at 3 000rpm for 10 minutes, the supernatant was transfered to a labelled Bijou bottle and stored frozen (-20 C) until required for VFA and ammonia determination. The frozen samples were thawed at room temperature and centrifuged at 1000 rpm (only if neccesary) before carrying out the analysis for vFAs and ammonia. VFAs were analysed by gas chromatography (using a GC : AMS Model 93), and ammonia concentrations were determined by colourimetric analysis using the indophenol blue method. To each $0.08 \mathrm{ml}$ of rumen liquor samples, $8 \mathrm{ml}$ of caustic phenol was added followed by $20 \mathrm{ml}$ of buffer solution (See Appendix $C$ for reagents). After mixing the samples were left at room temperature for at least one hour to allow the colour to develop. The samples and the standards were read using a spectrophotometer at $584 \mathrm{nM}$ which had been zeroed to a reagent blank. The absorbances of the blank and standard were used to draw a graph of nitrogen concentration versus absorbence. This graph was used to read off the nitrogen content of the samples.

\subsubsection{Measurement of dry matter digestion in the rumen}

The artificial fibre bag (in sacco) technique (Mehrez and Orskov, 1977) was used to measure the digestion of hay in the rumen. Known weights (approximately 2-3 grams) of finely chopped 
hay were placed in various weighed nylon bags. The hay was obtained from the same batch as was offered to the sheep, and had been chopped using a vegetable slicer to give an average particle length of approximately $10 \mathrm{~mm}$. The nylon bags were tied together in sets of four. Each set of bags was suspended by $2.5 \mathrm{~cm}$ long nylon string sheathed with a plastic tubing to avoid entanglement in the rumen while allowing free movement and easy mixing with the rumen contents. The fibre bags were incubated in the rumen of each sheep consecutively for a 24- and 48-hour period. Bags for 24-hour incubation were inserted at 0900 hours on day two of sampling week and removed at the same time on day three; and bags for the 48-hour period from 0900 hours on day three to 0900 hours on day five. After removing the bags at the end of the incubation period, they were washed under cold water to get rid of the ruminal contents from the outside of the bags. The bags were then cold washed in a pre-set automatic washing machine. After drying the bags in an oven at:60 C for 48 hours, the loss of dry matter from the bags was calculated by subtracting the resulting residual weight after incubation and drying, less bag weight, from the original dry matter weight of hay in the bag before incubation. The difference or dry matter loss was used to estimate the digestibility of hay dry matter in the rumen. The dry matter digestibilities (DMD) for the four bags were averaged to give the final figure for each sheep.

\subsubsection{IIquid outflow rate determination}

The liquid outflow was estimated by measuring the passage rate of chromium oxide from the rumen and this was done by 
determining the $\mathrm{Cr}$ concentration in the faeces. A single dose of $100 \mathrm{ml}$ chromium ethylenediaminotetracetic acid complex (Cr-EDTA) was administered into the rumen through the cannulae of each sheep just before morning feeding at 0900 hours on day one of each sampling week. Cr-EDTA was prepared by the Binnert (1968) method. Faeces collecting bags fitted with harnesses were attached to sheep on day two (the day after administration of $\mathrm{Cr}-$ EDTA) at 0900 hours, and faeces samples were collected the same day at 1230 and 1630, and on days three and four at 0900, 1230, and 1630 hours. This gave average sampling times of 25.75, $29.50,39.75,49.75,53.50,63.75,73.75,77.5$ and 87.75 hours after dosing with marker. The faecal samples were dried at $100 \mathrm{C}$ until no further weight loss was observed before they were milled through a $1 \mathrm{~mm}$ screen. Chromium in faeces was analysed using the modified wet digestion method of stevenson and clare (1963), followed by colourimetric determination. See Appendix $D$ for the detailed method. The outflow rate was then estimated by fitting faecal $\mathrm{Cr}$ concentrations to the bi-compartmental, time independent model of Grovum and Williams (1973). In this model, K1 has been shown to represent the rate of outflow from the rumen to the abomasum. $\mathrm{R} 2$ is thought to represent the overall rate from the abomasum through the rest of the gut and therefore depends mainly on the duration of retention in the hind gut. A computer program (see Appendix E) was used to fit the following equations,

$$
\begin{array}{lll}
Y=A e^{-k 1(t-T T)}-A e^{-k 2(t-T T)} & \text { for } t>T T, \\
Y=0 & \text { for } t<T T \text { where, }
\end{array}
$$


$y$ is the marker concentration in faecal dry matter at time $t_{;}$ TT is the time of first appearance of marker in faeces $(\mathrm{h})$; $\mathrm{kl}$ is the liquid turnover rate in the reticulo-rumen $\left(\mathrm{h}^{-1}\right)$ and $\mathbf{k} 2$ is considered to be the liquid turnover rate of marker in caecum and colon $\left(\mathrm{h}^{-1}\right)$.

\subsubsection{Determination of overall feed digestibility}

The digestibilities of organic matter (OM), neutral detergent fibre (NDF) and gross energy (GE) were determined by total faecal collection for three consecutive days starting on day 5 at 0900 hours and finishing at 0900 hours on day 8. All feed refusals and faeces were collected daily and dried to constant weight at $100^{\circ} \mathrm{C}$ to determine their dry matter content. OM was measured by heating at $450^{\circ} \mathrm{C}$ for 24 hours.

To determine NDF, approximately 0.5 grams of a dry sample were weighed into a sintered glass crucible (porosity 1.50). 40$60 \mathrm{~cm}^{3}$ of petroleum ether were flushed through the crucible to remove any oil in the sample. The sample was then placed in an oven at $60^{\circ} \mathrm{C}$ for 10 minutes before transfering it to a $500 \mathrm{ml}$ conical flask to which $50 \mathrm{ml}$ of a neutral detergent fibre (NDF) solution was added. The flask contents were heated to boiling and left boiling for 30 minutes at the end of this time, a further $50 \mathrm{ml}$ NDF solution was added. To this mixture, $2 \mathrm{ml}$ amylase solution was added (for the barley and maize) followed by another 30 minutes of boiling. The contents of the flask were then filtered using a pre-weighed sintered glass funnel on a Buchner flask. Hot water $(500 \mathrm{ml})$ was used to wash through the crucible to remove the detergent. Again, for starchy samples, 
$2 \mathrm{ml}$ amylase solution were added together with $30 \mathrm{ml}$ hot water. The sample was then allowed to stand for 15 minutes, filtered, and washed with $300 \mathrm{ml}$ hot water. The crucible contents were was rinsed twice with $10 \mathrm{ml}$ acetone and then left for 15 minutes to dry, before placing the crucible in a $100 \mathrm{C}$ oven overnight. After this the sample was cooled, weighed (A), and then ashed overnight at $500 \mathrm{C}$ and reweighed (B). The proportion of NDF in the sample is given by

\& NDF $=($ wt of crucible + fibre) - (wt of crucible - ash) $\times 100$ weight of sample

$$
=\frac{(A-B) \times 100}{\text { weight of sample }}
$$

Appendix $F$ shows the reagents for the neutral detergent fibre method.

\subsubsection{Data analysis}

Data were analysed using a model for the Latin square design. The model included sheep, periods, dietary treatments, Yea-sacc and time of sampling, for rumen metabolites. Differences between means were identified by Least significant Differences (LSD) method (Steel and Torrie, 1980). Analysis of variance tables are shown in appendices $G-K$. 
ChAPTER 3. RESULTS

\subsection{RUMEN METABOLITES}

\section{1 .1 Volatile fatty acids}

The total concentration of volatile fatty acids (VFAs) in the rumen fluid of sheep was not affected by increasing the proportion of concentrate to forage in the diets. Total VFA concentration ranged between 36.7 and $91.3 \mathrm{mM}$ in the rumen fluid of sheep fed the low concentrate (108 concentrate : 908 roughage) diet, between 51.1 and $87.5 \mathrm{mM}$ for the medium (358 concentrate : 658 roughage) and between 53.1 and $82.2 \mathrm{mM}$ for the high (608 concentrate : 408 roughage) concentrate diets. The mean VFA was highest, 69.2mM, with the high concentrate diet followed by the medium diet with $68.3 \mathrm{mM}$ and lastly the low concentrate diet with $65.8 \mathrm{mM}$ of rumen fluid although the differences were not significant $(P=0.05)$ (Table 14).

There was a significant positive response of total VFA concentration to sampling time $(P=0.001)$. Figure 7 shows how the VFA concentrations varied with time after feed consumption when sheep were fed with diets varying in the forage to concentrate ratios. Soon after feeding low and medium concentrate diets, the total VFA concentration in the rumen was depressed slightly before increasing and reaching peaks respectively six and three hours later. After that the VFA concentration decreased. When the diet fed to sheep was made up of 608 concentrate, the total VFA concentration increased soon after feeding, and reached maximum level six hours post-feeding. Thereafter the concentration decreased.

The inclusion of Yea-Sacc in the diets did not affect 
Table 14. Rumen metabolites

parameter

Concetrate Level

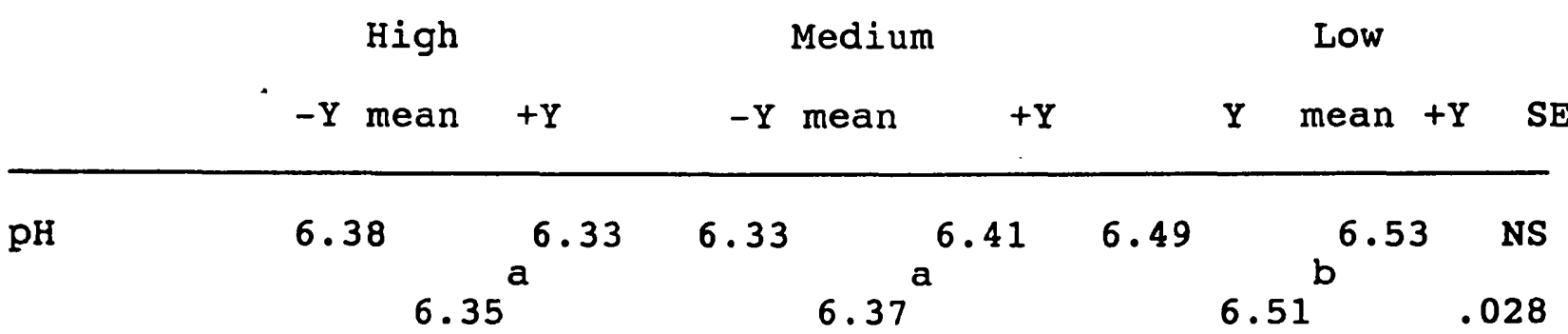

$\begin{array}{ccccccc}\text { total VFA } & 64.6 & 69.3 & 67.4 & 67.6 & 64.0 & \text { NS } \\ \mathrm{mM} & 69 . \mathrm{a}^{\mathrm{a}} & 68.3^{\mathrm{a}^{2}} & 65.8 & 2.81\end{array}$

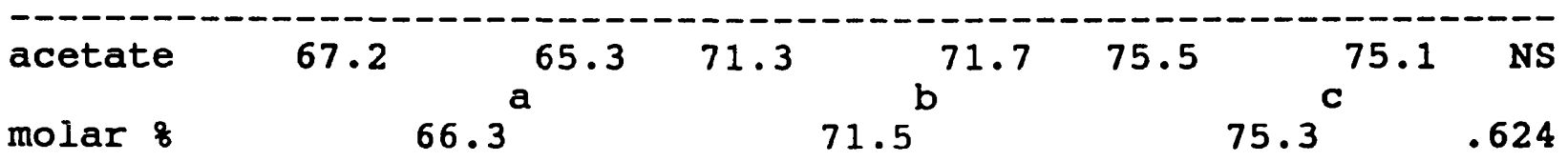

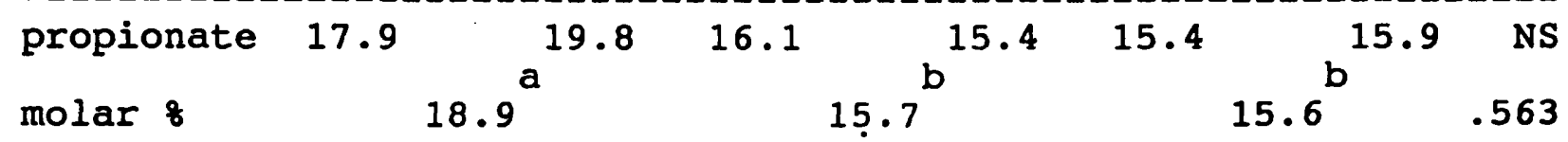

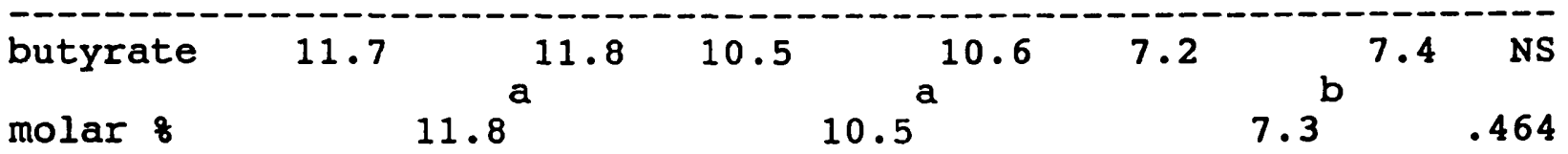

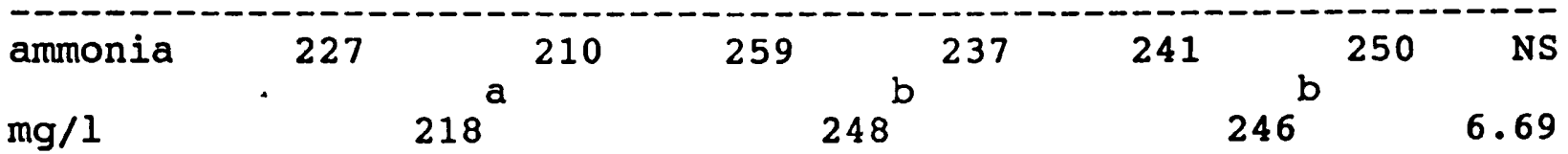

NS No significant effect due to Yea-Sacc $(Y) \quad(P=0.05)$

Means in the same line with different superscripts differ significantly $(P<0.05)$.

significantly $(P=0.05)$ the concentration of total VFA. For the high concentrate diet, Yea-Sacc appeared to increase the total VFA concentration (Table 14) although no significant concentrate $\mathbf{x}$ Yea-Sacc was obtained $(P=0.05)$ (Appendix G1). 


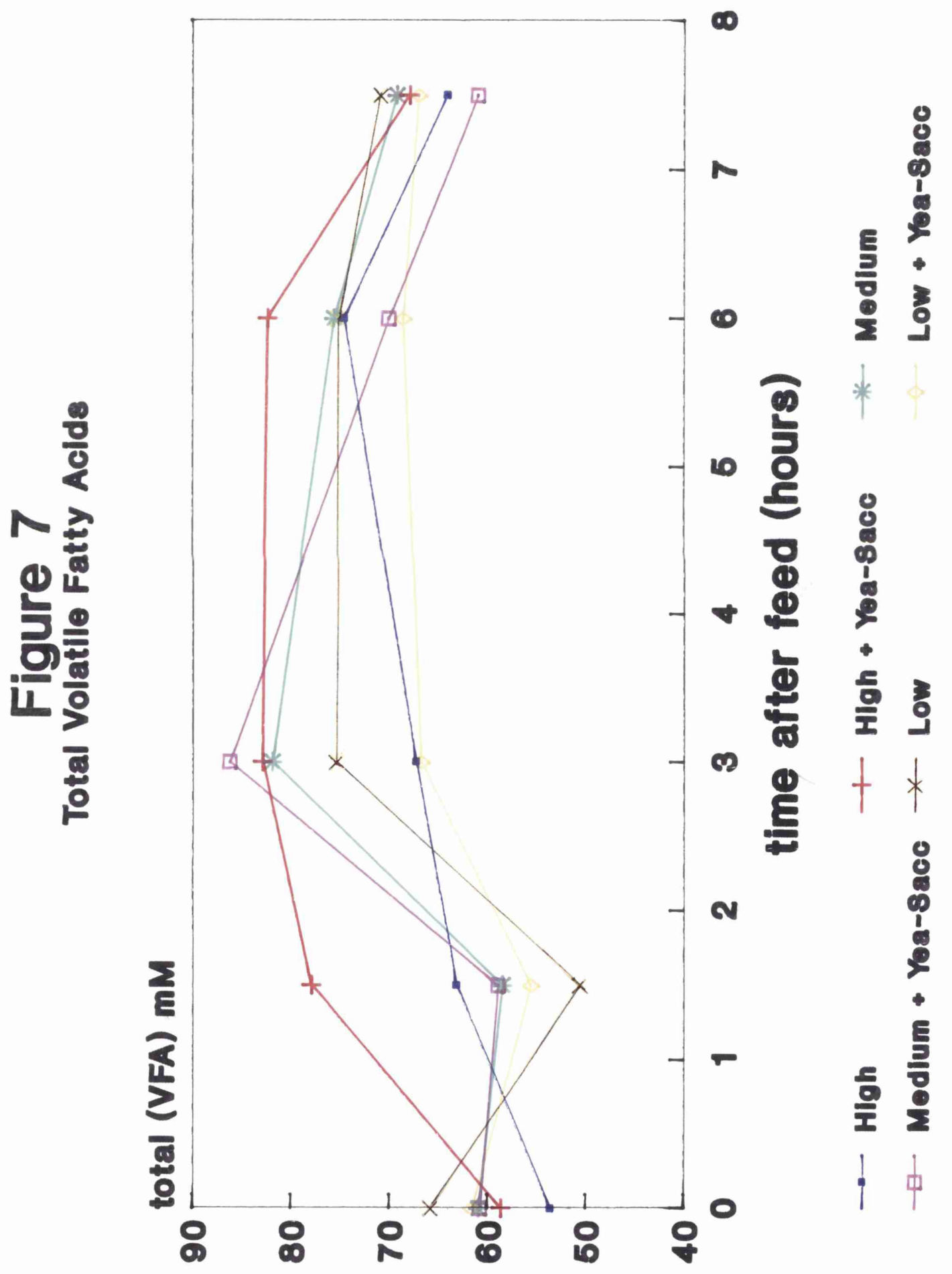




\subsubsection{Molar proportion of volatile fatty acids}

Forage to concentrate ratio and time of sampling significantly $(P<0.05)$ affected the molar proportions or 'fermentation patterns' of VFAs. The molar proportion of acetic acid was decreased $(P<0.001)$ by increasing the level of concentrate in the diets fed to sheep while those of propionic $(P<0.05)$ and that of butyric acid $(P<0.01)$ were increased (Table 14). Acetic acid dominated throughout and was never less than 528 of the VFA. When the concentrate level in the ration was changed from 108 (low) to 358 (medium), the decrease in acetate percentages $(P<0.01)$ was accompanied by a compensatory increase in butyrate percentages $(P<0.01)$ in the rumen fluid. A further increase in the concentrate proportion to $60 \%$ (high) in relation to forage proportion in the diet caused a further decrease $(P<0.01)$ in the rumen proportion of acetic acid but, in this case, the decrease $(P<0.01)$ was compensated by a significant increase in propionic acid $(P<0.01)$. This type of fermentation in the rumen which occurs when high proportions of concentrate are fed, in this case 608 concentrate, is generally referred to as a "propionate" type of fermentation. This differentiates it from the "acetate" type fermentation which occurs when high forage diets ( 908 in this case) are fed to animals. Some differences in rumen proportions were due to individual sheep differences $(P<0.05)$.

The molar proportion of acetic acid varied more $(P<0.001)$ throughout the day as compared to that of propionic acid $(P<0.01)$, while that of butyric acid was not affected much by 
sampling time when the three diets differing in the forage : concentrate ratios were fed to sheep (Figure 8,9 and 10). For the forage diet the molar proportion of the three acids remained fairly constant throughout the day. With medium and high concentrate diet being fed to sheep, acetate percentages decreased slightly soon after feeding and then rose to original levels (Figure 8 ). On the other hand, propionate percentages (Figure 9) increased slightly post-feeding before decreasing. The depression in molar acetate proportion coincided with the peak that occured for molar propionate, and the depressions in total VFA concentration at one and a half hours after feeding. The difference in the diurnal variation of propionate for the different diet types was statistically significant $(P<0.01)$ as shown by a significant concentrate $x$ time interaction (see Appendix G3) .

When Yea-Sacc was included in the high concentrate diet the molar proportion of propionic acid tended to be higher than that for the respective control diet (Figure 9), while the acetic acid proportion was slightly lower (Figure 8). Molar proportions of the VFAs were similar when low and medium diets were fed with or without Yea-Sacc (Table 14). The acetate : propionate ratios tended to be higher (4.66) when Yea-Sacc was included in the medium concentrate diet as compared to control (4.46). The acetate : propionate ratios for the low and high concentrate diets with or without Yea-Sacc were 4.73 and 4.91 , and 3.29 and 3.76 respectively. All the differences due to Yea-Sacc were not statistically significant $(P=0.05)$. 


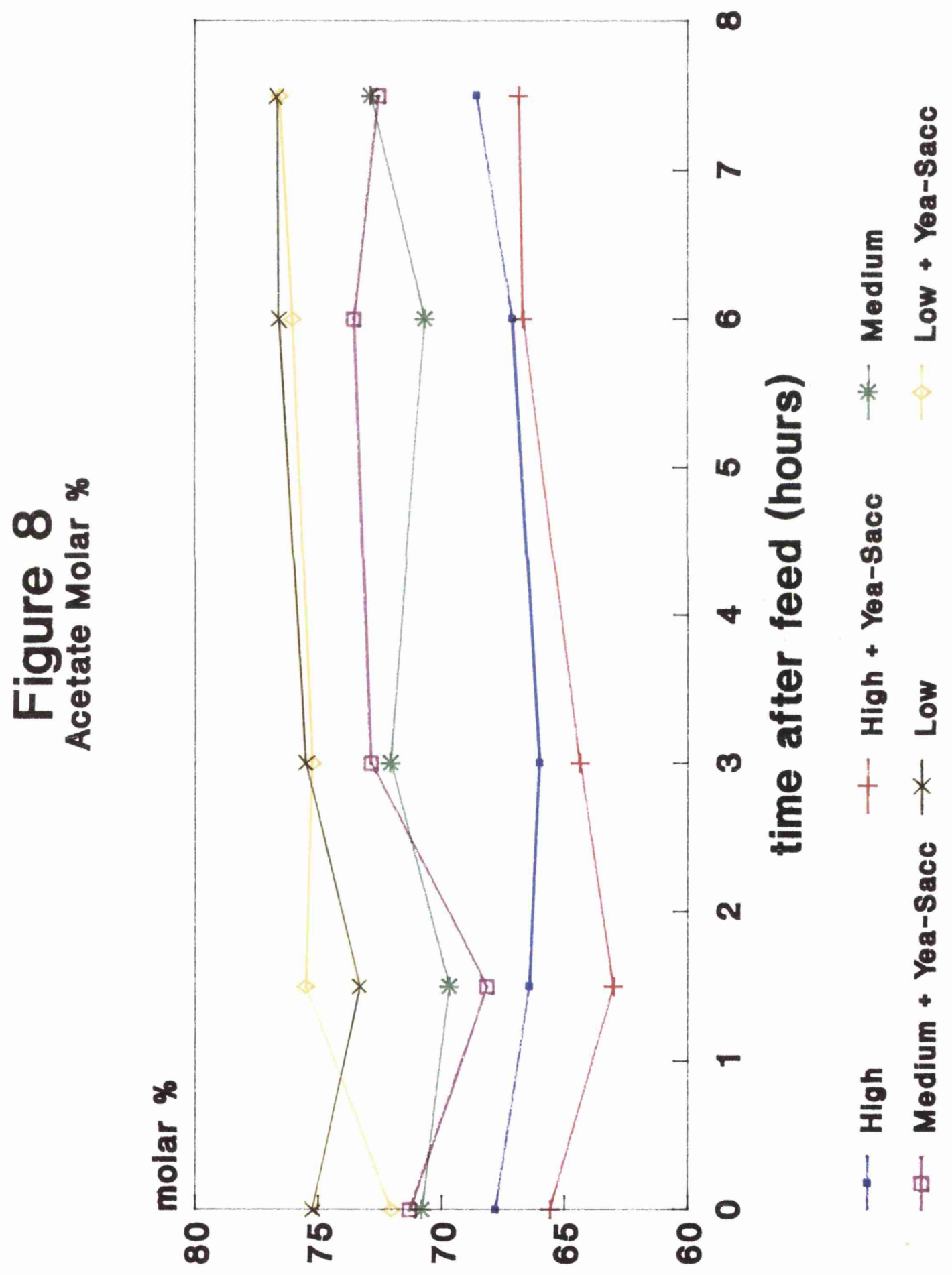




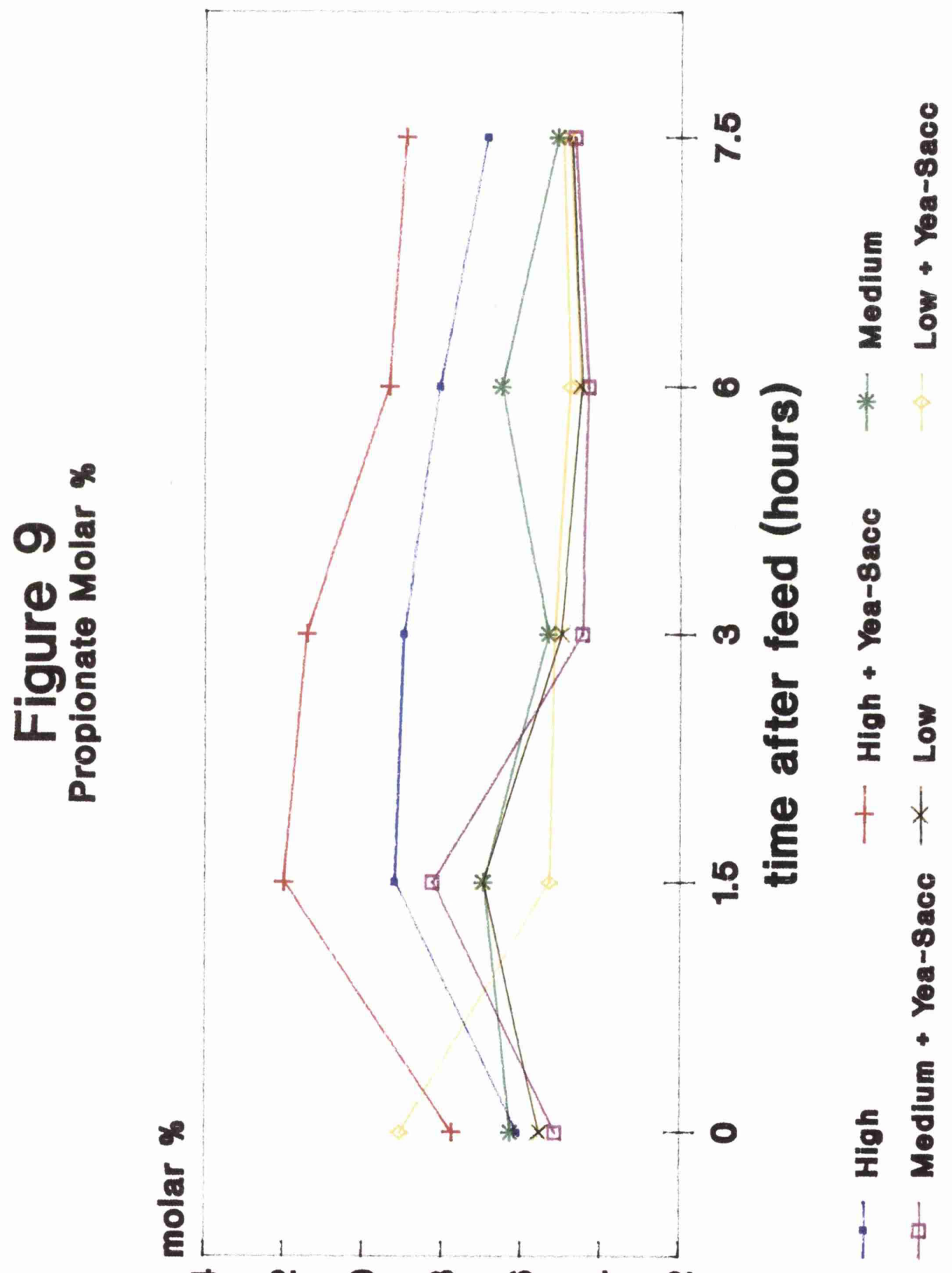




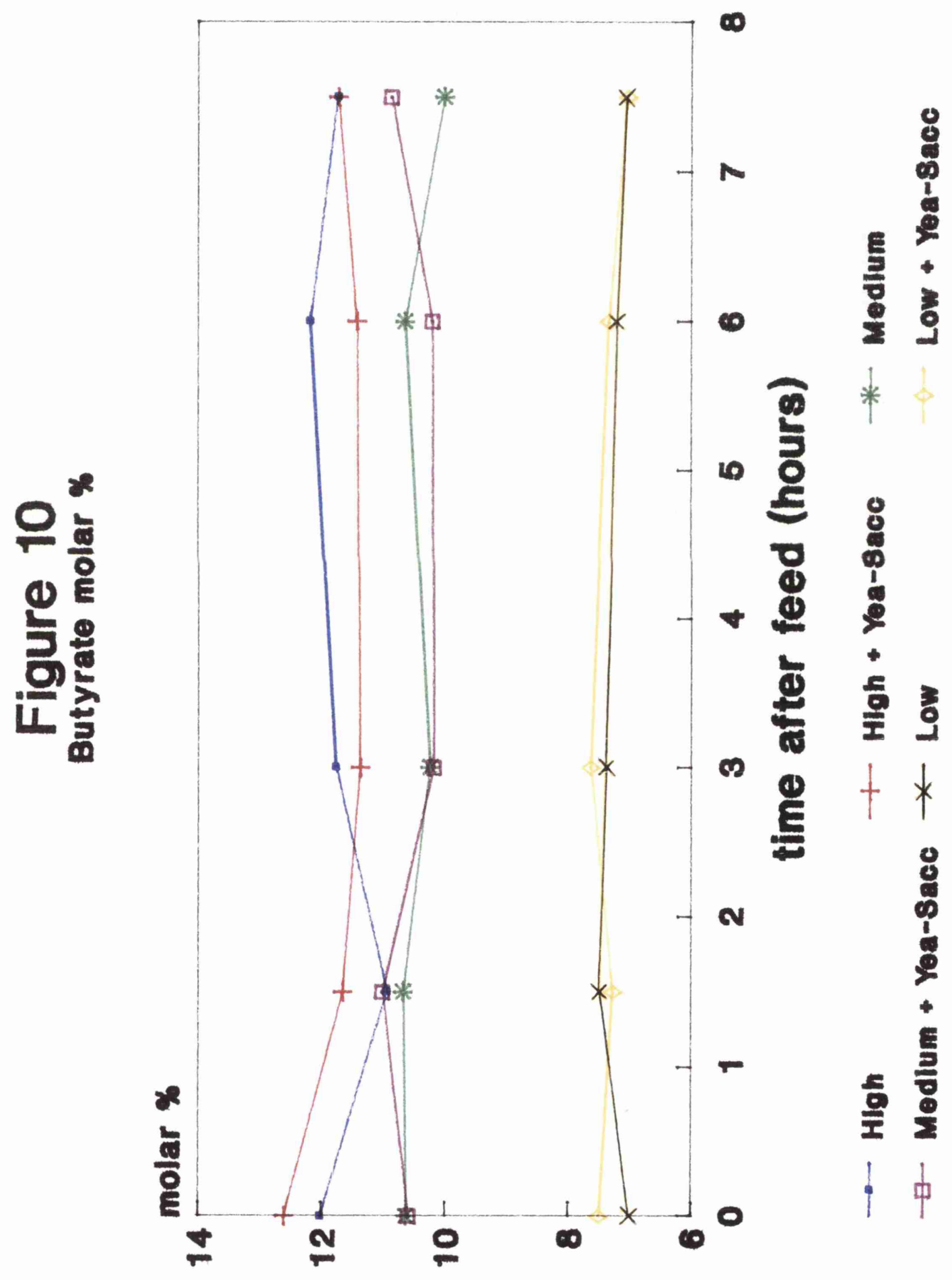




\subsubsection{Rumen pH}

The effect of forage : concentrate ratio on rumen $\mathrm{pH}$ of sheep is shown in Figure 11. Rumen $\mathrm{pH}$ was dependent on the level of concentrate in the diet $(P<0.05)$ as well as the time of sampling during the day $(\mathrm{P}<0.001)$. The mean rumen $\mathrm{pH}$ (averaged over all sampling times) were similar for the medium and high concentrate fed sheep ( 6.37 and 6.35 respectively) but lower than for the low concentrate diet fed sheep (6.51) (Table 14).

Following consumption of the low concentrate diet, rumen pH increased slightly and then decreased to a pH value of 6.37 at six hours post-feeding before rising again (Figure 11). Replacing the forage portion of the diet with concentrate resulted in rumen $\mathrm{pH}$ depression to 6.21 at six hours and 6.15 at three hours postfeeding for the 358 and 608 concentrate diets respectively. $\mathrm{pH}$ in the rumen fluid of sheep receiving the 608 concentrate diet was slightly higher than that for 358 and 108 concentrate fed sheep just before fresh feed was offered. After feed consumption, rumen $\mathrm{pH}$ was depressed more rapidly when the high concentrate diet was fed than for the other two diets. Sheep effects made rumen $\mathrm{pH}$ vary from 6.20 to 6.65 ( $\mathrm{P}<0.01)$ for individual sheep.

Including Yea-sacc in the diets had no statistically significant $(\mathrm{P}=0.05)$ effect on rumen $\mathrm{pH} . \mathrm{pH}$ tended to be $0.04 \mathrm{pH}$ units higher for the low plus Yea-Sacc diet, and $0.08 \mathrm{pH}$ units higher for the medium plus Yea-Sacc diet in comparison to their respective control diets. However rumen $\mathrm{pH}$ tended to be depressed by $0.05 \mathrm{pH}$ units when Yea-Sacc was added to the high concentrate diet. Diurnal variation of $\mathrm{pH}$ was not affected by the treatment. 


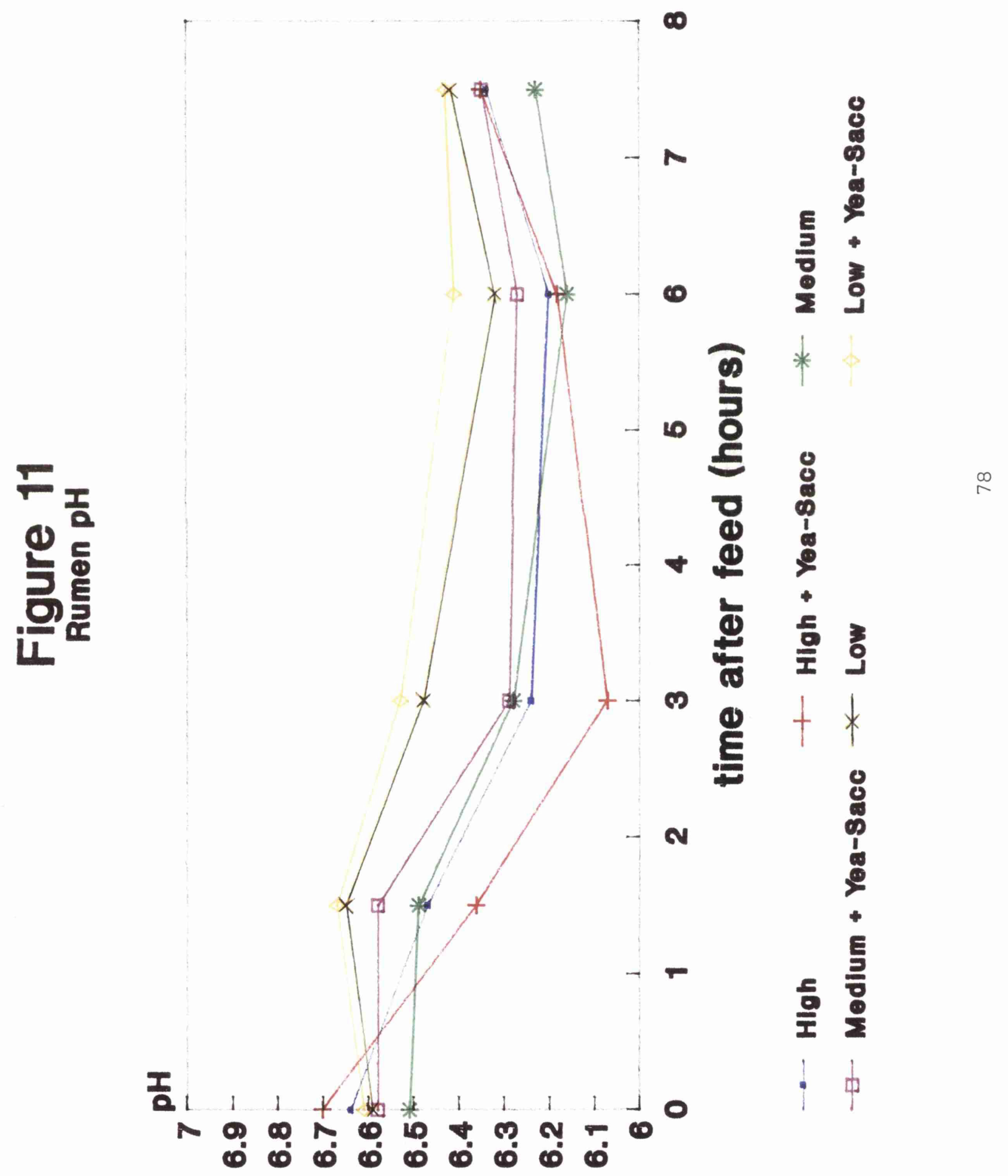




\subsubsection{Rumen ammonia concentration}

The concentration of ammonia in the rumen varied with diet forage to concentrate ratio $(P<0.05)$ as well as with the time of sampling $(P<0.001)$. Rumen ammonia concentrations tended to be similar (246 and $248 \mathrm{mg} / \mathrm{l}$ ) in rumen fluid of sheep fed the low and medium concentrate diets, and were lower $(P<0.05)$ at $218 \mathrm{mg} / 1$ when a high concentrate diet was fed to sheep (Table 14). Figure 12 shows how ammonia concentrations in the rumen varied with sampling time. Peak concentrations occured at about 90 minutes post-feeding with all diets. Thereafter rumen ammonia concentrations fell more rapidily when the medium and high concentrate diets were fed to sheep than when the low concentrate diet was being fed. The interaction of diet concentrate level and time was significant $(P<0.001)$ as shown by a significant concentrate $x$ time interaction (Appendix G5). Minor differences due to sheep were also observed $(P<0.05)$.

Rumen ammonia concentrations were not significantly $(P=0.05)$ altered by the inclusion of Yea-Sacc in the diets (Table 14). However there were slight consistent decreases in rumen ammonia concentrations when Yea-Sacc was included in the high and medium concentrate diets $(7 \%$ and $8 \%$ respectively). The rumen ammonia concentrations tended to be higher when Yea-Sacc was added to low concentrate diet. This apparent interaction was not statistically significant $(P=0.05)$.

\subsection{RUMEN LIOUID OUTFLOW RATE}

The rumen liquid outflow rate (LOR) from the reticulo-rumen as measured by $K 1$ values was significantly altered when sheep 


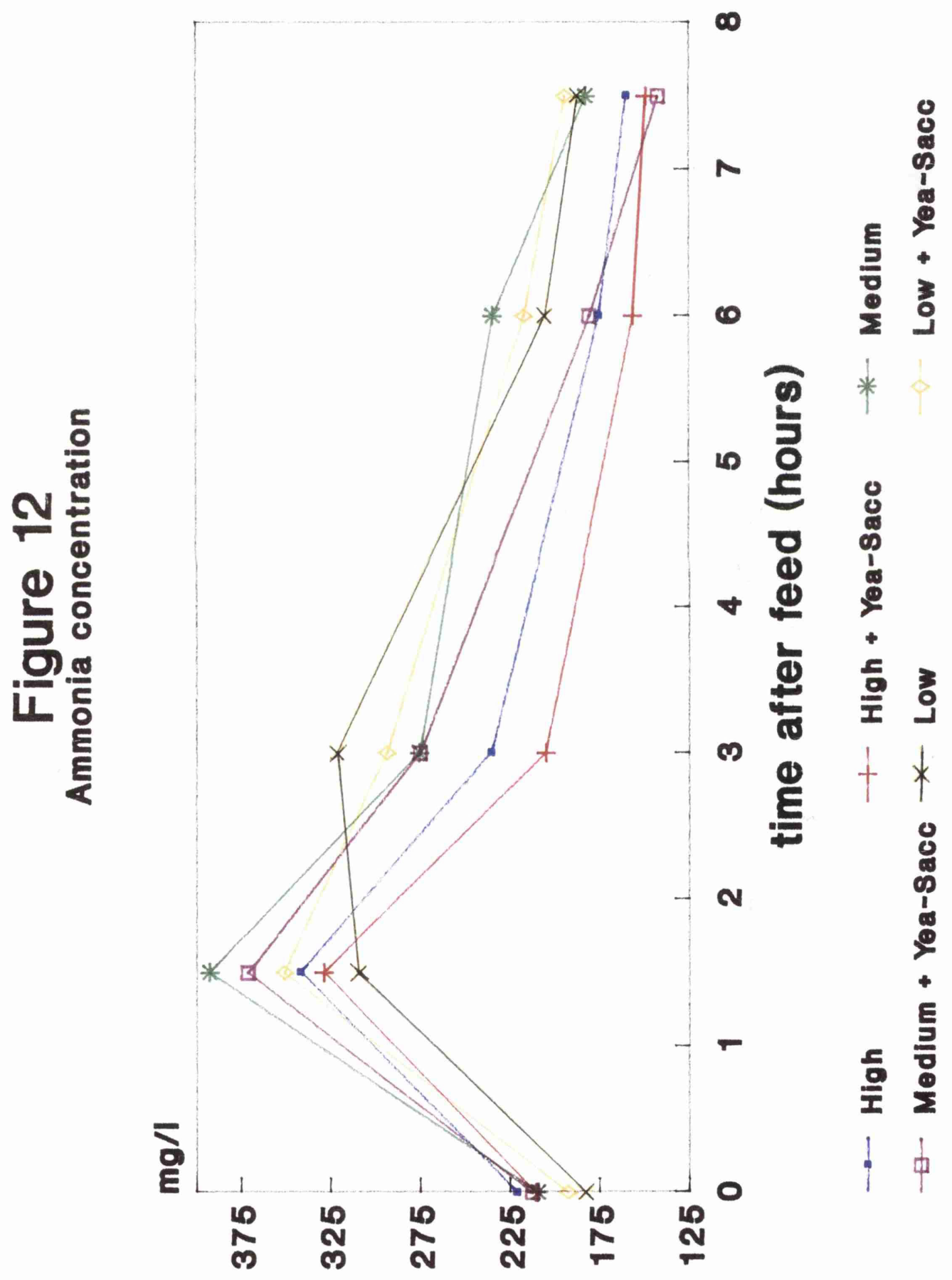


were fed on rations with various proportions of hay : concentrate. The $40: 60$ and $65: 35$, hay to concentrate rations gave higher LORs of $4.398 / \mathrm{hr}(P<0.1)$ and $4.118 / \mathrm{hr}(P<0.05)$ than the $90: 10$, forage : concentrate diet with $3.698 / \mathrm{hr}$ (Table 15). The mean $\mathrm{K} 2$ values or LORs from the caecum and colon, were not affected by increasing the concentrate proportions in the ration in relation to roughage. While the LOR from the rumen was increased by increasing concentrate levels in the diet, mean retention time of fluid in the rumen was depressed.

Including Yea-Sacc in the three control diets varying in their forage : concentrate ratios did not significantly $(P=0.05)$ affect the flow of fluid either from the reticulo-rumen (Table 16) or from the caecum and colon. Figure 13 shows that the outflow rate tended to be higher with Yea-Sacc added to the diet containing a high and a low level of concentrate but lower in the case of the medium concentrate diet although the concentrate $x$ Yea-Sacc interaction did not reach statistical significance (see Appendix $\mathrm{H} 1$ and $\mathrm{H} 2$ ).

Table 15. Liquid outflow rates from the reticulo-rumen (K1) and from the lower gut (K2).

\begin{tabular}{rrrr}
\hline $\begin{array}{r}\text { Hay } \\
\text { \& in the diet }\end{array}$ & \multicolumn{2}{c}{$\mathrm{K} 1$} & \multicolumn{2}{c}{$\mathrm{K} 2$} \\
\hline 90 & 10 & $8 / \mathrm{hr}$ \\
\hline 65 & 35 & 3.69 & 10.78 \\
40 & 60 & 4.11 & 6.41 \\
\hline
\end{tabular}




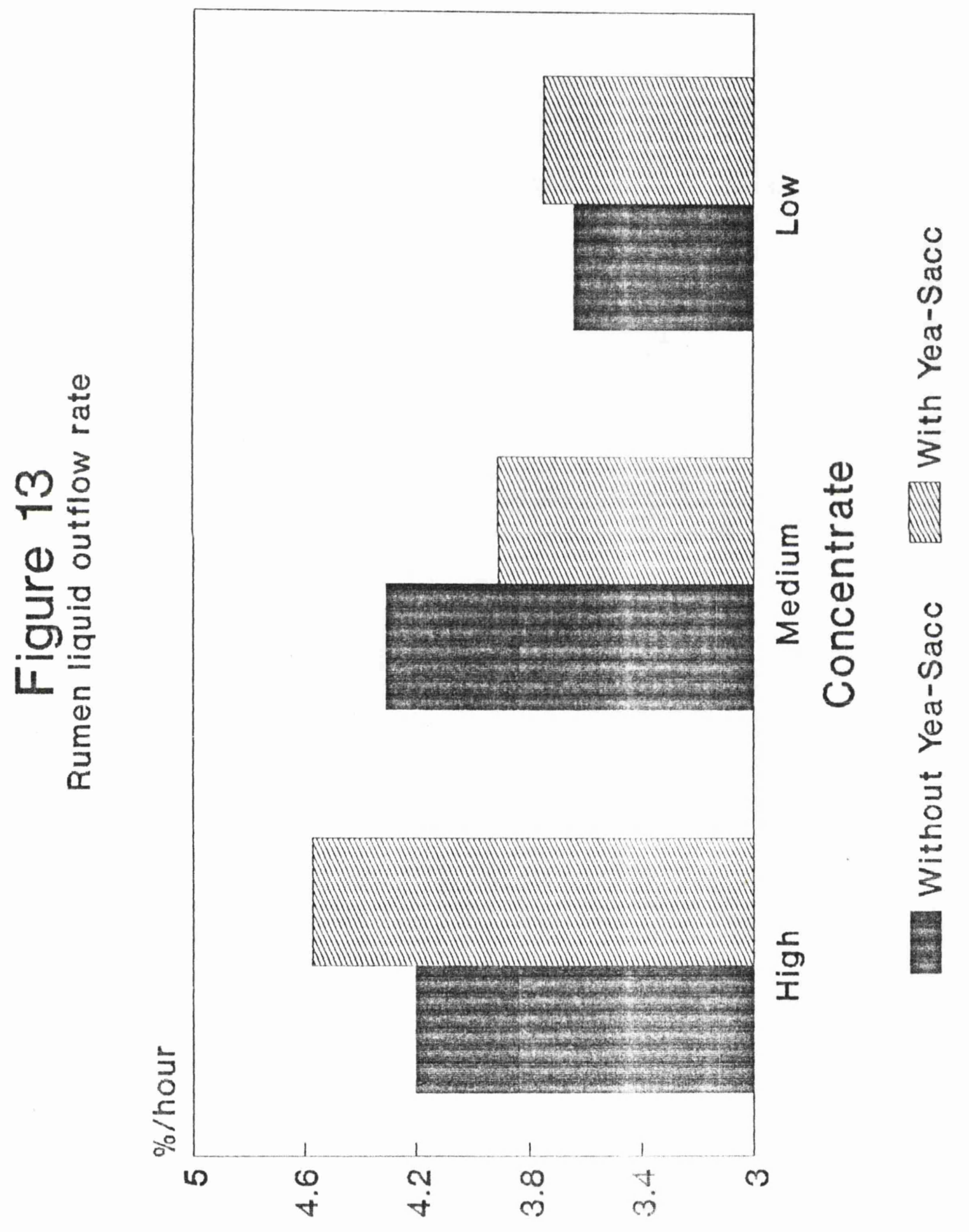


Table 16. The effects of including Yea-Sacc in diets on liquid outflow rates.

\begin{tabular}{lcccccc}
\hline & Low & $\begin{array}{c}\text { Low } \\
+ \\
\text { Yea-Sacc }\end{array}$ & Medium & $\begin{array}{c}\text { Medium } \\
+ \\
\text { Yea-Sacc }\end{array}$ & High & \multicolumn{1}{c}{$\begin{array}{c}\text { High } \\
+ \\
\text { Yea-Sacc }\end{array}$} \\
\hline K1 & 3.67 & 3.75 & 4.31 & 3.91 & 4.20 & 4.57 \\
R2 & 10.85 & 10.72 & 5.16 & 7.66 & 9.91 & 11.16 \\
\hline
\end{tabular}

K1 - liquid outflow rate from the rumen

K2 - liquid outflow rate from the lower gut

\subsection{IN SACCO DIGESTIBILITY OF HAY}

Increasing the concentrate proportion of the diet in relation to roughage proportion depressed the rate of in sacco hay digestion in the rumen $(P<0.01)$. The rate of hay digestion, estimated by the loss of dry matter from the rumen-incubated bags, was highest when sheep received a high forage diet (Table 17). More hay was digested after 48 hours than 24 hours of incubation, but the rate of disappearance of hay dry matter was more rapid during the first 24 hours of incubation than between the 24 and 48 hour incubation period (Figures 14a and 14b); and the rate of hay disappearance from the rumen was faster when the proportion of concentrate in the diet was small. There was a significant difference in hay dry matter digestibility (DMD) between individual sheep $(P<0.01)$, with the DMDs ranging from 32.48 to 48.38 , and 46.78 to 66.38 when the hay bags were incubated for either 24 or 48 hours respectively. 
Table 17. In vivo and in sacco digestibility measurements

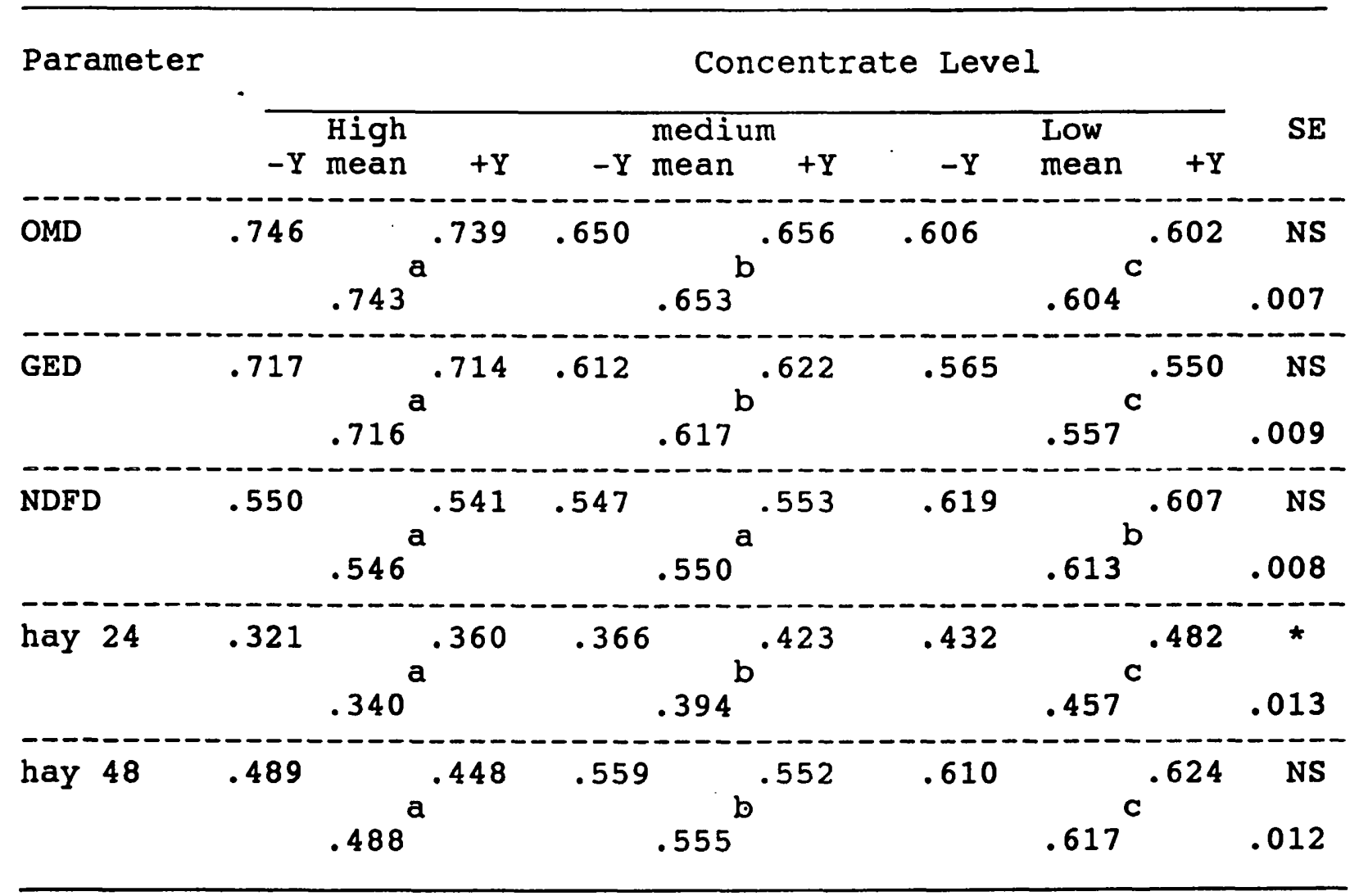

KEY : OMD diet organic matter digestibility measured in vivo

GED diet gross energy digestibility measured in vivo

NDFD. diet NDF digestibility measured in vivo

hay 24 hay DM disappearance after $24 \mathrm{hrs}$ incubation

in sacco

hay 48 hay DM disappearance after 48 hrs incubation in sacco

NS No significant effect due to Yea-Sacc $(P=0.05)$

* Significant effect due to Yea-Sacc $(P<0.05)$

Means in the same line with different superscripts differ significantly $(P<0.05)$ 


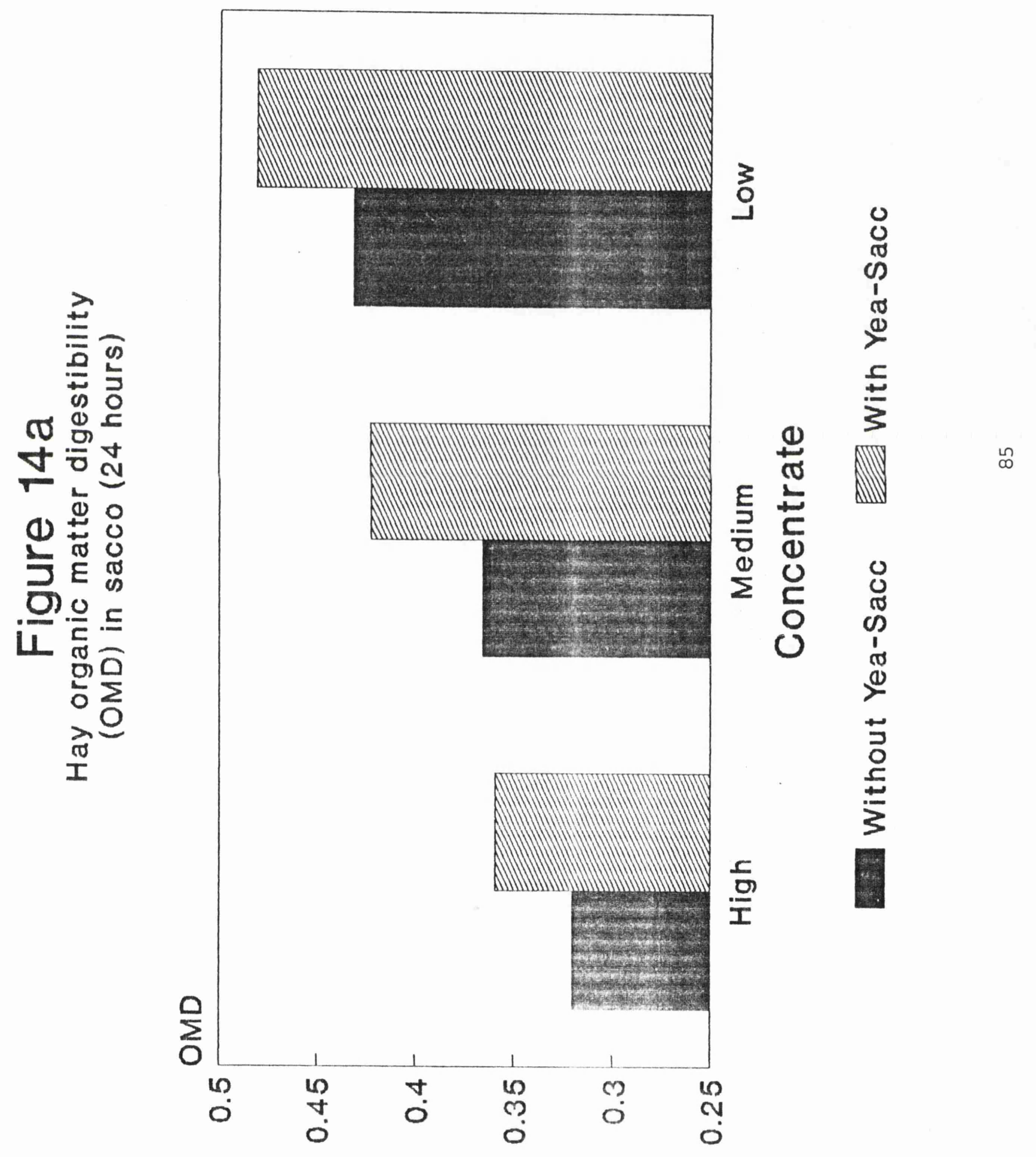




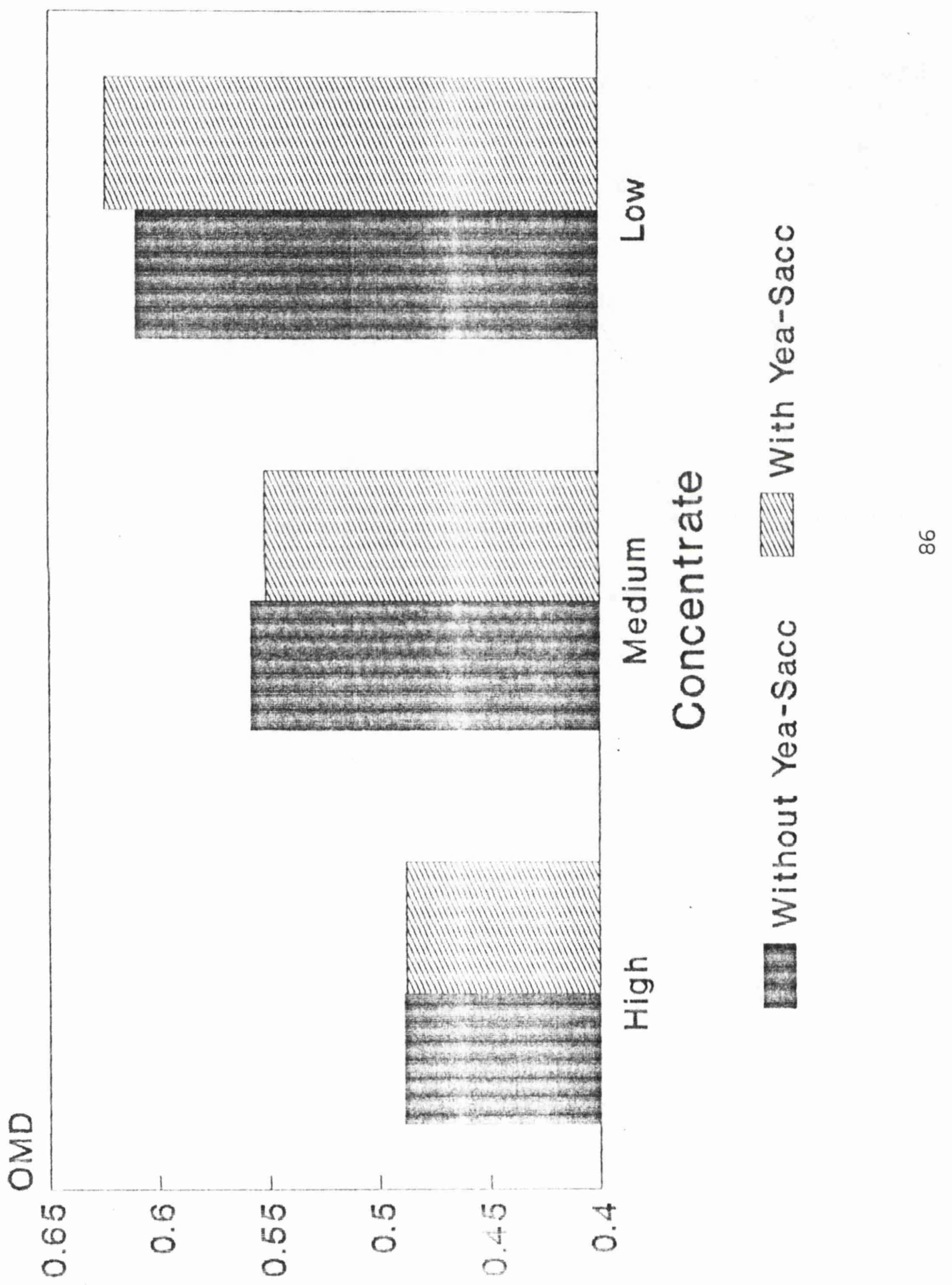


When Yea-Sacc was added to the three diets hay DMD was significantly improved during the 24 hour incubation period $(P<0.05)$ (Figure 14a), but not over the 48 hour incubation period (Figure 14b). Yea-Sacc addition increased the loss of hay DM from the bags after 24 hour incubation by 158,128 and 118 respectively for the medium, high and low concentrate diets (Table 17). After 48 hours of incubation in the rumen the hay DMDs were similar with or without Yea-sacc in the diet Table 17).

\subsection{OVERALL NUTRIENT DIGESTIBILITY}

The organic matter and gross energy digestibilities (OMD and GED) were improved by raising the proportions of concentrate in the diet from 108 to $608(P<0.001)$, while the neutral detergent fibre digestibility (NDFD) was depressed ( $P<0.01$ ) (Figure 15a and 15b). The depression in NDFD was more prominant as the concentrate level in the diet increased from 108 to 358 than from 358 to 608 concentrate.

The digestibilities of OM, NDF and GE (Table 14) were not significantly $(\mathrm{P}=0.05)$ affected by including Yea-Sacc in animal diets containing either $10 \%$ or $35 \%$ or $60 \%$ concentrate, but the three variables (OMD, NDFD, GED) tended to be higher when YeaSacc was added to the medium concentrate diet although the concentrate $x$ Yea-Sacc interaction was not significant (see Appendix $\mathrm{K} 1, \mathrm{~K} 2$ and $\mathrm{K} 3$ ). 


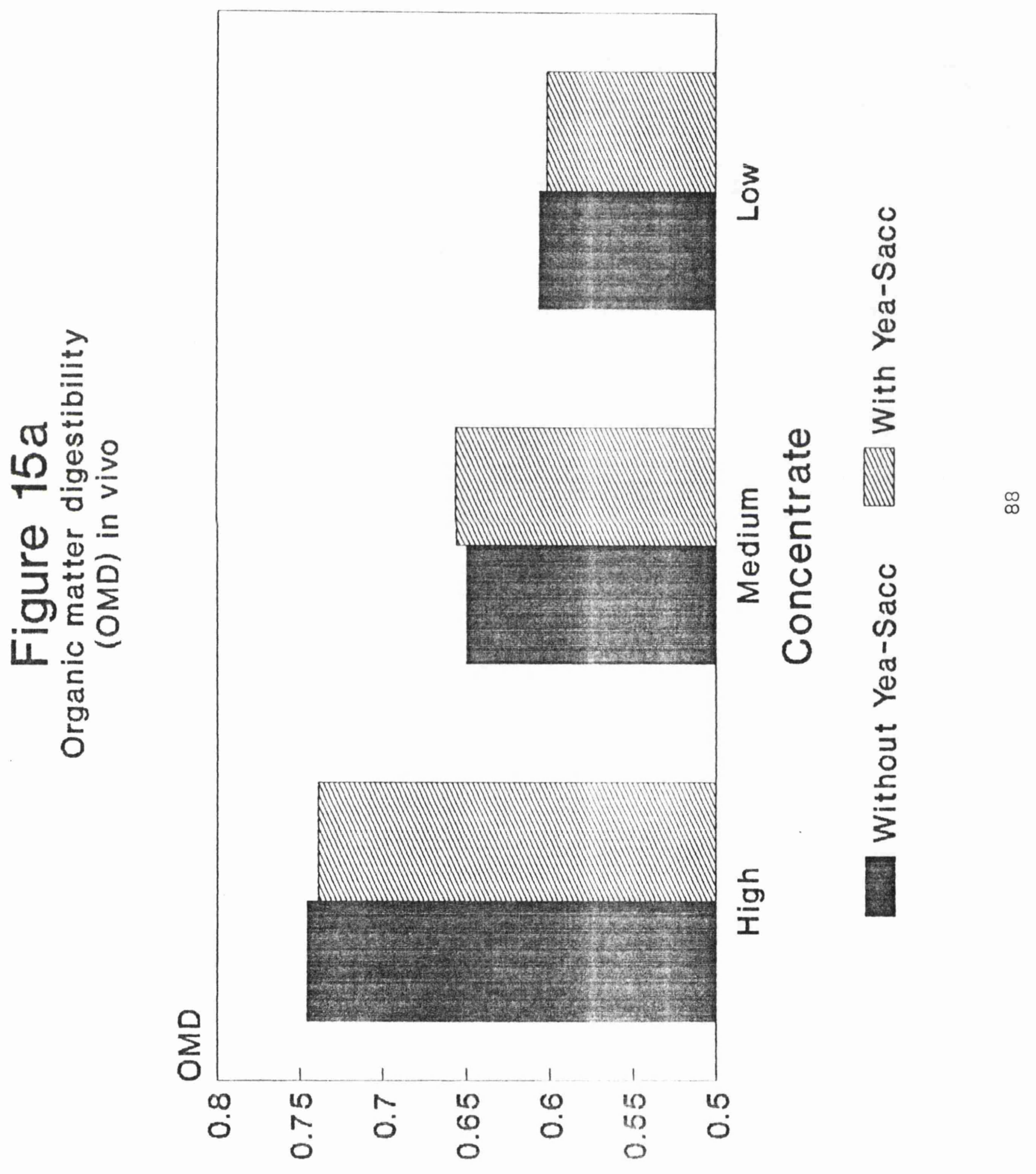




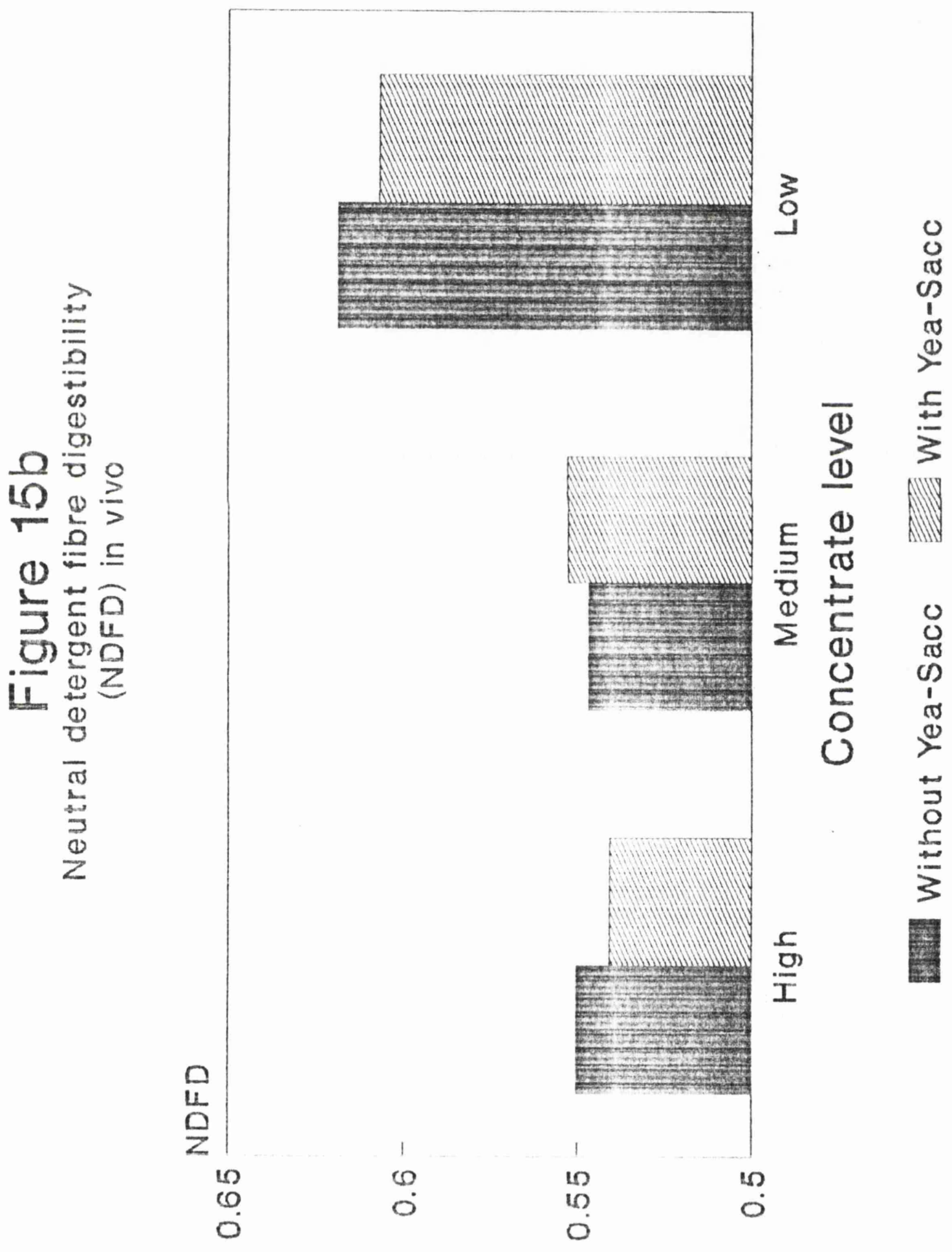




\subsection{THE EFFECT OF FORAGE : CONCENTRATE PROPORTION ON FERMENTATION CRARACTERISTICS}

The rate of fermentation in the rumen as assessed by rumen $\mathrm{pH}$ and total volatile fatty acids (VFAs) concentration showed considerable diurnal variation when a 'normal' or high forage feeding regime, in which a restricted amount of feed was offered twice daily. The fermentation rate was minimal before feeding and reached a peak about six hours after feeding. The fermentation rate progressed more rapidly when the forage portion was replaced by either 358 or 608 concentrate. This was shown by the lower rumen $\mathrm{pH}$ values observed when these diets were fed to sheep. High forage diets (108 concentrate) caused small depressions in rumen $\mathrm{pH}$, from $6.60 \mathrm{pH}$ before feeding to $6.37 \mathrm{pH}$ at maximum fermentation rate. In comparison, similar $\mathrm{pH}$ values for the medium and high concentrate diets were 6.54 and 6.67 respectively before feeding and were reduced to 6.21 and 6.15 respectively when rumen fermentation was greatest. It is well documented that rumen $\mathrm{pH}$ is depressed as the proportion of grain or cereal in the diet increases (Bath and Rook, 1963; Barry et al., 1977b; Mould et al., 1983/84).

Despite the presence of highly fermentable and easily digestible carbohydrates in the concentrate offered to sheep, the rumen $\mathrm{pH}$ was never below 6.0 the critical level. There are two possible reasons to explain this. Firstly, the high concentrate level choosen in this study was not "too high" to cause huge pH depressions. Rumen $\mathrm{pH}$ values of less than 6.0 are normally 
observed when the level of concentrate in relation to that of roughage exceeds 608. Secondly, the physical form of both hay and concentrate was not very fine. Grinding or pelleting concentrates normaly depress rumen $\mathrm{pH}$ more when high concentrate diets are fed (Mould et al., 1983/84).

In this study rumen $\mathrm{pH}$ was not closely associated with total VFAs in the rumen when medium and high concentrate diets were fed to sheep such that the lowest recorded $\mathrm{pH}$ values did not occur at the same times as the highest VFA concentration. This is in agreement with the observations made by Briggs et al. (1957), who observed that only on forage diets was rumen pH closely associated with VFA level in the rumen.

Compared to values for the concentrate diet, the fall in rumen $\mathrm{pH}$ and the rise in total VFA concentration were accompanied by a decrease in molar proportion of acetic acid and a complementary increase in molar proportion of both propionic and butyric acids when the diet fed contained 608 concentrate, or of butyric acid alone when the diets contained 358 concentrate. On the high forage diet, the molar ratios of acetic:propionic:butyric acids were $75: 16: 7$, but this changed to increased proportions of butyric acid (71:16:11) with the $35 \%$ concentrate diet, and to increased proportions of propionic acid (66:19:12) with the 60\% concentrate diet. Similar changes in the composition of the mixture of the fatty acids were reported in the literature for sheep fed rations containing varying proportions of hay : concentrate (Bath and Rook, 1963; Thomas and Rook, 1981; Mould et al., 1983/84). The fermentation type which occurs when high forage diets are fed to ruminants has been 
described as the "acetate fermentation" type while that resulting from high concentrate diets as the "propionate fermentation" type.

A strong relationship exists between the molar proportion of acetic acid and the structural carbobydrate content (as a percentage of organic matter) of the feed (Bath and Rook, 1963). As the content of structural carbohydrates increases, acetate percentages in the rumen liquor increased. This explains why the rumen fluid of forage-fed sheep contained proportionately more acetic acid in comparison to levels found in the rumen fluid of high concentrate fed sheep. The barley and maize cereals which constituted most of the concentrate portion of the diet contain more non-structural carbohydrates (NSC) which are rapidly fermented in the rumen and cause a shift in the VFA production away from acetate. A shift in the fermentation pattern from "acetate" to "propionate" type seemed to occur somewhere between the diet concentrate levels of 358 and 608 . Some research wokers have suggested that this change over in fermentation pattern occurs with 508 or more concentration in the diet (Bath and Rook, 1963 ; Mould et al, 1983/84).

The level of ammonia in the rumen fluid is dependent on the content and degradability of the protein in the diet, and on its rate of uptake by the rumen bacteria which is normally limited by the supply of fermentable energy available to the microbes. An increase in the level of concentrate in the ration may be expected to decrease the level of ammonia concentration in the rumen even if the dietary provision of rumen degradable protein 
(RDP) is constant due to increased microbial activity as more fermentable substrate is supplied. The ammonia concentration in the rumen depends on the balance between rate of ammonia release (which is related approximately to the dietary supply of RDP) and the rate of ammonia assimilation by microbes (which is related approximately to the dietary supply of metabolisable energy). In this experiment, the concentration of ammonia in the rumen fluid were lower $(218 \mathrm{mg} / 1)$ when the high concentrate diet was fed, and there was no difference between the ammonia levels for the medium $(248 \mathrm{mg} / 1)$ and low $(246 \mathrm{mg} / 1)$ concentrate diets. This difference may be explained by the fact that the $\mathrm{RDP} / \mathrm{ME}$ ratio (Table 18) was lowest for the high concentrate diet. Additionally there would be better synchronisation of ammonia release and uptake by the microbes when this diet was fed compared to that of the others. The initial rate of ammonia release following feeding would have been considerable for all diets as urea contributed approximately one third of the total RDP and would be better matched by the rapid fermentation rate of the starchy concentrates. Figure 12 shows the rapid disappearance of rumen ammonia when 608 concentrates were fed. Other workers have observed similar ammonia concentration response to increased high energy concentrates. Annison et al. (1954) observed that feeding large amounts of readily fermentable carbohydrates (RFC) in sheep diets depressed rumen ammonia concentrations. Similaly, Lewis (1956) showed that ruminal ammonia production was depressed when starch or flaked maize in the diet was increased in relation to hay.

Ammonia concentrations in the rumen were never below optimal levels for microbial growth published in the literature. The 
Table 18. Dry matter (DM), crude protein (CP), rumen degradable protein (RDP), and metabolisable energy (ME) intakes (I).

\begin{tabular}{|c|c|c|c|c|c|c|}
\hline & High & $\begin{array}{c}\text { High } \\
\stackrel{+}{\text { Yea-Sacc }}\end{array}$ & Medium & $\begin{array}{c}\text { Medium } \\
+ \\
\text { Yea-Sacc }\end{array}$ & Low & $\begin{array}{c}\text { Low } \\
+ \\
\text { Yea-Sacc }\end{array}$ \\
\hline FWI $g / d$ & 1388 & 1385 & 1262 & 1282 & 1053 & 973 \\
\hline DMI $g / d$ & 1157 & 1155 & 1048 & 1064 & 871 & 802 \\
\hline CPI g/d & 139 & 139 & 128 & 129 & 111 & 105 \\
\hline$R D P I g / d$ & 108 & 107 & 99 & 100 & 87 & 83 \\
\hline MEI MJ/d & 13.1 & 13.1 & 10.8 & 10.9 & 7.8 & 7.3 \\
\hline $\mathrm{RDP} / \mathrm{ME} \mathrm{g} / \mathrm{MJ}$ & 8.2 & 8.2 & 9.2 & 9.2 & 11.2 & 11.4 \\
\hline
\end{tabular}

optimum level of ammonia required for maximum microbial growth and microbial protein synthesis per unit substrate fermented is 50-60mg/l rumen fluid (Satter and slyter, 1974; Rogers et al., 1986). The highest estimated minimal level of ammonia concentration for maximal rate of carbohydrate fermentation is thought to be $235 \mathrm{mg} / 1$ (Mehrez et al., 1977) and it would therefore appear as if ammonia concentration might have limited fermentation when $60 \%$ of the ration feed to sheep was made up of concentrates. However the mean ammonia concentration ( $218 \mathrm{mg} / \mathrm{l})$ for this diet was only slightly lower than the optimum and significant limitation of fermentation seems unlikely.

$\mathrm{pH}$ is another factor which had been observed to influence the concentration of ammonia in the rumen though there were no indications that rumen $\mathrm{pH}$ was correlated with rumen ammonia in this study: A decrease in rumen $\mathrm{pH}$ has been associated with 
higher ammonia concentrations in the rumen since this would be in the ionised form $\left(\mathrm{NH}_{4}{ }^{+}\right)$and leads to reduced diffusion across the rumen wall (Hogan, 1961). Probably the pH values (6.15 lowest value reached over 8 hours of day sampling) obtained after feeding the sheep with a high concentrate diet were not low enough to reduce ammonia diffusion across rumen epithelium.

\subsection{THE EFFECT OF FORAGE : CONCENTRATE ON HAY DIGESTIBILITY}

The in sacco hay dry matter digestibility (DMD) was lowered by feeding increasing proportions of concentrate in hay : concentrate diets indicating a reduction in fibre digestion rate. This was in agreement with several workers who reported that the replacement of forages with readily fermentable sources of energy reduces the extent and rate of fibre digestion (El Shazky et al., 1961; Istasse and Orskov, 1983; Mould and Orskov, 1983/84; Mould et al., 1983/84). High proportions of readily fermentable carbohydrates in the diet depress fibre digestion partly due to the "carbohydrate effect" and partly due to a "pH effect" (Figure 16). The barley/flaked maize components, which replaced hay in the diets, are more preferred by the rumen microbial population because they are more soluble and more readily digested than the fibrous constituents of hay. As a result hay digestibility after 24 hours incubation was reduced from 43.28 to 36.68 and 32.18 for the diets containing 108,358 and 608 concentrates respectively. Low rumen $\mathrm{pH}$ which occured as a result of feeding high proportions of concentrates reduced-fibre digestion. It has been reported that as $\mathrm{pH}$ was reduced from about 6.8 to 6.0 only small depressions in fibre digestion occured, while a further decrease 


\section{Figure 16}

DM welght lose of ground hay due to supplementation of hay-based dlet

with pelleted barley (Mould et al., 1983/84).

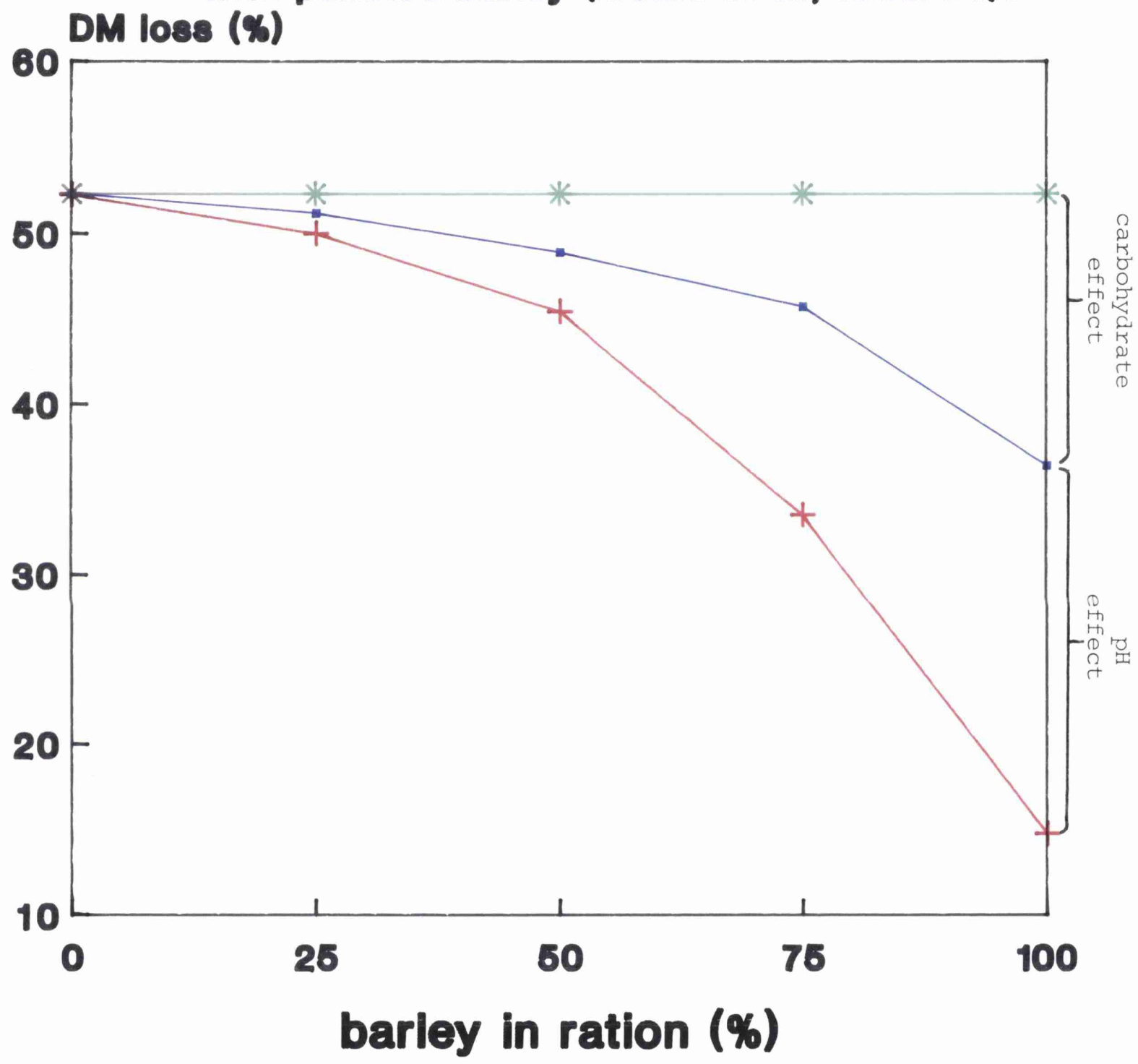

- with blcarbonate + without bicarbonate 
to below 6.0 caused severe inhibition in fibre digestion (Mould and Orskov, 1983/84). Mertens (1979) observed that 808 of that fibre digested at optimal pHs (6.7-7.1) was digested when the $\mathrm{pH}$ was reduced to 6.4 , and only 658 of the fibre was digested when $\mathrm{pH}$ changed from 6.4 to 6.0 . The mean $\mathrm{pH}$ values observed in the current study were $6.51,6.37$ and 6.35 when low, medium and high concentrate diets were fed to sheep, suggesting the reduction in that $\mathrm{pH}$ contributed to the depression in hay digestibility. Also, the fibre-digesting microorganisms in the rumen which work best at $\mathrm{pH}$ levels above 6.7 were less active, while the starch digesters which are capable of surviving low rumen $\mathrm{pH}$ levels increased their activity. The latter group of microbes therefore dominated with the high concentrate diets being fed, further reducing cellulolysis. Fibre digestion was however not completely inhibited because rumen $\mathrm{pH}$ was never below the critical levels of 6.0 . The lowest $\mathrm{pH}$ value of 6.15 was obtained with 608 concentrate in the diet.

\subsection{THE EFFECT OF FORAGE : CONCENTRATE RATIO ON IIOUID OUTFLOW}

\section{RATE}

An increase in the rumen liquid outflow rate (LOR) is sometimes associated with a rise in molar proportion of acetic acid and a fall in that of propionic acid (Harrison et al., 1975; Hodgson and Thomas, 1975) but the reverse has been found in other experiments. Also, increased LOR has been linked to improved microbial protein sythesis (Harrison et al., 1975; 1976; Adams et al., 1981). Inducing an increased outflow rate in vivo would be beneficial to dairy cows receiving high proportions of 
concentrate in their diets since it may lead to increased acetate proportion and hence improved butterfat content in milk. Animals will also benefit from increased microbial protein yield as a result of increased rumen LOR. Response of LOR to increased concentrate : roughage ratios has been inconsistent. In an analysis of data from the literature for sheep and cattle, Evans (1981) observed that rumen fluid turnover rates increased with increased dry matter intake $(P<0.05)$ but did not respond to changes in the forage content of the diet. Digestible energy (DE) was however negatively correlated to LOR although decreasing diet forage content generally corresponds with increased DE or increased grain content of the diet. Similarly, Owens et al. (1979) found the liquid dilution rate to be similar in steers fed either high concentrate or all-alfalfa hay diets at the same level of intake; and Prange et al. (1979) observed little changes on the outflow rate of liquid when iso-nitrogenous diets varying in hay to grain proportion were offered to animals at constant dry matter intake. On the other hand Hodgson and Thomas (1975) reported that LOR was negatively correlated with grain content of the diet at constant intake.

In the current study, increasing concentrate proportion in the hay based diets increased the outflow of liquid from the rumen. As a result LOR was positively related to molar proportion of propionic acid. A number of factors, for example the physical characteristic of both hay and concentrate, the dry. matter intake of the ration, and the method of feeeding (whether concentrate and hay were fed mixed or separately), probably 
influenced the LORs. It could be possible that, because the hay was fed separately, the rumination and salivation processes which cause secretion of large amounts of saliva accounting for a large proportion of the fluid leaving the rumen (and hence influencing LOR) was not affected by increasing the concentrate proportion from 108 to 608 . In order to manipulate LOR for efficient animal production more research is still required to establish all the various factors which influence the liquid outflow rate in the rumen.

\subsection{THE EFFECT OF FORAGE : CONCENTRATE RATIO ON NUTRIENT DIGESTIBILITY}

The effect of replacing hay with concentrate was to improve the organic matter and gross energy digestibilities (OMD and GED) and lower the neutral detergent fibre digestibility (NDFD) as expected from the work of Colucci et al. (1982) and Uden (1984). The improved OMD was due to the increased readily fermentable carbohydrates in the concentrate portion of the ration which was digested at the expense of the forage portion. In the current study, the NDFD decreased from 61.38 to 55.08 ( $P<0.01)$ as the concentrate proprortion was increased from 108 to 358. A further increase in concentarate proportions to 608 slightly further decreased NDFD. The significantly higher $(P<0.05)$ NDFD for the low concentrate diet than the other diets presumably as a result of greater cellulolytic activity in the rumen due to the higher pH for this diet. Thus NDFD was decreased for the same reasons as the in sacco dry matter digestibility for high concentrate diet. 


\subsection{THE EFFECT OF YEA-SACC ON RUMEN FERMENTATION CHARACTERISTICS}

The dietary inclusion of Yea-Sacc in various diets with different forage : concentrate ratios did not alter the rumen fermentation characteristics. The acetate : propionate ratio tended to be higher when Yea-Sacc was included in the medium concentrate diet than when the medium diet was fed without YeaSacc (4.7:1.0 versus 4.4:1.0). Similar statistically insignificant increases in the acetate : propionate ratios were reported by Dawson (1987) and Wiliams (1988). The former worker found values of $3.2: 1.0$ versus $3.1: 1.0$, and the latter 2.3:1.0 versus $1.6: 1.0$. This however was not always the cases. When Yea-Sacc was added to mixed diets for dairy cows (wiedmeier and Arambel, 1987), and for steers (Adams et al., 1981) containing 508 concentrate no changes in acetete : propionate ratios were observed. The small increases in acetate : propionate observed in the present study were due to decreased proportions of propionic acid rather than increased acetic acid. These differences also appear too small to account for the improved butter fat content observed in practice when yeast cultures are added to cows' rations.

It has been suggested in the available literature that the inclusion of yeast cultures in ruminant rations improved fibre digestion through the modulation of rumen pH. The results obtained in the present study showed that the rumen pH was not affected by including Yea-Sacc at any dietary concentrate level. For the medium concentrate diet, Yea-Sacc increased the pH by almost $0.1 \mathrm{pH}$ units but this was not statistically significant. Dawson (1987) reported that the presence of Yea-Sacc in fermenter 
cultures was sufficient to raise the $\mathrm{pH}$ by approximately $0.2 \mathrm{pH}$ units.

Ammonia concentrations in the rumen tended to be lower when Yea-Sacc wàs added to high and medium concentrates diets fed to sheep. Similar statistically insignificant decreases in the rumen ammonia concentrations were reported by Adams et al. (1981) and Dawson (1987). Decreased ammonia would suggest that rumen microbes are working more efficiently, and potential supply of amino acids to the host animal may be improved.

\subsection{THE EFFECTS OF YEA-SACC ON IN SACCO HAY DIGESTIBILITY}

For 24 hour incubations, addition of Yea-Sacc to the diet significantly $(P<0.05)$ increased the disappearance of hay organic matter (OM) from the nylon bags incubated in the rumen. This effect was apparent for every sheep and for every diet. The in sacco dry matter digestibility (DMD) was increased by approximately 158, 128 and 118 for the medium, high and low concentrate diets respectively. However, Yea-Sacc had no effect on hay disappearance following 48 hours of rumen incubation which is consistent with the observations that OMD and NDFD measured in vivo were not affected. The in sacco results suggests that YeaSacc may have increased the initial rate of forage digestion in the rumen without affecting the ultimate extent of digestion. This could be due to increased cellulolytic numbers and to the favourable changes in the rumen enviroment as a result of YeaSacc addition. Wiedmeier and Arambel (1987) observed that hemicellulose digestibility was increased by $6.58(P<0.05)$, and the numbers and proportions of cellulolytic organisms were 
increased when a basal diet (508 concentrate) was supplemented with a yeast culture. Newbold (1988) also observed similar increases in cellulolytic organisms. This therefore suggests that increased cellulolytic numbers could have lead to the improvement in fibre digestion observed in the current experiment. Rumen $\mathrm{pH}$ was not significantly altered by dietary inclusion of Yea-Sacc and similar observations were made by Wiedmeier and Arambel (1987). $\mathrm{pH}$ modulation therefore is not likely to have a major contribution to the improved fibre digestion.

If increased disappearance of hay $O M$ was due to increased microbial numbers, then it could be due to supply of growth factors by the yeast culture to the cellulolytic bacteria. Lyons suggested that the yeast cells, together with the media on which the cells were grown, when included in the diets, could supply growth factors such as the B-vitamins or branched chain fatty acids to the rumen bacteria.

An increase in the initial rate of forage digestion in the rumen may be expected to lead to increased forage intake in ad lib. feeding situations and could account for the increased silage intake observed in the recent dairy cow experiment carried out at the Crichton Royal Farm (Bax, 1988).

\subsection{THE EFFECT OF YEA-SACC ON THE LIQUID OUTFLOK RATE}

The effect of dietary inclusion of Yea-Sacc on liquid outflow rate (LOR) was determined in the present study because of the possibility that responses of Yea-Sacc in the rumen could be mediated through increased saliva production. In most cases 
increased saliva production accounts for the large proportion of fluid leaving the rumen, and increased LOR is associated with more efficient microbial protein sythesis and increased flow of alpha-linked glucose and amino acids to the duodemum. Propionic acid has also been reported to decrease when LOR increases. Feeding control diets containing 108,358 and 608 concentrate plus Yea-Sacc did not alter the LOR although it tended to be higher $(4.20$ versus $4.578 / \mathrm{hr})$ when Yea-Sacc was added to the high concentrate diet. Propionic acid proportions were not affected. Such small increases in LOR had been reported by Adams et al. (1981), an increase from 3.7 to $4.41 / \mathrm{hr}$ when a 508 concentrate diet plus a yeast culture was fed. Wiedmeier and Arambel (1987) observed an increase in LOR from 4.53 to $4.881 / \mathrm{hr}(P<0.05)$ but these could have been due to increased dry matter intakes observed. Increase in saliva production in the rumen would have improved rumen $\mathrm{pH}$ too, but this was not the case. The possibility that Yea-Sacc might influence saliva flow has not been therefore confirmed in the current study.

\subsection{THE EFFECT OF YEA-SACC ON NUTRIENT DIGESTIBILITY}

Digestibilities of organic matter (OM), neutral detergent fibre (NDF) and gross energy (GE) were not overall affected by inclusion of Yea-Sacc although values tended to be higher with Yea-Sacc for the 358 concentrate diet (medium) (i.e. OM - 64.998 versus 65.608 ; NDF - 54.688 versus 55.288 ; and GE - 61.20 versus 62.208). This is in agreement with the small changes observed by Adams et al. (1981). In their experiment DMD, OMD and ADFD (acid detergent fibre digestibility) were insignificantly altered from 
69.08 to $70.48 ; 70.28$ to 71.68 and 45.58 to 44.48 respectively when a yeast culture was added to control diets containing 508 concentrate. Fallon (1987), and Wiedmeier and Arambel (1987) however observed increases of up to 28 in DMD of the feed. Therefore, Yea-Sacc does not appear to have any great influence on the overall nutrient digestibility.

\subsection{CONCLUSION}

Supplementation of three diets differing in forage: concentrate ratio with yeast culture (Yea-sacc) did not significantly $(\mathrm{P}<0.05)$ affect rumen $\mathrm{pH}$, rumen ammonia concentration, volatile fatty acids concentration, rumen liquid outflow rate, overall digestibility of organic matter, energy or neutral detergent fibre. There was a tendency for slight statistically insignificant increases in acetate : propionate ratios and rumen $\mathrm{pH}$ levels, as well as decreases in the rumen ammonia concentration when Yea-Sacc was included in the diets.

Yea-Sacc supplementation significantly $(P<0.05)$ increased the disappearance of hay organic matter from nylon bags incubated in the rumen for 24 hours although the values for 48 hours were unaffected. This suggests that Yea-Sacc supplement increases the initial rate of forage digestion. The mechanism of this effect is not known at this time. It is however suggested that Yea-Sacc supplement imight alter the microbial population numbers in the rumen, particularliy those of the fibre-digesters. It may be possible that Yea-Sacc supplement is supplying some stimulatory growth factors to rumen bacteria giving rise to greater concentration of cellulolytic bacteria leading to increased rates 
of fibre digestion. This effect would be expected to increase forage intakes since it would increase the rate of rumen emptying and therefore would reduce the time required for the stretch receptors in the rumen wall to initiate hunger. Improved animal performance would normally be anticipated as a result of increased forage intake although in all cases it would present the opportunity to reduce feed costs by reducing concentrate inputs. Alternatively, although nọt confirmed in the present study, modulation of rumen $\mathrm{pH}$ when sheep consume diets supplemented with Yea-Sacc may be part of the mechanism leading to improved fibre digestion.

It is therefore suggested that a further investigation be carried out to examine the response of ruminal microbial population - the total anaerobic bacteria and total cellulolytic bacteria - to addition of Yea-Sacc to diets varying widely in forage : concentrate ratio. If an increase in the number of cellulose degraders in the rumen is observed, this could explain the increased fibre digestion observed in the present study. Detailed biochemical/microbiological experiments would then be required to discover the reason for the stimulatory effect of yeast cells on cellulolytic bacteria. At the same time, the rumen concentration of viable yeast cells could be examined so as to establish whether yeast cells actually multiply and grow in the rumen. Finally, further research on the dose-response to Yea-Sacc at different forage to concentrate ratios could be examined. 


\section{APPENDIX $\underline{\text { A }}$}

Latin Square change over design.

\begin{tabular}{|c|c|c|c|c|c|c|c|c|}
\hline & & & & & Per & & & \\
\hline & & Ear tag & 1 & 2 & 3 & 4 & 5 & 6 \\
\hline & 1 & 89 & $\mathrm{H}$ & HY & $\mathbf{M}$ & MY & L & $L Y$ \\
\hline & 2 & 90 & HY & MY & $\mathrm{H}$ & LY & M & L \\
\hline Sheep & 3 & 85 & M & H & $I$ & HY & LY & MY \\
\hline & 4 & 475 & MY & LY & HY & L & $\mathrm{H}$ & $\mathbf{M}$ \\
\hline & 5 & 464 & L & $\mathbf{M}$ & LY & H & MY & HY \\
\hline & 6 & 425 & LY & L & MY & $\mathbf{M}$ & HY & H \\
\hline
\end{tabular}

H - high; M - medium; L - low; Y - with Yea-Sacc

\section{APPENDIX B}

Amounts offered per feed ( $g /$ day fresh weight)

Diet

\begin{tabular}{lccc}
\cline { 2 - 4 } Feedstuff & High & Medium & Low \\
\hline hay & 572 & 930 & 1286 \\
rolled barley & 418 & 244 & 70 \\
flaked maize & 418 & 244 & 70 \\
urea & 14 & 14 & 14 \\
mineral & 14 & 14 & 14 \\
total fresh weight & 1436 & 1446 & 1454 \\
intake & & & \\
\hline
\end{tabular}




\section{APPENDIX C}

Reagents for the colour analysis for ammonia determination.

1. Caustic Phenol - $2.4 \mathrm{~g}$ Sodium Hydroxide $20.0 \mathrm{~g}$ Phenol

$$
0.1 \mathrm{~g} \text { Sodium Nitroprusside }
$$
made up to $1600 \mathrm{~cm}^{3}$ with distilled water.

2. Buffer - $\quad 10.0 \mathrm{~g}$ Sodium Hydroxide

$7.48 \mathrm{~g}$ anhydrous $\mathrm{Na}_{2} \mathrm{HPO}_{4}$

$63.6 \mathrm{~g} \mathrm{Na}_{3} \mathrm{HPO}_{4} \cdot 12 \mathrm{H}_{2} \mathrm{O}$

$20 \mathrm{~cm} 3$ sodium hypochlorite

made up to 4 litres with distilled water.

The reagents were stored in dark winchesters in a refridgerator, and were allowed to warm to room temperature before use. 


\section{APPENDIX D}

Determination of chromium oxide in the faeces.

\section{Reagents}

1. Acid mixture was made up by mixing slowly, with cooling, the following:
a. $250 \mathrm{~cm}^{3}$ concentrate Sulphuric acid $\left(\mathrm{H}_{2} \mathrm{SO}_{4}\right)$
b. $250 \mathrm{~cm}^{3}$ Phosphoric acid $\left(\mathrm{H}_{2} \mathrm{PO}_{4}\right)$ (SG 1.75)
c. $500 \mathrm{~cm}^{3}$ distilled water
d. $50 \mathrm{~cm}^{3} 158$ Manganase sulphate $\left(\mathrm{MnSO}_{4}\right)$

2. 4.58 Potassium bromate (KBr)

3. 0.458 Potassium bromate

4. Colour reagent made by filtering a 0.258 solution of 1.5 Diphenyl-carbazide in Ethanol 10 volumes of $0.25 \mathrm{M}$ Sulphuric acid using filter paper number 42 .

5. Potassium dichromate $\left(\mathrm{K}_{2} \mathrm{Cr}_{2} \mathrm{O}_{7}\right)$ standards were made by disolving $1.936 \mathrm{~g} \mathrm{~K}_{2} \mathrm{Cr}_{2} \mathrm{O}_{7}$ in one litre of distilled water $(1.936 \mathrm{~g} / \mathrm{l})$. This was further diluted to give appropriate individual standards.

\section{Method}

The method involved two distinct processes:

a. The quantitative oxidation of chromium oxide $\left(\mathrm{Cr}_{2} \mathrm{O}_{2}\right)$ to dichromate ion $\left(\mathrm{Cr}_{2} \mathrm{O}_{7}^{-2}\right)$.

b. Estimation of the dichromate ion concentration. Part a.

A representative subsample (appoximately $2 \mathrm{~g}$ ) was taken from each of the dried and milled faeces samples and weighed in a crucible. The subsample was heated at $550^{\circ} \mathrm{C}$ for 48 hours. The resulting ash was quantitatively brushed into a dry $50 \mathrm{~cm}^{3}$ conical 
flask and the crucible was washed with two $3 \mathrm{~cm}^{3}$ portions of the acid mixture and the washings were added to the conical flask. The flask was heated on a hot plate until the mixture boiled. After that $3 \mathrm{~cm}^{3}$ of $4.58 \mathrm{KBrO}_{3}$ solution was added and boiling was continued until production of bromine ceased. The flask was then allowed to cool at room temperature for appoximately 10 minutes. $20 \mathrm{~cm}^{3}$ of $0.458 \mathrm{KBrO}_{3}$, a dilute solution of $\mathrm{KBrO}_{3}$, was then added and the mixture boiled for a further 3-4 minutes to complete the oxidation. After cooling to room temperature, the solution was made up to $50 \mathrm{~cm}^{3}$ with distilled water and transfered to $7 \mathrm{ml}$ Bijou bottles until required for estimation of the chromium concentration.

\section{Part $\underline{b}$.}

A range of potassium dichromate standards were prepared at concentrations $0.5,10,20$, and $30 \mathrm{mg} / 1$. $0.4 \mathrm{ml}$ of the clear golden yellow supernatant solution in the Bijou bottles was taken by pipette into $10 \mathrm{~cm}^{3}$ test tube, then $0.6 \mathrm{~cm}^{3}$ of distilled water was added followed by the colour reagent. After mixing the sample, absorbance was read at $550 \mathrm{~nm}$ using a spectrophotometer model PYE UNICAM SP8-500. The measurements for the blanks and standards were used to draw a graph of chromium concentration against absorbance. The chromium concentration of the samples were then read off the graph. 
DEF FNA $(X)=(I N T(X+1000+.5)) / 1000$

DIn TTT $(30)$, CC (30), TB(10), CB $(10), T A(28), C A(28)$, CAL $(28), C P B(10), C P B L(10)$

DIK $D(30), P(30), P R C(30), K 1(10), K 2(10), K 3(10), A 1(10), A 2(10), A 3(10)$

DIH RI (10), R2(10), R3(10),A12(10), 21(10), 22110), Z3(10), TT(10)

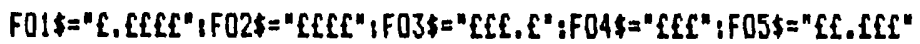

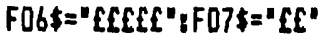

REM DATA SHEEP/PERIOD ID

REK DATA HINS, CTCONC

REH TERHINATE 1000,1000

IF END 13 THEN 10000

INPUT "ENTER DATA FILE NAME";F\$

DPEN F\$ AS 3

0.100 PRINT:PRINTIPRINT

LPRINTERIPRINTIPRINT

$N=0$

READ [J\}ID\$

FOR 2l\%=1 TO 100:PRINT "-" INEXT IZ\%,PRINT

PRINTIPRIHT CHR $\$(14)$;F\$;" ";D\$

PRINTIPRINT TAB(20); "Tine Hrs"; TAB (35);"Cr g/100g OH"

FOR $2 Z X=20$ TO 50:PRINT TAB(ZZ\%)," "IINEXT ZZh:PRINT

FOR $I=1$ TO 30

READ $\{3, T, C$

IF $T=1000$ AND $C=1000$ THEN $I=30: 60 T 01.0$

$T=T / 60$

TIT(I) $=T_{1}$ CC $(3)=C$

PRINT TAB (22); FNA(T); TAB (3B); FNA(C)

$\mathrm{N}=\mathrm{N}+1$

1.0 NEXT I

PRINTIPRINT Ni" Pairs"

CONSOLE

PRINT IDF:PRINT

CONT $=0$

FOR SKIP $=3$ TO 9

CONT $=$ CONT $+1: B=0: A=0$

PRINT "ITERATION "iCONT

REY SPLIT DATA

FOR I $=1$ TO $N$

If $I\langle=5 K$ JP THEN $B=B+1: T B(B)=T T T(I): C B(B)=C C(1): 60 T 05.0$

$A=A+1 ; T A(A)=T T T(1): C A(A)=C C(I): C A L(A)=L O G(C A(A))$

5.0 NEXT I

REM FIRST REGRESSION ON AFTERS

FOR $I=1$ TO A

$O(I)=T A(I): P(I)=C A L(I)$

NEXT I

$Z=A:$ GOSUB 1000

$K I$ (CONT) $=A B S(B 4): A I$ (CONT) $=E X P(C L): R \perp(C O N T)=R: l 1$ (CONT) $=l$

REM CALCULATE EXTRAPOLATED CONCS FOR BEFORES

FOR $I=1$ TO $B$

$X=A I$ (CONT) $+(E X P(-I * K I$ (CONT) ETB $(I)))$

$C P B(I)=X-C B(I)$

IF CPB(I)<O THEN I=B:FAULT\%=1:60TO 5.5

$C P B L(I)=L O G(C P B(I))$ 
IF FAULT\% $\%=1$ THEN FAULT $\%=0: 60 T 06.0$

REM REGRESSION ON CONC DIFFERENCES FOR BEFORES

FOR $I=1$ TO B

$O(I)=T B(I): P(I)=C P B L(I)$

REM PRINT O(I);P(I)

NEXT I

REM PRINT

$l=B:$ GOSUB 1000

$K 2($ CONT) $=A B 5(B 4): A 2(C O N T)=E X P(C 1): R 2(C O N T)=R: 22$ (CONT) $=I$

REM CALCULATE TT AND A

TT (CONT) $=$ (LOG (A2 (CONT)) -LOG (A) (CONT) ) / (K2 (CONT)-K1 (CONT))

Al2 (CONT) $=$ AI (CONT) $*$ (EXP $(-1$ EK1 (CONT) $* T T$ (CONT) )

REN PRINT "TT,A"; TT (CONT), PAI2 (CONT)

REN CALCULATE PREDICTED CONCS FOR BEFORE AND AFTER

FOR $I=1$ TO $N$

PRC (I) =AI2 (CONT) *EXP $(-1 * K !($ CONT) * $(T T T(1)-T T($ CONT) ))

PRC (I) =PRC (I)- (ALI (CONT) \&EXP (-I \&KZ ICONT) \&(TTT(I)-TT(CONT)I))

NEXT I

REM REGRESSION BETHEEN ACTUAL/PREDICTED CONCS BEFORE AND AFTER

FOR $I=1$ TO $N$

$O(1)=C C(1), P(I)=P R C(1)$

NEXT I

$l=N:$ GOSUB 1000

$K 3($ CONT $)=B 4: A 3($ CONT $)=C 1: R 3($ CONT $)=R: 23($ CONT $)=$ ?

6.0 NEXT SKIP

REM DUTPUT

LPRINTER

PRINT

PRINT "N1"; TAB (B) ; "KI" TAB (17); "A1" TAB (28) ; "R1"; TAB (41) ; "N2";

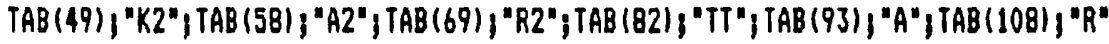

PRINT

FOR I=I TO CONT

PRINT USING FO7\$+" "+FD1\$+" "+FO2\$+" "F05\$+" "FO3\$+" "+1

$\mathrm{F01} \$+"$ "F06\$" "+F05\$+" "F03\$+" "+F06\$+" "F05\$\$1

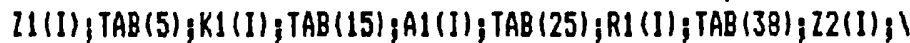

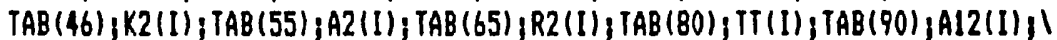

$T A B(105) ; R 3(I)$

PRINT

NEXT I

PRINTIPRINT:PRINT:PRINTIPRINT

GOTO 0.100:REN RECYCLE

$1000 T 1=0: T 2=0: 51=0: 52=0: \times 1=0$

FOR $x=1$ TO 2

$T 1=T 1+0(X): T 2=T 2+P(X): 51=51+10(X) \div 0(X)): 52=52+(P(X) \geq P(X)): X 1=x 1+(0(X)+P(X))$

NEXT $X$

$A A=S 1-\left((T I)^{\wedge} 2 / Z\right): B B=S 2-\left(\left(T 2^{\wedge} 2\right) / Z\right)$

$C=X 1-(1 T 1 * T 2) / 2)$

IF $(A A * B B)<0$ THEN $R=0: 60 T 01000.1$

$R=C / S Q R(A A \notin B B)$

$1000.1 \quad B 4=[/ A A: J=T 2 / Z: K=B 4 *(T I / Z): C l=-K+]$

RETURN

10000 CLOSE 3

STOP 


\section{APPENDIX $\mathbf{F}$}

Reagents for the neutral detergent fibre determination.

1. Neutral detergent fibre solution

Sodium Dodecyl Sulphate

$30.00 \mathrm{~g} / 1$

EDTA (disodium salt) Dihydrate

$18.61 \mathrm{~g} / 1$

Sodium Tetraborate (Borax)

$6.80 \mathrm{~g} / 1$

Disodium Hydrogen Phosphate

$4.56 \mathrm{~g} / 1$

2-Ethoxyethanol

$10.00 \mathrm{ml} / 1$

Use distilled water to dissolve.

Make sure that $\mathrm{pH}$ is between 6.9 and 7.1 .

2. Amylase solution

$2 \mathrm{~g}$ amylase in $90 \mathrm{~cm}^{3}$ distilled water

Ensure enzyme has dissolved, filter if necessary. Then add

$10 \mathrm{~cm}^{3}$ 2-Ethoxyethanol.

This solution should be prepared daily. 


\section{APPENDIX G1}

Analysis of Variance Table for Total Volatile Fatty Acids

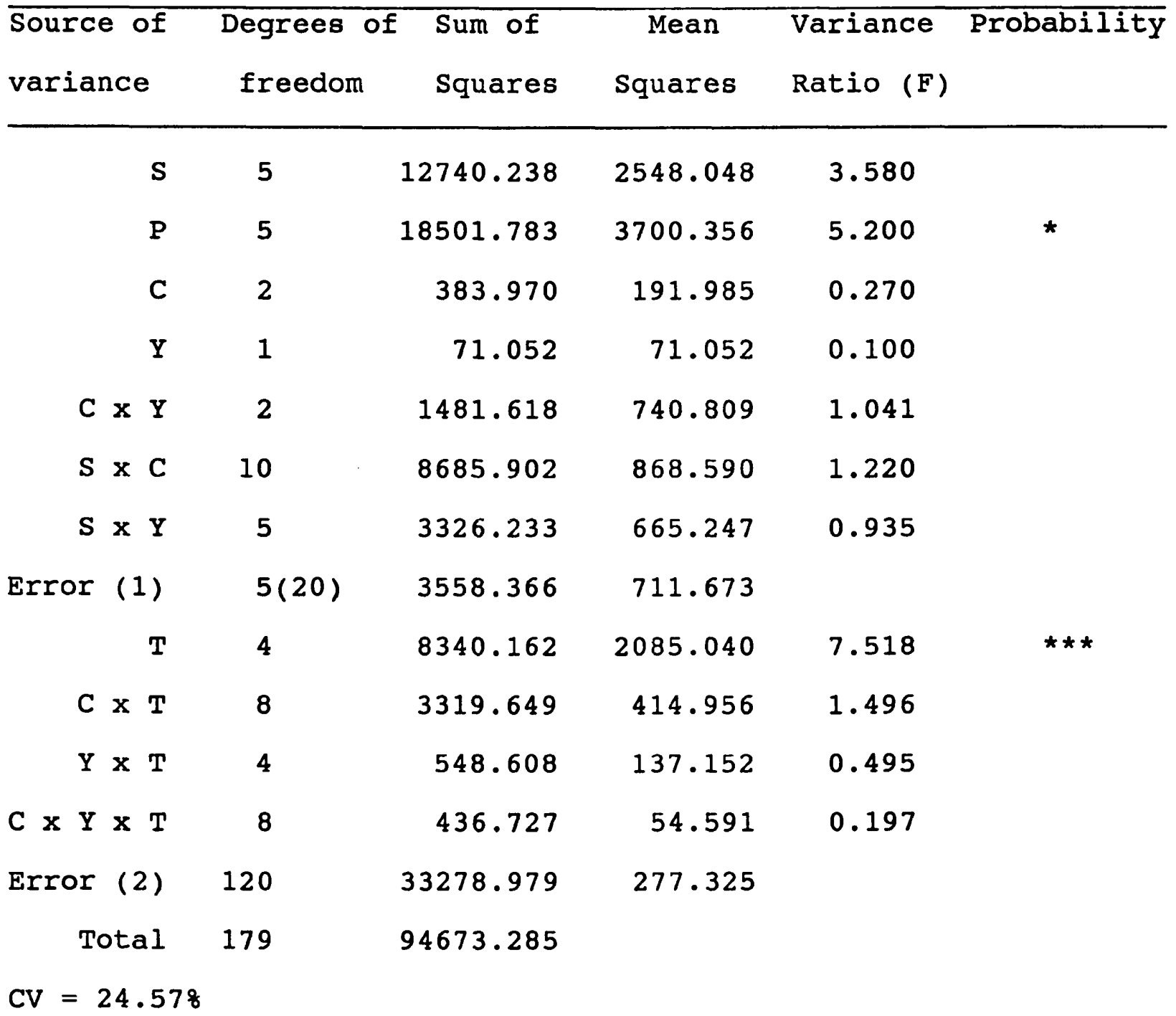

\footnotetext{
Key: $\quad$ S - sheep

P - Period

C - Concentrate level

$Y$ - Yea-Sacc

* $-\mathrm{P}<0.05$

$\star *-\mathrm{P}<0.01$

$\star \star *-P<0.001$
} 


\section{APPENDIX G2}

Analysis of Variance Table for Acetate Molar \&

\begin{tabular}{|c|c|c|c|c|c|}
\hline $\begin{array}{l}\text { Source of } \\
\text { variance }\end{array}$ & $\begin{array}{l}\text { Degrees of } \\
\text { freedom }\end{array}$ & $\begin{array}{l}\text { Sum of } \\
\text { Squares }\end{array}$ & $\begin{array}{c}\text { Mean } \\
\text { Squares }\end{array}$ & $\begin{array}{l}\text { Variance } \\
\text { Ratio (F) }\end{array}$ & Probability \\
\hline $\mathbf{S}$ & 5 & 328.744 & 65.749 & 2.811 & \\
\hline $\mathbf{P}$ & 5 & 363.196 & 72.639 & 3.106 & \\
\hline $\mathrm{C}$ & 2 & 2468.712 & 1234.356 & 52.780 & $\star * *$ \\
\hline$Y$ & 1 & 16.417 & 16.417 & 0.702 & \\
\hline$C \times Y$ & 2 & 43.149 & 21.574 & 0.923 & \\
\hline$S \times C$ & 10 & 717.065 & 71.706 & 3.066 & \\
\hline$S X Y$ & 5 & 288.339 & 57.668 & 2.466 & \\
\hline Error (1) & $5(20)$ & 116.934 & 23.387 & & \\
\hline $\mathbf{T}$ & 4 & 198.946 & 49.736 & 6.499 & $\star \star \star$ \\
\hline$C \times T$ & 8 & 70.908 & 8.846 & 1.158 & \\
\hline $\mathrm{Y} \times \mathrm{T}$ & 4 & 24.994 & 6.248 & 0.816 & \\
\hline$C \times Y \times T$ & 8 & 64.196 & 8.024 & 1.049 & \\
\hline Error (2) & 120 & 918.376 & 7.653 & & \\
\hline Total & 179 & 5619.976 & & & \\
\hline
\end{tabular}

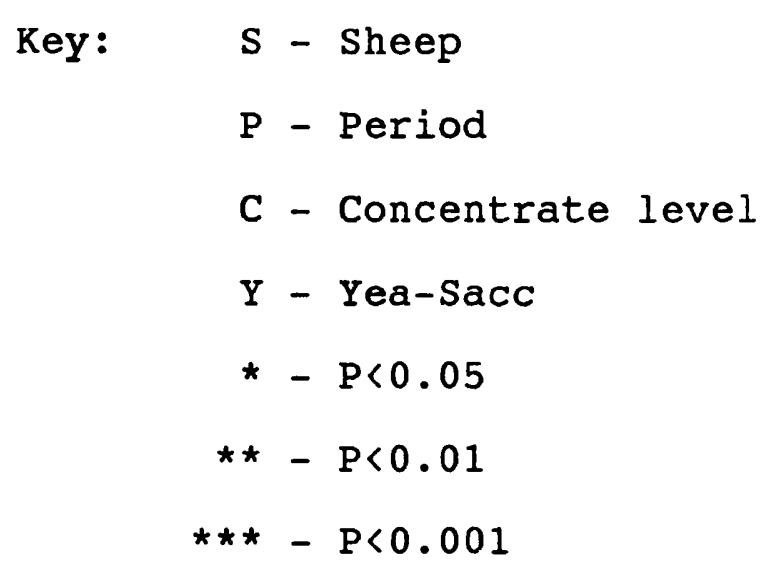


APPENDIX G3

Analysis of Variance Table for Propionate Molar 8

\begin{tabular}{|c|c|c|c|c|c|}
\hline $\begin{array}{l}\text { Source of } \\
\text { variance }\end{array}$ & $\begin{array}{l}\text { Degrees of } \\
\text { freedom }\end{array}$ & $\begin{array}{l}\text { Sum of } \\
\text { squares }\end{array}$ & $\begin{array}{l}\text { Mean } \\
\text { Squares }\end{array}$ & $\begin{array}{l}\text { Variance } \\
\text { Ratio (F) }\end{array}$ & Probability \\
\hline $\mathbf{S}$ & 5 & 315.598 & 63.120 & 3.319 & \\
\hline $\mathrm{P}$ & 5 & 155.483 & 31.096 & 1.635 & \\
\hline $\mathrm{C}$ & 2 & 410.975 & 205.488 & 10.807 & $\star$ \\
\hline$Y$ & 1 & 17.063 & 17.063 & 0.897 & \\
\hline$C \times Y$ & 2 & 54.322 & 27.161 & 1.428 & \\
\hline$S \times C$ & 10 & 630.945 & 63.094 & 3.318 & \\
\hline$S \times Y$ & 5 & 205.237 & 41.048 & 2.159 & \\
\hline Error (1) & $5(20)$ & 95.075 & 19.015 & & \\
\hline $\mathbf{T}$ & 4 & 103.157 & 25.789 & 4.376 & $\star \star$ \\
\hline $\mathrm{C} \times \mathrm{T}$ & 8 & 129.929 & 16.241 & 2.756 & $\star \star$ \\
\hline $\mathbf{Y} \mathbf{X} \mathrm{T}$ & 4 & 11.452 & 2.863 & 0.486 & \\
\hline$C \times Y \times T$ & 8 & 55.352 & 6.919 & 1.174 & \\
\hline Error (2) & 120 & 707.160 & 5.893 & & \\
\hline Total & 179 & 2891.748 & & & \\
\hline
\end{tabular}

$$
\begin{array}{ll}
\text { Key: } & S-\text { Sheep } \\
& P-\text { Period } \\
C & - \text { Concentrate level } \\
Y & - \text { Yea-Sacc } \\
& *-P<0.05 \\
\star * & -P<0.01 \\
\star * *-P<0.001
\end{array}
$$




\section{APPENDIX G4}

Analysis of Variance Table for Butyrate Molar $\&$

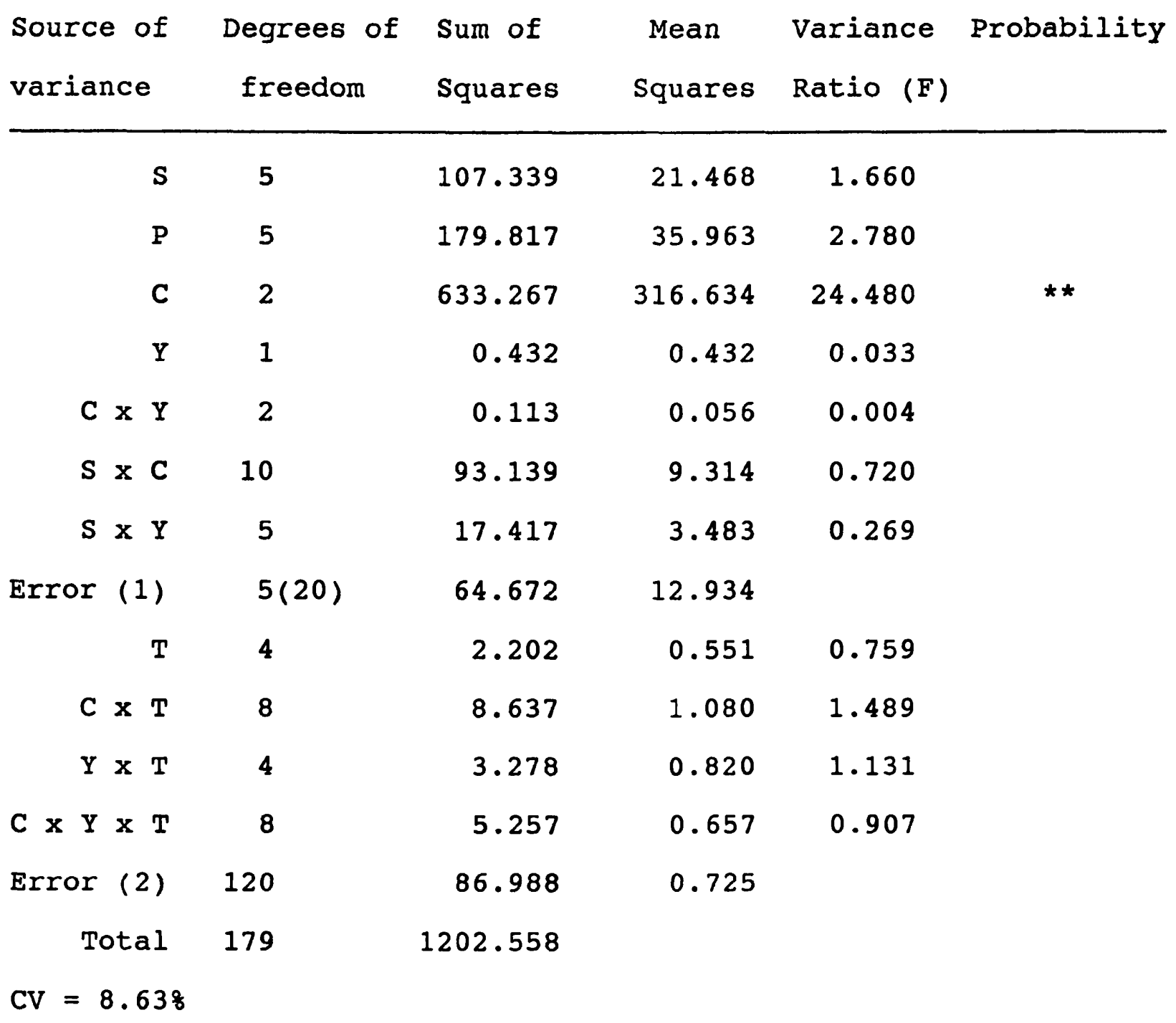

$\begin{aligned} & \text { Key: } \text { S - Sheep } \\ & P-\text { Period } \\ & C-\text { Concentrate level } \\ & Y- \text { Yea-Sacc } \\ & *-P<0.05 \\ & * *-P<0.01 \\ & \star * *-P<0.001\end{aligned}$




\section{APPENDIX G5}

Analysis of Variance Table for Rumen Ammonia concentration

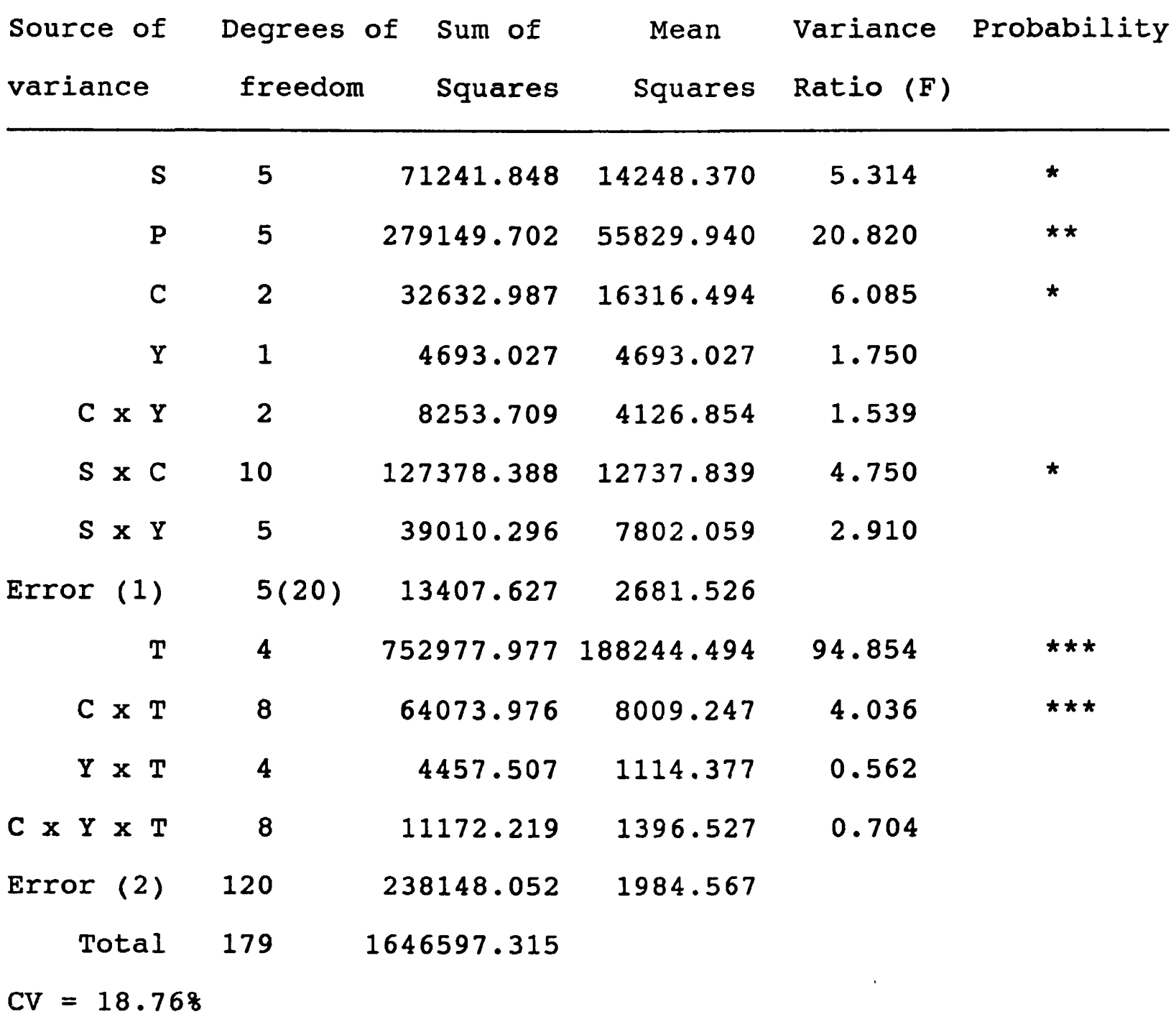

\footnotetext{
Key: $\quad$ S - Sheep

P - Period

C - Concentrate level

$Y$ - Yea-Sacc

* $-P<0.05$

** $-\mathrm{P}<0.01$

$\star * *-\mathrm{P}<0.001$
} 


\section{APPENDIX G6}

Analysis of Variance Table for Rumen pH

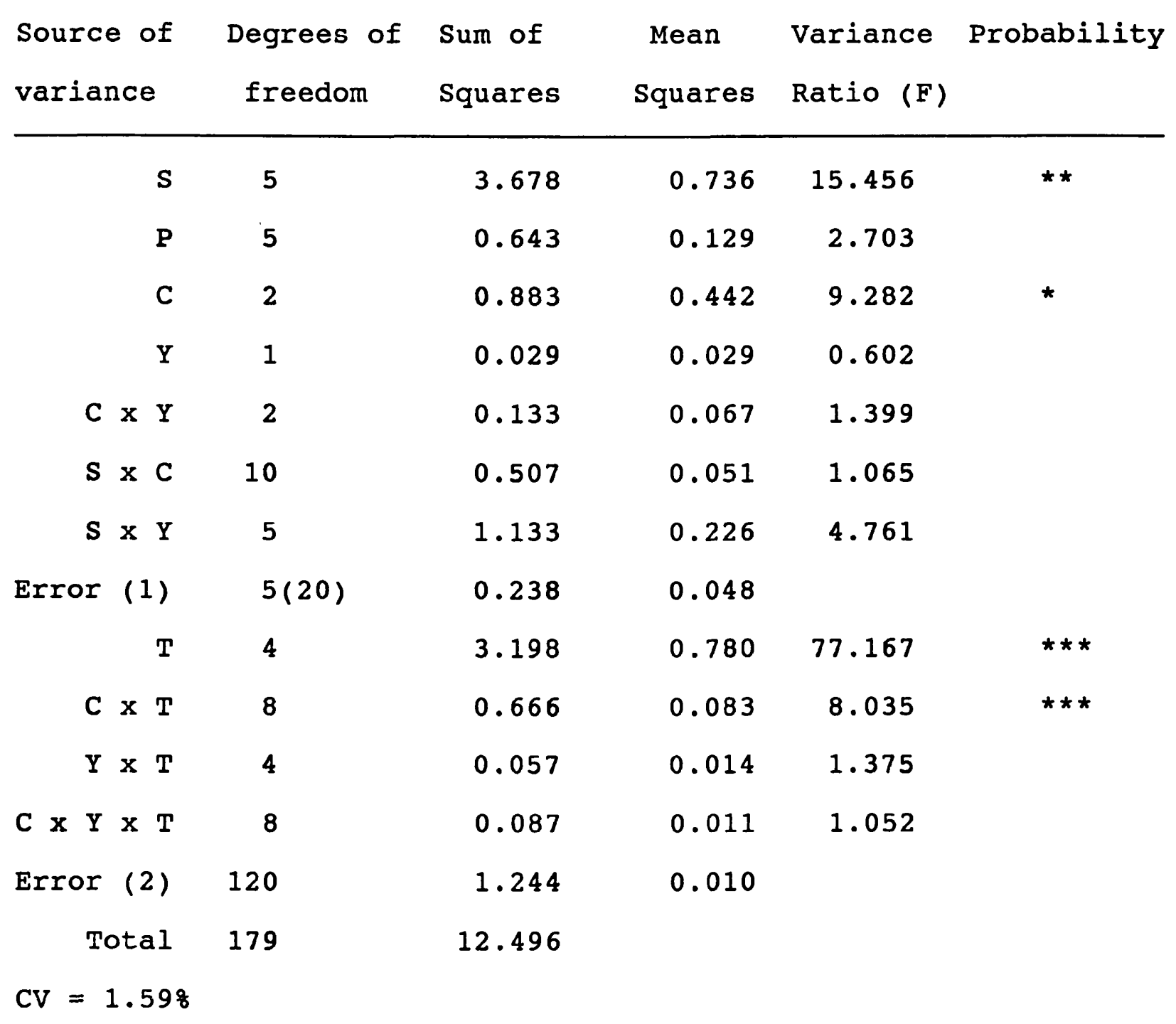

$$
\begin{array}{ll}
\text { Key: } & \text { S - Sheep } \\
& P-\text { Period } \\
& C \text { - Concentrate level } \\
Y & - \text { Yea-Sacc } \\
& \star-P<0.05 \\
* *-P<0.01 \\
\star * \star-P<0.001
\end{array}
$$




\section{APPENDIX J1}

Analysis of Variance Table for Hay Organic

Matter Digestibility in sacco (24 hours)

$\begin{array}{rrrrrr}\text { Source of } & \text { Degrees of } & \text { Sum of } & \text { Mean } & \text { Variance } & \text { Probability } \\ \text { variance } & \text { freedom } & \text { Squares } & \text { Squares } & \text { Ratio (F) } \\ \text { S } & 5 & 1189.014 & 237.803 & 11.151 & \text { ** } \\ \text { P } & 5 & 430.133 & 86.027 & 4.034 & \text { ** } \\ \text { C } & 2 & 817.372 & 408.686 & 19.164 & \text { * } \\ \text { Y } & 1 & 210.830 & 210.830 & 9.886 & \\ \text { S X C } & 10 & 182.200 & 18.220 & 0.854 & 0.806 \\ \text { S X Y } & 5 & 85.948 & 17.190 & 0.113 \\ \text { C X Y } & 2 & 4.810 & 2.405 & & \\ \text { Error } & 5 & 106.631 & 21.326 & & \end{array}$

$\begin{array}{ll}\text { Key: } & \text { S }- \text { Sheep } \\ & P-\text { Period } \\ & \text { C - Concentrate level } \\ Y & - \text { Yea-Sacc } \\ & *-P<0.05 \\ * *-P<0.01 \\ * * *-P<0.001\end{array}$




\section{APPENDIX J2}

Analysis of Variance Table for Hay Organic Matter Digestibility in sacco (48 hours)

\begin{tabular}{|c|c|c|c|c|c|}
\hline $\begin{array}{l}\text { Source of } \\
\text { variance }\end{array}$ & $\begin{array}{l}\text { Degrees of } \\
\text { freedom }\end{array}$ & $\begin{array}{l}\text { Sum of } \\
\text { Squares }\end{array}$ & $\begin{array}{c}\text { Mean } \\
\text { Squares }\end{array}$ & $\begin{array}{l}\text { Variance } \\
\text { Ratio (F) }\end{array}$ & Probability \\
\hline $\mathbf{S}$ & 5 & 1912.107 & 382.421 & 14.168 & $\star *$ \\
\hline $\mathbf{P}$ & 5 & 949.013 & 189.803 & 7.032 & * \\
\hline C & 2 & 991.736 & 495.868 & 18.371 & $\star \star$ \\
\hline$Y$ & 1 & 0.319 & 0.319 & 0.012 & \\
\hline$S \times C$ & 10 & 232.312 & 23.231 & 0.861 & \\
\hline$S \times Y$ & 5 & 104.719 & 20.944 & 0.776 & \\
\hline$C \times Y$ & 2 & 7.002 & 3.501 & 0.130 & \\
\hline Error & 5 & 134.958 & 26.992 & & \\
\hline Total & 35 & 4332.167 & & & \\
\hline$C V=9.398$ & & & & & \\
\hline
\end{tabular}

$\begin{array}{ll}\text { Key: } & S-\text { Sheep } \\ & P-\text { Period } \\ & \text { C - Concentrate level } \\ Y & - \text { Yea-Sacc } \\ & *-P<0.05 \\ * *-P<0.01 \\ * * *-P<0.001\end{array}$




\section{APPENDIX H1}

Analysis of Variance Table for Rumen Liquid

Outflow Rate $\mathrm{K} 1$

\begin{tabular}{|c|c|c|c|c|c|}
\hline $\begin{array}{l}\text { Source of } \\
\text { variance }\end{array}$ & $\begin{array}{l}\text { Degrees of } \\
\text { freedom }\end{array}$ & $\begin{array}{l}\text { Sum of } \\
\text { Squares }\end{array}$ & $\begin{array}{c}\text { Mean } \\
\text { Squares }\end{array}$ & $\begin{array}{l}\text { Variance } \\
\text { Ratio (F) }\end{array}$ & Probability \\
\hline $\mathbf{S}$ & 5 & 1.799 & 0.360 & 2.503 & \\
\hline $\mathbf{P}$ & 5 & 5.508 & 1.101 & 7.665 & * \\
\hline $\mathrm{C}$ & 2 & 2.927 & 1.464 & 10.183 & * \\
\hline $\mathrm{Y}$ & 1 & 0.006 & 0.006 & 0.045 & \\
\hline$S \times C$ & 10 & 2.772 & 0.277 & 1.929 & \\
\hline$S X Y$ & 5 & 0.944 & 0.189 & 1.314 & \\
\hline$C \times Y$ & 2 & 0.918 & 0.459 & 3.194 & \\
\hline Error & 5 & 0.719 & 0.144 & & \\
\hline Total & 35 & 15.594 & & & \\
\hline$C V=9.348$ & & & & & \\
\hline
\end{tabular}

$\begin{array}{ll}\text { Key: } & \text { S }- \text { Sheep } \\ & \text { P }- \text { Period } \\ \text { C }- \text { Concentrate level } \\ Y \text { - Yea-Sacc } \\ *-P<0.05 \\ * *-P<0.01 \\ * * *-P<0.001\end{array}$


APPENDIX \#2

Analysis of Variance Table for Rumen Liquid

Outflow Rate $\mathrm{K} 2$

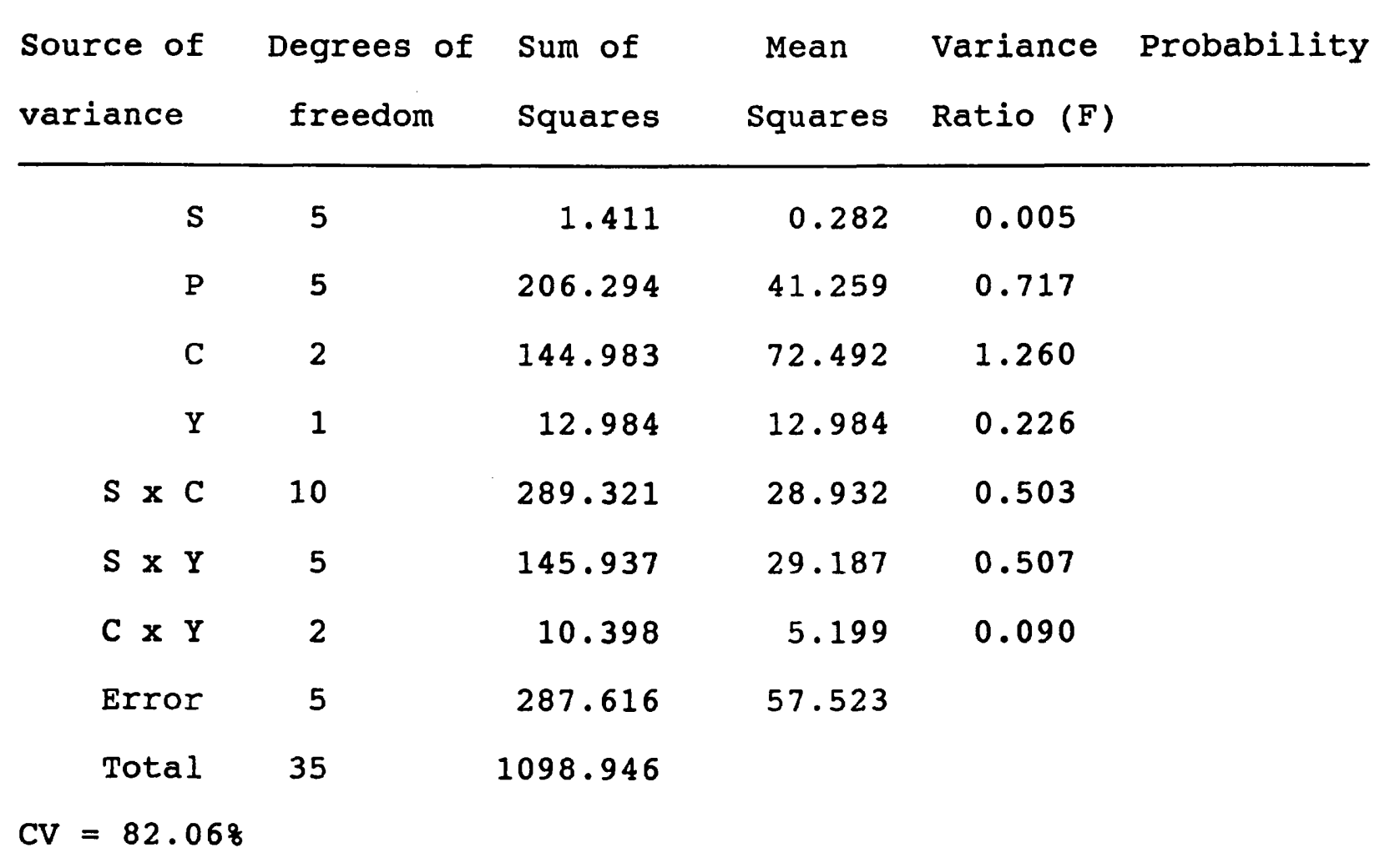

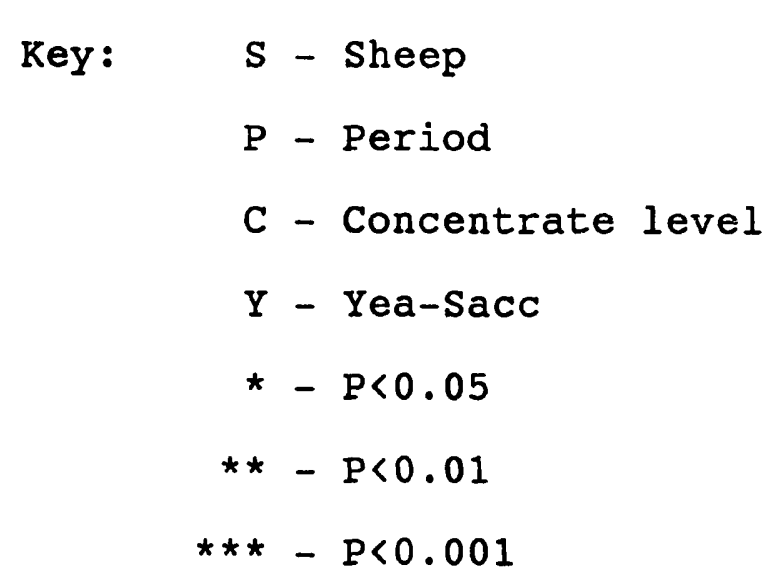


APPENDIX $\underline{\text { R1 }}$

Analysis of Variance Table for Organic Matter

Digestibility in vivo

\begin{tabular}{|c|c|c|c|c|c|}
\hline $\begin{array}{l}\text { Source of } \\
\text { variance }\end{array}$ & $\begin{array}{l}\text { Degrees of } \\
\text { freedom }\end{array}$ & $\begin{array}{l}\text { Sum of } \\
\text { Squares }\end{array}$ & $\begin{array}{c}\text { Mean } \\
\text { Squares }\end{array}$ & $\begin{array}{l}\text { Variance } \\
\text { Ratio (F) }\end{array}$ & Probability \\
\hline $\mathbf{S}$ & 5 & 301.256 & 60.251 & 7.411 & * \\
\hline $\mathbf{P}$ & 5 & 22.566 & 4.513 & 0.555 & \\
\hline $\mathbf{C}$ & 2 & 1188.034 & 594.017 & 73.068 & $* * *$ \\
\hline $\mathbf{Y}$ & 1 & 0.284 & 0.284 & 0.035 & \\
\hline$S \times C$ & 10 & 85.863 & 8.586 & 1.056 & \\
\hline$S X Y$ & 5 & 34.048 & 6.810 & 0.838 & \\
\hline$C \times Y$ & 2 & 2.911 & 1.455 & 0.179 & \\
\hline Error & 5 & 40.648 & 8.130 & & \\
\hline Total & 35 & 1675.609 & & & \\
\hline$C V=4.288$ & & & & & \\
\hline
\end{tabular}

$$
\begin{aligned}
& \text { Key: S - Sheep } \\
& \text { P - Period } \\
& \text { C - Concentrate level } \\
& Y \text { - Yea-Sacc } \\
& \text { * }-P<0.05 \\
& \text { ** }-P<0.01 \\
& * * *-\mathrm{P}<0.001
\end{aligned}
$$




\section{APPENDIX K2}

Analysis of Variance Table for Neutral Detergent Fibre Digestibility in vivo

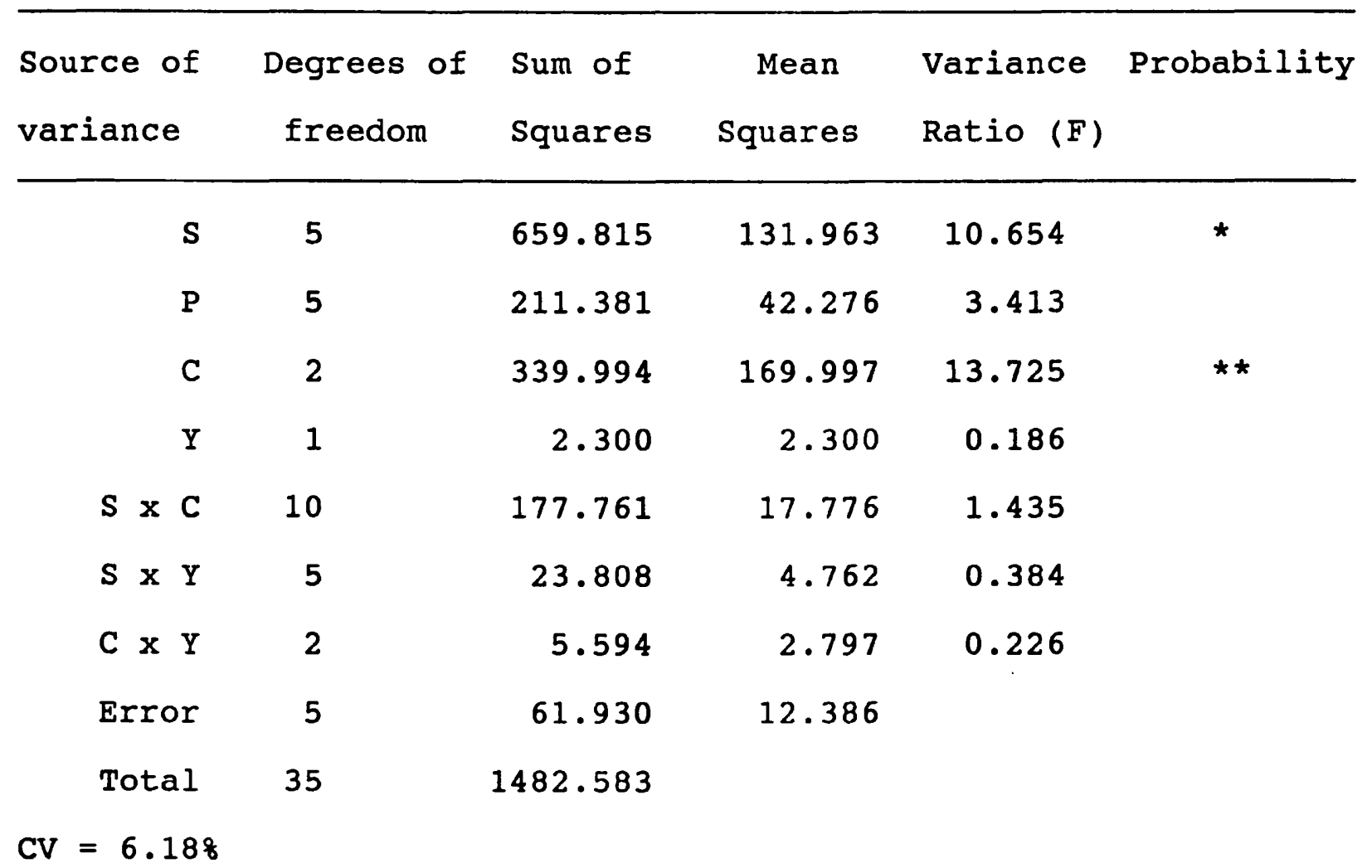

$\begin{array}{ll}\text { Key: } & S-\text { Sheep } \\ & P-\text { Period } \\ & C-\text { Concentrate level } \\ Y & - \text { Yea-Sacc } \\ & \star-P<0.05 \\ & -P<0.01 \\ \star * * & -P<0.001\end{array}$


APPENDIX $\underline{\mathrm{K} 3}$

Analysis of Variance Table for Gross Energy

Digestibility in vivo

\begin{tabular}{|c|c|c|c|c|c|}
\hline $\begin{array}{l}\text { Source of } \\
\text { variance }\end{array}$ & $\begin{array}{l}\text { Degrees of } \\
\text { freedom }\end{array}$ & $\begin{array}{l}\text { Sum of } \\
\text { Squares }\end{array}$ & $\begin{array}{c}\text { Mean } \\
\text { Squares }\end{array}$ & $\begin{array}{l}\text { Variance } \\
\text { Ratio (F) }\end{array}$ & Probability \\
\hline $\mathbf{S}$ & 5 & 321.311 & 64.262 & 4.699 & \\
\hline $\mathbf{P}$ & 5 & 91.618 & 18.324 & 1.340 & \\
\hline C & 2 & 1532.357 & 766.179 & 56.021 & $\star * *$ \\
\hline$Y$ & 1 & 0.562 & 0.562 & 0.041 & \\
\hline$S \times C$ & 10 & 92.699 & 9.270 & 0.678 & \\
\hline$S \times Y$ & 5 & 63.466 & 12.693 & 0.928 & \\
\hline$C \times Y$ & 2 & 9.632 & 4.816 & 0.352 & \\
\hline Error & 5 & 68.384 & 13.677 & & \\
\hline Total & 35 & 2180.030 & & & \\
\hline$C V=5.87 \%$ & & & & & \\
\hline
\end{tabular}

$$
\begin{aligned}
& \text { Key: S - Sheep } \\
& \text { P - Period } \\
& \text { C - Concentrate level } \\
& Y \text { - Yea-Sacc } \\
& \text { * }-P<0.05 \\
& \star *-P<0.01 \\
& * * *-\mathrm{P}<0.001
\end{aligned}
$$




\section{RERFERENCES}

1. AAFCO. (1986). Official Publication of the Association of American Feed Control officials Incoorporated.

2. ADAMS, D.C., GALYEAN, M.L., KIESLING, H.E., WALLACE, J.D. and FINRER, M.D. (1981). Influence of Viable Yeast Culture, Sodium Bicarbonate and Monensin on liquid dilution rate, rumen fermentation and feedlot performance of growing steers and digestibility in lambs. Journal of Animal Science, 53: 780-789.

3. AKIN, E. (1986). Chemical and biological structure in plants as related to microbial degradation of forage cell wall. Control of digestion and metabolism in ruminants. 139. Cited by snifen 1987.

4. ANNISON, E.F., CHALMERS, M.I., MARSHALL, S.B.M. and SYNGE, R.L.M. (1954). Ruminal ammonia formation in relation to the protein requirements of sheep. 3) Ruminal ammonia formation with various diets. Journal of Agricultural Science Cambridge, 44: 270-273.

5. ARMSTRONG, D.G., and BLAXTER, K.L. (1957). The utilization of Acetic, Propionic and Butyric acids by fattening sheep. British Journal of Nutrition, 11: 413-425.

6. BARRY, T.N., THOMPSON, A. and ARMSTRONG, D.G. (1977a). Rumen fermentation studies in two contrasting diets. 1) Some characteristics of the in vivo fermentation with special reference to the composition of the gas phase, oxidation/reduction state and volatile fatty acids proportions. Journal of Agricultural Science Cambridge, 89 : $183-194$. 
7. BARRY, T.N., THOMPSON, A. and ARMSTRONG, D.G. (1977b). Rumen fermentation studies in two contrasting diets. 2) Comparison of the performance of an in vitro continous culture fermentation with in vivo fermentation. Journal of Agricultural Science Cambridge, 89 : 197-208.

8. BATH, T.N. and ROOK, J.A. (1963). The evaluation of cattle foods and diets in terms of the ruminal concentrations of volatile fatty acids. 1) Effect of level of intake, frequency of feeding, ratio of hay to concentrate in diet and supplementary feeds. Journal of Agricultural Science Cambridge, 61: 341-348.

9. BALCH, C.C. (1971). Proposal to use time spend chewing as an index of the extend to which diets for ruminations posses the physical property of fibrousness characteristic of roughages. British Journal of Nutrition, 26: 383-392.

10. BAUCHOP, T. (1979). Rumen anaerobic fungi of cattle and sheep. Applied Environmental Microbiology, 38: 148-158. 11. BINNERT, W.T., KLOOSTER, A.T. and FREUIS, A.M. (1968). Soluble chromium indicator measured by atomic absorption in digestive experiments. Veterinary Research, 82: 470 . 12. BRIGGS, P.K., HOGAN, J.P. and REID, R.L. (1957). The effect of volatile fatty acids, lactic acid and ammonia on rumen $\mathrm{pH}$ in sheep. Australian Journal of Agricultural Research, 8: 674-690.

13. CARTWRIGHT, C.P., JUROSZEK, J.R., BEAVAN, M.J., RUBY, F.M.S., dé MORAIS, S.M.F. and ROSE, A.H. (1986). Ethanol. 
dissipates the proton-motive force across the plasma membrane of Saccharomyces cerevisiae. Journal of General Microbiology, 132: 369-377.

14. CHENG, K.J., STEWART, C.S., DINSDALE, D. and COSTERTON, J.W. (1984). Electron microscopy of bacteria involved in the digestion of plant cell walls. Animal Feed Science Technology, 10: 93-120.

15. COLEMAN, S. (1975). The interrelationship between rumen ciliate protozoa and bacteria. In: Digestion and Metabolism in the Ruminant. I.W. McDonald and A.C.I. Warner, eds. University of New England. Australia. page $149-164$.

16. COLUCCI, P.E., CHASE, L.E. and VAN SOEST, P.J. (1982). Feed intake, apparent diet digestibility, and rate of particulate passage in dairy cattle. Journal of Dairy Science, 65: 1445-1456.

17. CORSE, D.A. (1981). The application of non-protein nitrogen, protected protein and rumen fermentations in U.K. Feeding Systems. In: Recent Developments in Ruminant Nutrition. W. Haresign and D.J.A. Cole eds. Butterworths. London. page 215-227.

18. CZERKWASKI, J.W. (1986). An introduction to rumen studies. Pergamon Press. Whectan \& Company Limited. Exeter, Britain.

19. DAWSON, K.D. (1987). Mode of action of Yeast Culture, Yea-Sacc, in the rumen: A natural Fermentation Modifier. In: Biotechnology in the Feed Industry. T.P. Lyons ed. Alltech Technical Publication. Nicholasville, Kentucky. 
20. DE MOT,. (1987). Cited by Williams, 1988.

21. DUNCAN, W.R.H., ORSKOV, E.R. and GARTON, G.A. (1972). Fatty acid composition of triglycerides of lambs fed on barley-based diets. Proceedings of the Nutrition Society, 31: 19A.

22. EADIE, J.M. and MANN, S.O. (1970). Developments and instability of rumen microbial populations. In: Physiology of Digestion and Metabolism in the Ruminant. A.T. Phillipson ed. Oriel Press Limited. p. 335-337. 23. ELLIOT, J.M. and LOOSI, J.K. (1959). Relationship of milk production efficiecny to the relative proportions of rumen volatile fatty acids. Journal of Dairy Science, 55: 843-848.

24. EL SHAZLKY, K., DEHORITY, B.A. and JOHNSON, R.R. (1961). Effect of starch on the digestion of cellulose in vitro and in vivo by rumen microorganisms. Journal of Animal Science, 20: 268-273.

25. EVANS, E. (1981). An evaluation of the relationship between dietary parameters and rumen liquid dilution rate. Canadian Journal of Animal Science, 61: 91-96.

26. FALLON, R.J. (1987). Yeast culture in calf rations. In: Biotechnology in the Feed Industry. T.P. Iyons ed. Alltech Technical Publication. Nicholasville, Kentucky. 27. GIESECKE, D. (1970). Comparative Microbiology of the alimentary tract. In: Physiology of Digestion and Metabolism in the Ruminant. A.T. Phillipson ed. Oriel Press Limited, p. 306-318. 
28. GOETSCH, A.I. and GALYEAN, M.L. (1982). Effect of dietary concentrate level on rumen fluid dilution rate. Canadian Journal of Animal Science, 62: 649-652.

29. GROVUM; W.L. and WILLIAMS, V.J. (1973). Rate of passage of digesta in sheep. 4) Passage of marker thruogh the alimentary tract and the biological relevance of rate constants derived from the changes in concentration of markers in faeces. British Journal of Nutrition, 30 : 313-329.

30. HARRISON, D.G., BEEVER, D.E., THOMPSON, D.J. and OSBOURN, D.F. (1975). Manipulation of rumen fermentation in sheep by increasing the rate of flow of water from the rumen. Journal of Agricultural Science Cambridge, 85: 93-101.

31. HARRISON, D.G., BEEVER, D.E., THOMPSON, D.J. and OSBOURN, D.F. (1976). Manipulation of fermentation in the rumen. Journal of Science of Food and Agriculture, 27: 617-620. 32. HOGAN, J.P. (1961). The absorption of ammonia through the rumen of sheep. Australian Journal of Biological Sciences, $14: 448-460$.

33. HODGSON, J.C. and THOMAS, P.C. (1975). A relationship between molar proportion of propionic acid and clearance rate of the liquid phase in the rumen of sheep. British Journal of Nutrition, 33: 447-456.

34. HOOVER, W.H., (1986). Chemical factors involved in ruminal fibre digestion. Journal of Dairy Science, 69: 27552766 .

35. HUNGATE, R.E. (1963). Symbiotic Associations: The rumen 
bacteria. In: The 13th Symposium of the Society for General Microbiology. Symbiotic Associations. P.S. Nutman and B. Mosse eds. University Press. Cambridge, p. 266.

36. HUNGATE, R.E. (1966). The rumen and its microbes. Academic Press. New York.

37. ILIAN, M.A., RAZZAQUE, M.A., SUlimAN, A.R., SALMAN, A.J. and SALMAN, A.R. (1986). Effect on performance and rumen characteristics. Nutrition Abstracts and Reviews, 56: 4377 .

38. ISTASSE, L. and Orskov E.R. (1983). The correlation between the extend of $\mathrm{pH}$ and degradability of washed hay in sheep given hay and concentrates. Proceedings of Nutrition Society, 42: 32A.

39. ISHAQUE, M., THOMAS, P.C. and ROOK, J.A.F. (1971). Consequences to host changes in rumen microbial activity. Nature New Biology, 231: 253-256.

40. JOHNSON, R.R. (1976). Influence of solubility on non-protein -nitrogen utilisation in the ruminant. Journal of Animal Sçience, 43: 184-191.

41. KLUSMEYER, T.H., CLARK, J.H., VICINI, J.L., MURPHY, M.R. and FAHEY, G.C. (1987). Effects of feeding or infusing ammonium salts of volatile fatty acids on ruminal fermentation, plasma characteristics and milk production of cows. Journal of Dairy Science, 70: 506-563.

42. KOVACIK, A.M., LOERCH, S.C. and DEHORITY, B.A. (1986). Effects of supplementary Sodium Bicarbonate on nutrient 
digestibility and ruminal pH measured continously. Journal of Animal Science, 62: 226-234.

43. LEEDLE, J.A.Z., BRYANT, M.P. and HESPELL, R.B. (1982). Diurnal variation in bacterial numbers and fluid parameters in ruminal contents of animals fed low- or high-forage diets. Applied Environmental Microbiology, $44: 402-412$.

44. LE GENDRE, J.R., TOTUSEK, R. and GALLUP, W.D. (1957). The effect of live-cell yeast on nitrogen retention and digestibility of ration by beef cattle. Journal of Animal Science, 16: 671-674.

45. LEMENAGER, R.P., OWENS, F.N., SHOCKEY, B.J., LUSBY, K.S. and TOTUSEK, R. (1978). Monensin effects on rumen turnover rate, twenty-four hour volatile fatty acid pattern, nitrogen components and cellulose disappearance. Journal of Animal Science, 47: 255-261.

46. LEWIS, D. (1956). Blood urea concentration in relation to protein utilization in the ruminant. Journal of Agricultural Science Cambridge, 48: 438-446.

47. LEWIS, P. and HILL, K.J. (1983). The provision of nutrients. In: Nutritional Physiology of Farm Animals. J.A.F. Rook and P.C. Thomas eds. Longman, London \& New York. p. $3-40$.

48. LYONS, T.P. (1987). The role of biological tools in Feed Industry. In: Biotechnology in the Feed Industry. T.P. Lyons ed. Alltech Technical Publication. Nicholasville, Kentucky. 
49. MCDONALD, P., EDWARDS, E.A. AND GREENHALGH, J.F.D. (1988). Animal Nutrition. Longman. London and New York.

50. MEHREZ, A.Z. and ORSKOV, E.R. (1977). A study of the artificial fibre bag technique for determing the digestibility of feeds in the rumen. Journal of Agricultural Science Cambridge, 88: 645-665.

51. MEHREZ, A.Z., ORSKOV, E.R. and MCDONALD, I. (1977). Rates of rumen fermentation in relation to ammonia concentration. British Journal of Nutrition, 38: 437-443.

52. MERTENS, D.R. (1979). Effect of buffers upon fibre digestion. Cited by Rlusmeyer, et al. (1987).

53. MOULD, F.L. and ORSKOV, E.R. (1983/84). Manipulation of rumen fluid and its influence on cellulolysis in sacco, dry matter degradation and rumen micro-flora of sheep offered hay or concentrate. Animal Feed Science and Technology, 10: 1-14.

54. MOULD, F.L., ORSKOV, E.R. and MANN, S.O. (1983/84). Associative effects of mixed diets. 1) Effects of type and level of supplementation and the influence of the rumen fluid $\mathrm{pH}$ on cellulolysis in vivo and dry matter digestion of various roughages. Animal Feed Science Technology, 10: 15-30.

55. NEWBOLD, (1987). Cited by Williams, P.E.V. (1988) • 56. NICHOLSON, J.W.G. and SUTTON, J.D. (1969). The effect of diet composition and level of feeding on digestion in the stomach and intestine of sheep. British Journal of Nutrition, 23: 585-601.

57. OFFER, N.W. (personal communication). 
58. ORPIN, C.G. $(1983 / 84)$. The role of ciliate protozoa and fungi in the rumen digestion of plant cell wall. Animal Feed Science Technology, 10: 121-143.

59. ORPIN, C.G. and ANDERSON, J.M. (1988). The animal envinment. In: Microorganisns in action: Concepts and Applications in Microbial Ecology. J.M. Lynch and J.E. Hobbie eds. Blackwell Science Publications. page 163.

60. ORSKOV, E.R. and ALLEN, D.M. (1966). Utilization of volatile fatty acids by growing sheep. 1) Acetate, propionate and butyrate as sources of energy for young growing lambs. British Journal of Nutrition, 20: 295-305.

61. ORSKOV, E.R. and FRASER, C. (1975). The effects of processing of barley-based supplements on rumen pH, rate of digestion and voluntary intake of dried grass in sheep. British Journal of Nutrition, 34: 493-500.

62. ORSKOV, E.R., FRASER, C. and GORDON, J.G. (1974). Effects of processing cereals on rumen fermentation, digestibility, rumination time and firmness of subcuteneous fat in lambs. British Journal of Nutrition, 32: 59-69.

63. OWENS, F.N., KAZEMI, M., GALYEAN, M.L., MIZWICKI, K.I. and SOLAIMAN, S.G. (1979). Ruminal turnover rate. Influence of additives, feed intake.and roughage level. Oklahama Agriculture Experiment Station. MP 104: 27-29.

64. PEPPLER, H.J., (1982). Yeast Extracts. In: Fermented Foods. A.H. Rose ed. Academic Press. London. page 293-312.

65. PHILLIPS, W.A. and VON TUNGELN, D.L. (1985). The effect of Yeast Culture on the post-stress performance of feeder 
calves. Nutritional Reports International, 32: 287-294.

66. PRANGE, R.W., DAVIS, C.L. and CLARK, J.H. (1978). Propionate production in the rumen of Holstein steers fed either a control or monensin supplemented diet. Journal of Animal Science, 46: 1120-1124.

67. PRESTON, T.N. and LENG, R.A. (1988). Matching ruminant production systems with available resources in the tropics and sub-tropics. Penambul Books. Armidale, New South Wales, Australia.

68. REID. R.L., HOGAN, J.P. and BRIGGS, P.K. (1957). The effect of diet on individual volatile fatty acids in rumen of sheep, with particular reference to the effect of low rumen $\mathrm{pH}$ and adaptation on high starch diets. Australian Journal of Agricultural Research, 8: 691-710.

69. RICHARDSON, D., BAKER, F.H., HARRIS, J.O., SMITH, E.F., COX, R.F. and BOWMAN, O.M. (1956). The use of Live-Yeast suspensions in beef cattle rations. Kansas Agriculture Experiment Circus, 335: 54-57.

70. ROGERS, J.A., MARKS, B.C., DAVIS, C.L. and CLARK, J.H. (1979). Alteration of rumen fermentation in steers by increasing rumen fluid dilution rate with mineral salts. Journal of Dairy Science, 62: 1599-1605.

71. ROGERS, J.A., DAVIS, C.I. and CLARK, J.H. (1982). Alteration of rumen fermentation, milk fat synthesis and nutrient utilization with mineral salts in dairy cows. Journal of Dairy Science, 65: 577-586.

72. ROGERS, J.A., CONRAD, H.R., DEHORITY, B.A. and GRUBB, J.A. (1986). Microbial numbers, rumen fermentations and 
nitrogen utilization of steers using wet and dried brewers' grains. Journal of Dairy Science, 59: 745-753. 73. ROSE, A.H. (1980). Recent research on industrial important strains of Saccharomyces cerevisiae. In: Biology and Activity of Yeasts. F.A. Skinner, S.M. Passmore and R.R. Davenport eds. page 103-121.

74. ROSE, A.H. (1987). Yeast Culture, a microorganism for all species: A theoratical look at its mode of action. In: Biotechnology in the Feed Industry. T.P. Lyons ed. Alltech Technical Publication. Kentucky.

75. RUF, E.W., HALE, W.H. and BURROUGHS, W. (1953). Observations upon an unidentified factor in feedstuffs stimulatory to cellulose digestion in the rumen and improved live weight gains in lambs. Journal of Animal Science, 12: 731-739.

76. SATTER; L.D. and SLYTER, L.L. (1974). Effect of ammonia concentration on rumen microbial protein production in vitro. British Journal of Nutrition, 32: 199-208.

77. SHRIVER, B.J., HOOVER, W.H., SARGENT, J.P., CRAWFORD(Jr), R.J. and THAYNE, w.V. (1986). Fermentation of a high concentrate diet as affected by ruminal $\mathrm{pH}$ and digesta flow. Journal of Dairy Science, 69: 413-419. 78. SNIFFEN, C.J. (1987). Rumen microbial ecology. In: Biotechnology in the Feed Industry. T.P. Lyons ed. Altech Technical Publication. Kentucky. page 79-98. 79. STEEL, R.G.D. and TORRIE, J.H. (1980). Principles and Procedures in Statistics. 2nd ed. McGraw-Hill Book 
Company Inc. New York.

80. STEVENSON, A.E. and CLARE, N.T. (1963). Measurement of feed intake by grazing cattle and sheep. 9) Determination of chromic oxide in faeces using an Auto-Analyser. New Zealand Journal of Agricultural Research, 6: 121-126.

81. STEWART, C.S. (1977). Factors affecting cellulolytic activity of rumen contents. Applied Environmental Microbiology, $33: 497-502$.

82. STEWART, G. and RUSSELL, I. (1981). Yeast. A step to energy independence. Altech Technical Publications. Lexington. Kentucky. page 113-126.

83. SUTTON, J.D. (1968). The fermentation of carbohydrates in the rumen contents of cows fed diets containing large proportions of hay. British Journal of Nutrition, 22: 689-712.

84. TERRY, R.A., TILLEY, J.M.A. and OUTEN, G.E. (1969). Effects of $\mathrm{pH}$ on cellulose digestion under in vitro conditions. Journal of Science of Food and Agriculture, 20: 317-332. 85. THOMAS, P.C. and ROOK, A.F. (1981). Manipulation of rumen fermentations. In: Recent Developments in Animal Nutrition. W. Haresign and D.J.A. Cole eds. Butterworths. page 157-183.

86. UDEN, P. (1984a). The effect of intake and hay : concentrate ratio upon digestibility and digesta passage. Animal Feed Science Technology, 11: 167-179.

87. UDEN, P. (1984b). Digestibility and digesta retention in dairy cows receiving hay or silage at varying concentrate levels. Animal Feed Science Technology, 11: 
$279-291$.

88. VAN SOEST, P.J. (1982). Nutritional Ecology of the Ruminant.

$O$ and B Books, Inc. Corvallis, U.S.A.

89. VERNON, P.S. and ROSE, A.H. (1976). Absorption of silicane antifoam by Saccharomyces cerevisiae. Journal of Institute of Brewing, 82: 336-340.

90. WELCH, J.D. and SMITH, A.M. (1971a). Physical stimulation of rumination activity. Journal of Animal Science, 38 : 1118-1123.

91. WELCH, J.D. and SMITH, A.M. (1972). Milk fat depression and rumination stimulation. Journal of Dairy Science, 58: $678-681$.

92. WELCH, J.D. (1982). Rumination, particle size and passage from the rumen. Journal of Animal Science, 54: 885-894.

93. WIEDMEIER, R.D., ARAMBEL, M.J. and WALTERS, J.L. (1987). Effect of Yeast Culture and Aspergillus oryzae Fermentation extract on ruminal characteristic and nutrient digestibilty. Journal of Dairy Science, 70: 2063-2068.

94. WILLIAMS, A.G. (1986). Rumen Holotrich Ciliate Protozoa. Microbial Reviews, 50: 25-49.

95. WILLIAMS, P.E.V. (1988). Understanding the biochemical mode of action of the Yeast Culture, Yea-Sacc. Rowert Research Institute. Aberdeen, Britain.

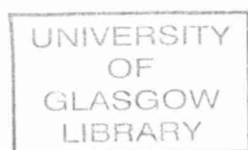

138

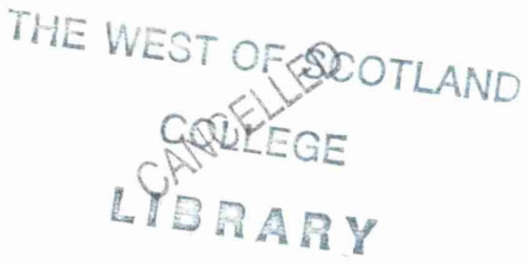

